\title{
Selective Monoacylation of Diols and Asymmetric Desymmetrization of Dialkyl meso-Tartrates Using 2-Pyridyl Esters as Acylating Agents and Metal Carboxylates as Catalysts
}

Yuki Hashimoto, ${ }^{\dagger}$, Chiaki Michimuko, ${ }^{\ddagger}$ Koki Yamaguchi,${ }^{\dagger}$ Makoto Nakajima,${ }^{\ddagger}$ Masaharu Sugiura ${ }^{*} \dagger$

${ }^{\dagger}$ Faculty of Pharmaceutical Sciences, Sojo University, 4-22-1 Ikeda, Nishi-ku, Kumamoto 860-0082, Japan

*Graduate School of Pharmaceutical Sciences, Kumamoto University, 5-1 Oe-honmachi, Chuo-ku, Kumamoto 862-0973, Japan

\section{Supporting Information}

Table of Contents

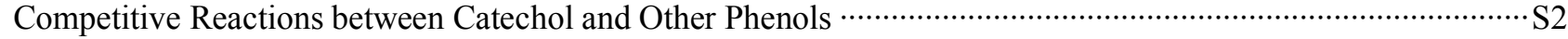

Screening of Chiral Ligands in $\mathrm{Ni}(\mathrm{OAc})_{2}$ Complexes for Desymmetrization of Dibenzyl meso-Tartrate $\cdots \cdots \cdots \cdots \cdots \cdot . \cdot \mathrm{S} 2$

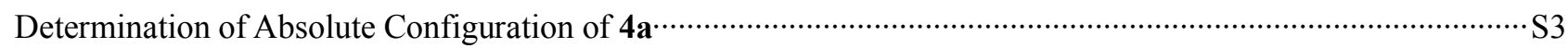

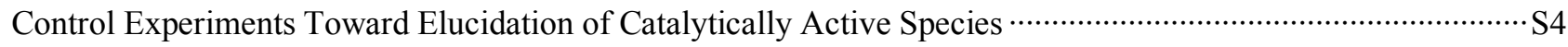

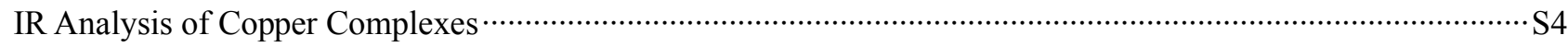

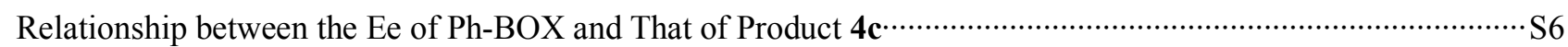

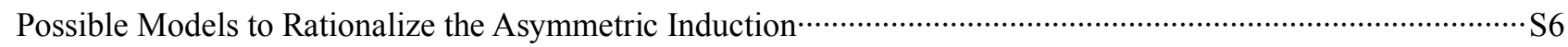

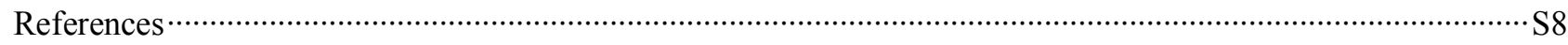

${ }^{1} \mathrm{H}$ and ${ }^{13} \mathrm{C}$ NMR Spectra of New Compounds; ${ }^{1} \mathrm{H}$ NMR Spectra of Known Compounds …….............................S9

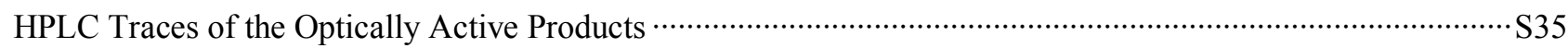




\section{Competitive Reactions between Catechol and Other Phenols}

Under argon atmosphere, a 20-mL, screw-top test tube was charged with 2-pyridyl ester 1c (0.1 mmol, $31.1 \mathrm{mg})$, catechol $(0.1 \mathrm{mmol})$, another phenol $(0.1 \mathrm{mmol})$, and $\mathrm{CH}_{3} \mathrm{CN}(0.5 \mathrm{~mL})$. Zinc acetate $(0.9 \mathrm{mg}, 5 \mathrm{~mol} \%)$ was added to the mixture. After being stirred at $50{ }^{\circ} \mathrm{C}$ for $24 \mathrm{~h}$, the resulting mixture was passed through silica gel $(0.5 \mathrm{~g})$ in a Pasteur pipette with EtOAc to remove catalyst. The eluent was concentrated under reduced pressure and the residue was purified by column chromatography $\left(\mathrm{SiO}_{2} 3.0 \mathrm{~g}, \mathrm{Hex} / \mathrm{EtOAc}=5: 1\right)$ to give the monoacylated products. Scheme S1 summarizes the results thus obtained.

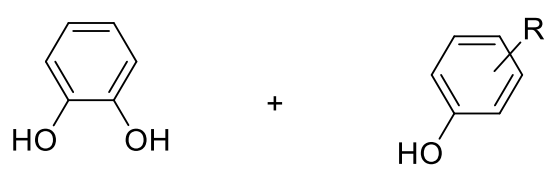

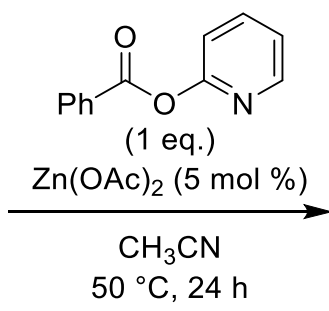

$\begin{array}{ll}\mathrm{R}=p-{ }^{t} \mathrm{Bu}(2 \text { eq.) } & 96 \% \text { yield } \\ \mathrm{R}=m-\mathrm{OH}(1 \text { eq.) } & 93 \% \text { yield } \\ \mathrm{R}=p-\mathrm{OH}(1 \text { eq.) } & 97 \% \text { yield }\end{array}$

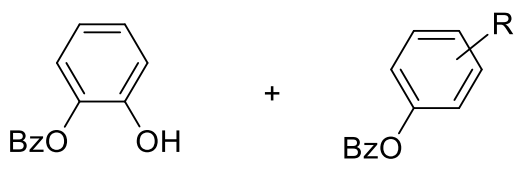

$4 \%$ yield

$0 \%$ yield $3 \%$ yield

Scheme S1. Competitive Reactions between Catechol and Other Phenols.

Screening of Chiral Ligands for $\mathrm{Ni}(\mathrm{OAc})_{2}$ Complexes for Desymmetrization of Dibenzyl meso-

\section{Tartrate}

A mixture of $\mathrm{Ni}(\mathrm{OAc})_{2} \bullet 4 \mathrm{H}_{2} \mathrm{O}(0.01 \mathrm{mmol}, 2.5 \mathrm{mg})$ and a chiral ligand $(0.012 \mathrm{mmol})$ in $\mathrm{CH}_{3} \mathrm{CN}(0.5 \mathrm{~mL})$ was stirred at $\mathrm{rt}$ for $10 \mathrm{~min}$ under argon atmosphere. Pyridyl ester $\mathbf{1 a}(0.1 \mathrm{mmol}, 31.1 \mathrm{mg})$ and dibenzyl meso-tartrate $(0.1 \mathrm{mmol}$, $33.0 \mathrm{mg}$ ) were successively added to the mixture. The reaction mixture was stirred at $\mathrm{rt}$ for $3 \mathrm{~h}$ and passed through silica gel $(0.5 \mathrm{~g})$ in a Pasteur pipette with EtOAc to remove catalyst. The eluent was concentrated under reduced pressure and the residue was purified by column chromatography $\left(\mathrm{SiO}_{2} 3.0 \mathrm{~g}, \mathrm{Hex} / \mathrm{EtOAc}=5: 1\right)$ to give product 2a. Scheme S2 summarizes the results thus obtained.

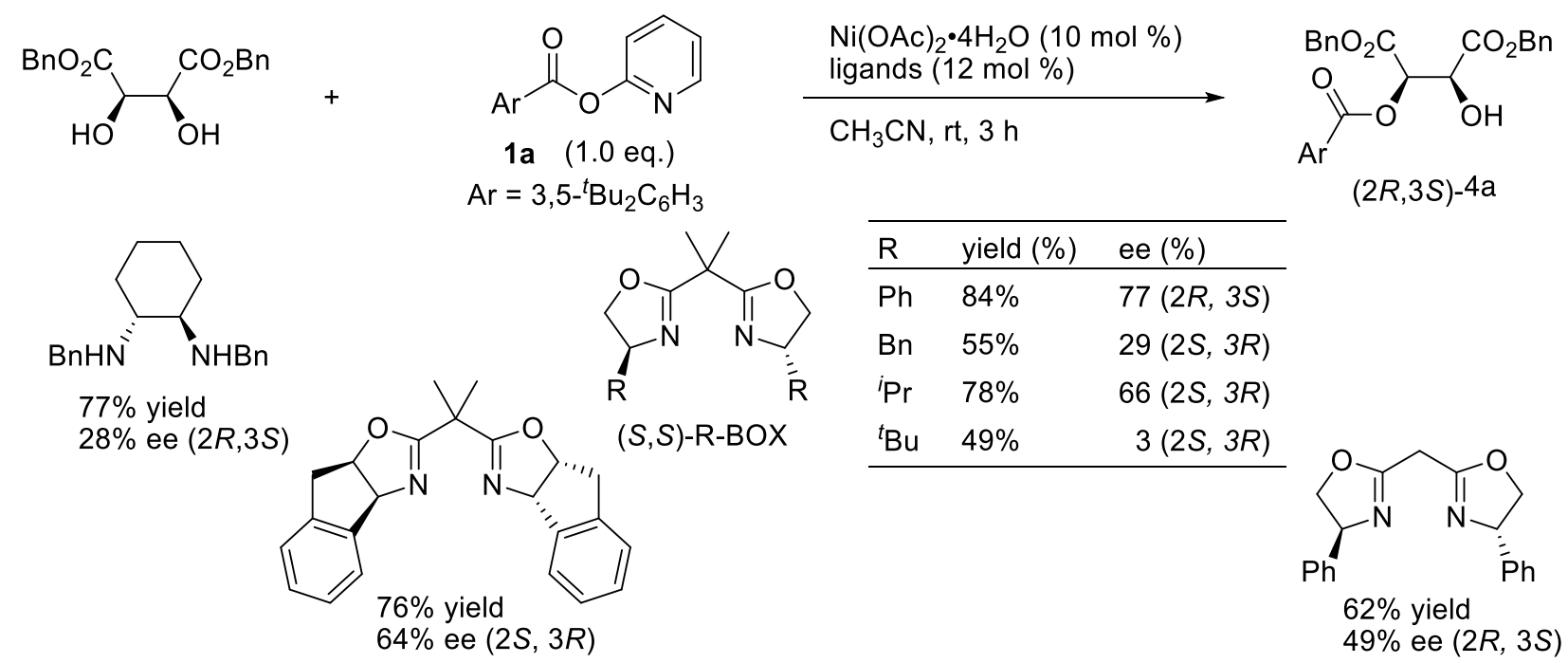

Scheme S2. Desymmetrization of Dibenzyl meso-Tartrate Catalyzed by $\mathrm{Ni}(\mathrm{OAc})_{2} /$ Chiral Ligand. 


\section{Determination of Absolute Configuration of 4 a}

According to the literature procedure, ${ }^{1}$ thionyl chloride $(0.067 \mathrm{mmol}, 4.9 \mu \mathrm{L})$ was added to a mixture of $4 \mathbf{a}(0.056$ mmol, $30.5 \mathrm{mg}, 48 \%$ ee) and pyridine $(0.067 \mathrm{mmol}, 5.4 \mu \mathrm{L})$ in $\mathrm{CHCl}_{3}(0.1 \mathrm{~mL})$ at $\mathrm{rt}$. The mixture was heated at $110{ }^{\circ} \mathrm{C}$ for $15 \mathrm{~min}$. After cooling to $\mathrm{rt}$ and addition of water, the mixture was extracted with $\mathrm{Et}_{2} \mathrm{O}$, washed with water, sat. aqueous $\mathrm{NaHCO}_{3}$, and water. The organic layer was dried over $\mathrm{Na}_{2} \mathrm{SO}_{4}$, filtered, and concentrated under reduced pressure. The crude chlorinated product was used in the next step without purification.

Tributyltin hydride $(0.067 \mathrm{mmol}, 22.2 \mu \mathrm{L})$ and AIBN $(0.5 \mathrm{mg})$ were added to a solution of the crude chlorinated product in toluene $(0.3 \mathrm{~mL})$. The mixture was heated at $80^{\circ} \mathrm{C}$ for $2 \mathrm{~h}$. AIBN $(0.5 \mathrm{mg})$ was added again and the mixture was further heated at $80{ }^{\circ} \mathrm{C}$ for $2 \mathrm{~h}$. After cooling to rt, the mixture was directly purified by column chromatography on silica gel (Hex only then $\mathrm{Hex} / \mathrm{CH}_{2} \mathrm{Cl}_{2}=1: 1$ and 1:2) to give the desired deoxygenated product ( $3.9 \mathrm{mg}, 13 \%$ yield). The absolute configuration was assigned by HPLC analysis using the authentic samples prepared from $( \pm)$ - and $(S)$-malic acid as shown in Scheme S3.

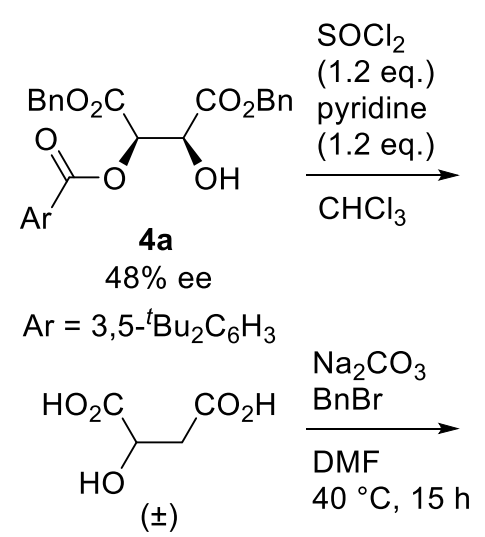

$( \pm)$

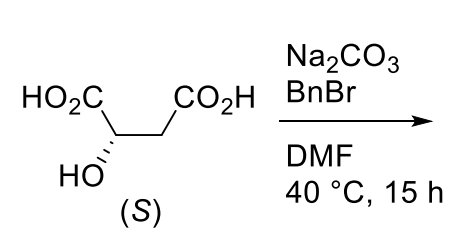

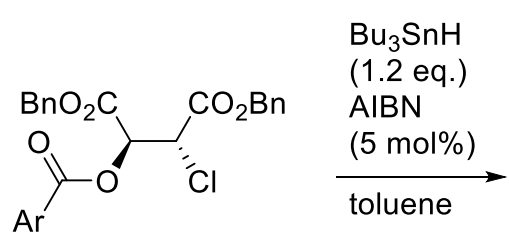

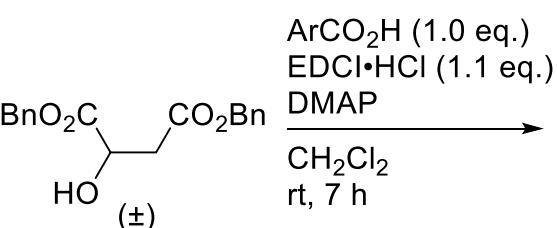

$66 \%$ yield

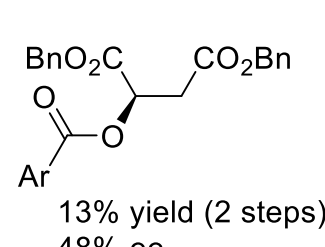

$48 \%$ ee

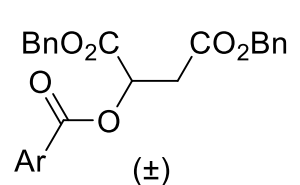

$33 \%$ yield
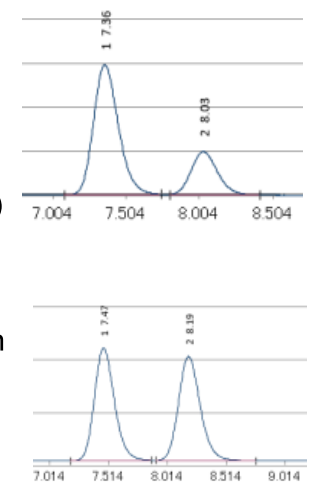

$\mathrm{ArCO}_{2} \mathrm{H}(1.0$ eq. $)$

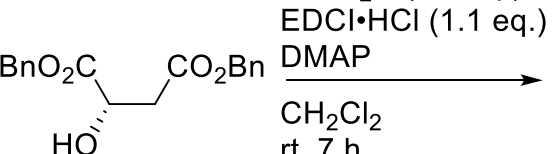

(S)

$\mathrm{rt}, 7 \mathrm{~h}$

$68 \%$ yield

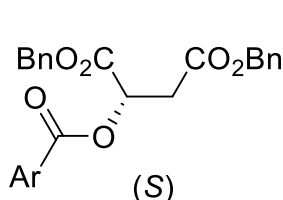

$(S)$

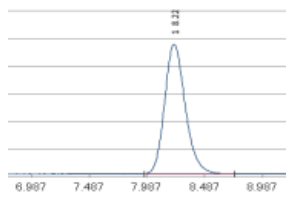

$98 \%$ yield

Scheme S3. Determination of Absolute Configuration of $\mathbf{4 a}$.

\section{Dibenzyl (S)-2-((3,5-di-tert-butylbenzoyl)oxy)succinate}

TLC: $\mathrm{R}_{f} 0.31$ ( $\mathrm{Hex} / \mathrm{CH}_{2} \mathrm{Cl}_{2}=1: 2$, stained blue with phosphomolybdic acid).

$[\alpha]_{\mathrm{D}}{ }^{25}-5.5\left(c 1.0, \mathrm{CHCl}_{3}\right)$ for $100 \%$ ee $(S)$.

IR (film on $\mathrm{NaCl}, \mathrm{cm}^{-1}$ ) 2964, 1742, 1601, 1456, 1235, 1165, 1122, 745, 698.

${ }^{1} \mathrm{H} \mathrm{NMR}\left(\mathrm{CDCl}_{3}\right) \delta 7.88(\mathrm{~d}, J=1.8 \mathrm{~Hz}, 2 \mathrm{H}), 7.64(\mathrm{t}, J=1.8 \mathrm{~Hz}, 1 \mathrm{H}), 7.36-7.21$

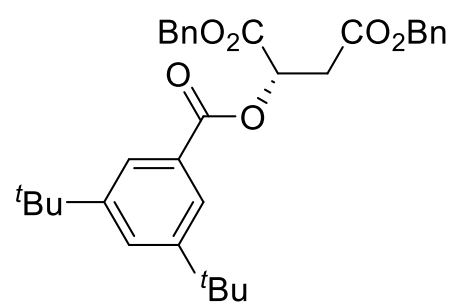

(m, 10H), 5.81-5.76 (m, 1H), $5.15(\mathrm{~d}, J=12.4 \mathrm{~Hz}, 1 \mathrm{H}), 5.15(\mathrm{~d}, J=12.4, \mathrm{~Hz}, 1 \mathrm{H}), 5.11(\mathrm{~d}, J=12.4 \mathrm{~Hz}, 1 \mathrm{H}), 5.10$

(d, $J=12.4 \mathrm{~Hz}, 1 \mathrm{H}), 3.11-3.08(\mathrm{~m}, 2 \mathrm{H}), 1.33(\mathrm{~s}, 18 \mathrm{H})$.

${ }^{13} \mathrm{C}\left\{{ }^{1} \mathrm{H}\right\} \mathrm{NMR}\left(\mathrm{CDCl}_{3}\right) \delta 168.9,168.8,166.2,151.1,135.3,135.1,128.6,128.5,128.4,128.2,128.1,124.1,68.8$, 67.4, 66.9, 36.4, 34.9, 31.3.

HRMS (ESI+): Calcd for $\mathrm{C}_{33} \mathrm{H}_{38} \mathrm{O}_{6} \mathrm{Na}\left(\mathrm{M}+\mathrm{Na}^{+}\right)$553.2566, found 553.2551.

HPLC (Daicel Chiralpak AD-H, Hex $/{ }^{i} \mathrm{PrOH}=19: 1,1.0 \mathrm{~mL} / \mathrm{min}, 254 \mathrm{~nm}$ ) $t_{\mathrm{R}}=7.4 \mathrm{~min}(R), 8.0 \mathrm{~min}(S)$. 


\section{Control Experiments Toward Elucidation of Catalytically Active Species}

According to General Procedure B, several control experiments shown in Table S1 were performed. Higher yields and enantioselectivities were obtained with the combination of $\mathrm{CuCl}_{2}$ and $\mathrm{Cu}(\mathrm{OAc})_{2}$ (entries 3-5) compared to either $\mathrm{CuCl}_{2}$ or $\mathrm{Cu}(\mathrm{OAc})_{2}$ (entries 1 and 2). These results would support formation of copper monochloride monocarboxylate as catalytically active species under equilibrium between $\mathrm{CuCl}_{2}$ and $\mathrm{Cu}(\mathrm{OAc})_{2}$.

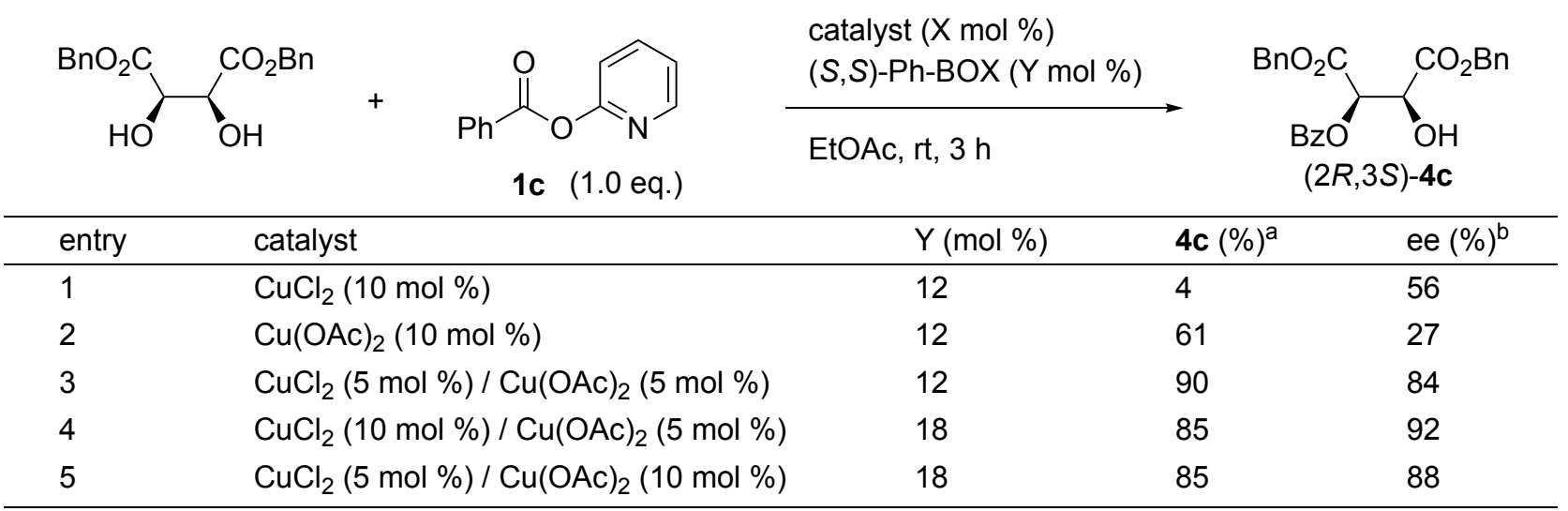

alsolated yield. betermined by HPLC analysis.

Table S1. Control Experiments: Effect of Combination of $\mathrm{CuCl}_{2}$ and $\mathrm{Cu}(\mathrm{OAc})_{2}$.

\section{IR Analysis of Copper Complexes}

Under an argon atmosphere, a screw-top test tube was charged with $\mathrm{CuCl}_{2}$ or $\mathrm{Cu}(\mathrm{OAc})_{2}(0.02 \mathrm{mmol}),(\mathrm{S}, S)-\mathrm{Ph}$ BOX $(6.7 \mathrm{mg}, 0.02 \mathrm{mmol})$, and $\mathrm{CH}_{3} \mathrm{CN}(1 \mathrm{~mL})$ at rt. The mixture was stirred for $10 \mathrm{~min}$. Several drops of the resulting solution were placed on a $\mathrm{NaCl}$ plate and the solvent was removed under reduced pressure. This operation was repeated twice and an IR spectrum was measured. Figure S1-(b) and (c) show the IR spectra of $\mathrm{CuCl}_{2} /(S, S)$ $\mathrm{Ph}-\mathrm{BOX}$ and $\mathrm{Cu}(\mathrm{OAc})_{2} /(S, S)$-Ph-BOX complexes, respectively. For comparison, IR spectra of $(S, S)$-Ph-BOX and $\mathrm{Cu}(\mathrm{OAc})_{2}$ are shown in Figure S1-(a) and (d), respectively. The peak highlighted in yellow can be assigned to $v_{\mathrm{C}=\mathrm{N}}$ of Ph-BOX, and the peaks highlighted in blue can be assigned to $v_{\mathrm{C}=\mathrm{O}}$ of copper acetate. Next, the solution of $\mathrm{CuCl}_{2} /(S, S)-\mathrm{Ph}-\mathrm{BOX}$ in $\mathrm{CH}_{3} \mathrm{CN}$ and the solution of $\mathrm{Cu}(\mathrm{OAc})_{2} /(S, S)-\mathrm{Ph}-\mathrm{BOX}$ in $\mathrm{CH}_{3} \mathrm{CN}$ were mixed in a 1:1 molar ratio. The resulting solution was then analyzed in the same way as $\mathrm{CuCl}_{2} /(S, S)-\mathrm{Ph}-\mathrm{BOX}$ complex [Figure $\mathrm{S} 1$-(e)]. The peak highlighted in pink, which was not in spectra (b) and (c), was observed. A similar peak was also observed in the IR spectrum of $\mathrm{CuCl}_{2} / \mathrm{AgOPiv} /(S, S)$-Ph-BOX $(1: 1: 1)$ complex [Figure S1-(f)]. We speculate formation of copper monochloride monocarboxylate species in (e) and (f). 
(a) $(S, S)-\mathrm{Ph}-\mathrm{BOX}(\mathrm{KBr})$

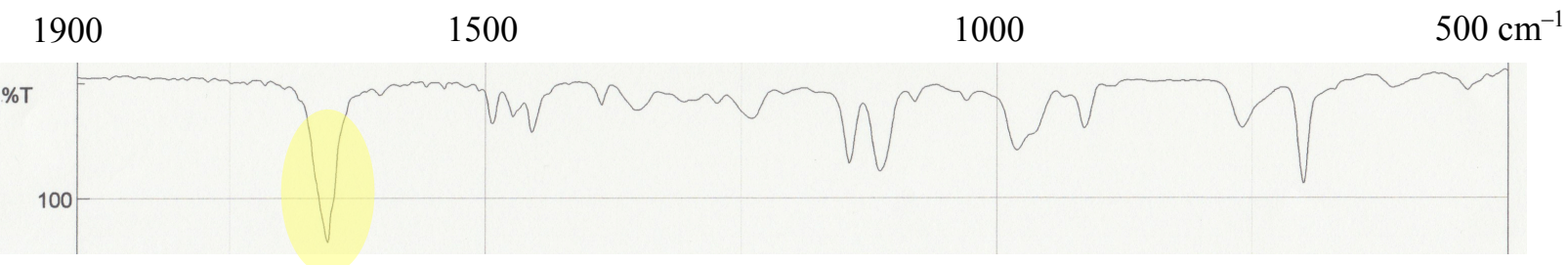

(b) $\mathrm{CuCl}_{2} /(S, S)-\mathrm{Ph}-\mathrm{BOX}(1: 1)$ (film on $\mathrm{NaCl}$ )

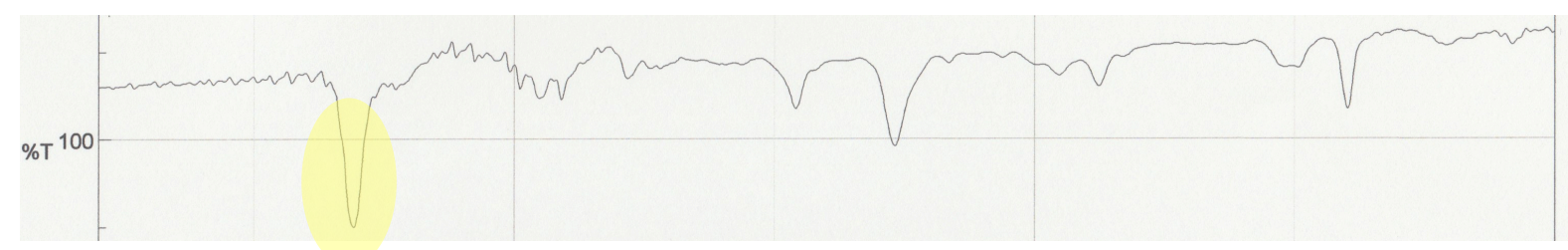

(c) $\mathrm{Cu}(\mathrm{OAc})_{2} /(S, S)-\mathrm{Ph}-\mathrm{BOX}(1: 1)($ film on $\mathrm{NaCl})$

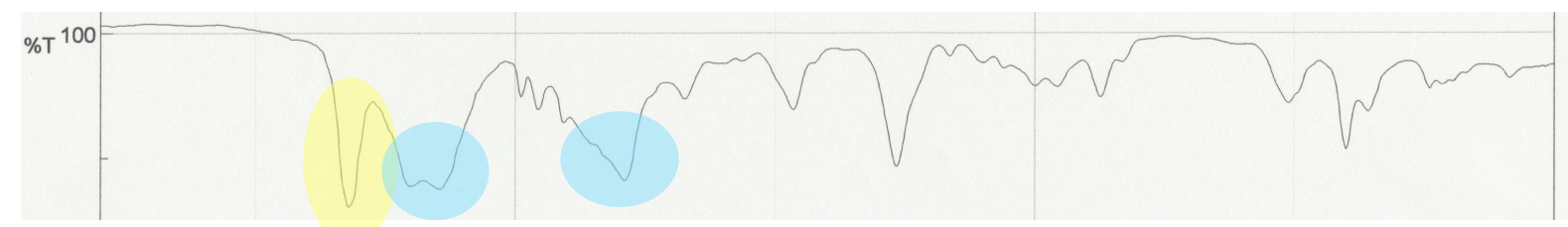

(d) $\mathrm{Cu}(\mathrm{OAc})_{2}(\mathrm{KBr})$

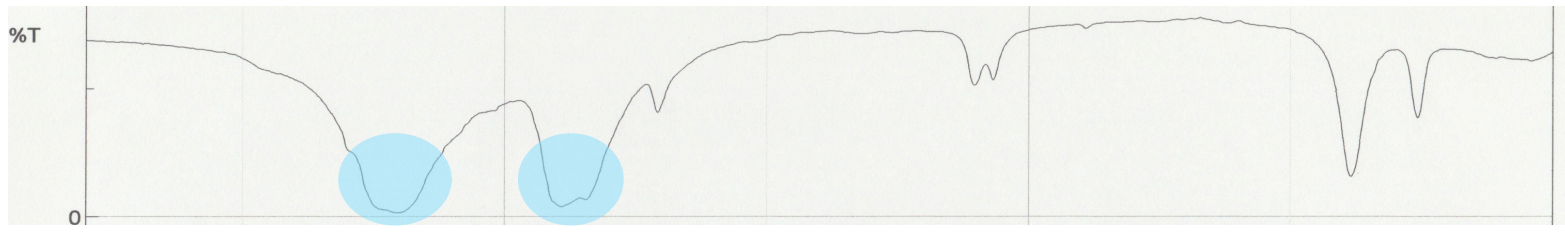

(e) $\mathrm{CuCl}_{2} /(S, S)-\mathrm{Ph}-\mathrm{BOX}(1: 1)+\mathrm{Cu}(\mathrm{OAc})_{2} /(S, S)-\mathrm{Ph}-\mathrm{BOX}$ (1:1) (film on $\left.\mathrm{NaCl}\right)$

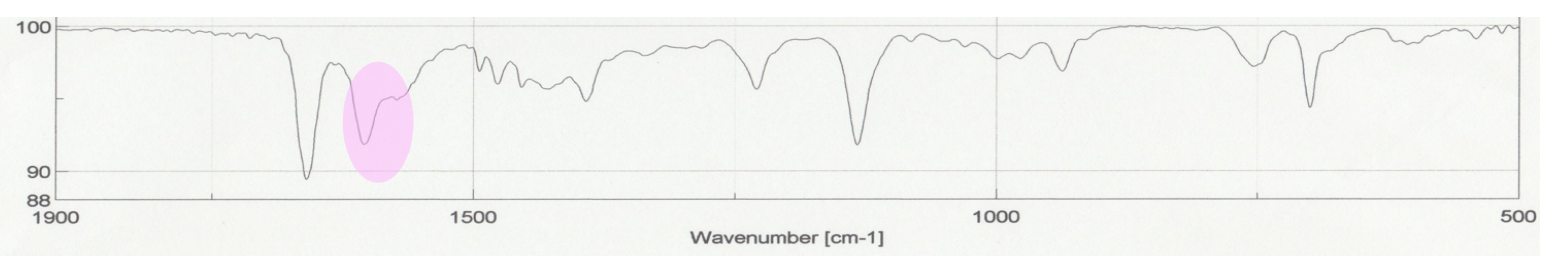

(f) $\mathrm{CuCl}_{2} / \mathrm{AgOPiv} /(S, S)-\mathrm{Ph}-\mathrm{BOX}(1: 1: 1)$ (film on $\left.\mathrm{NaCl}\right)$

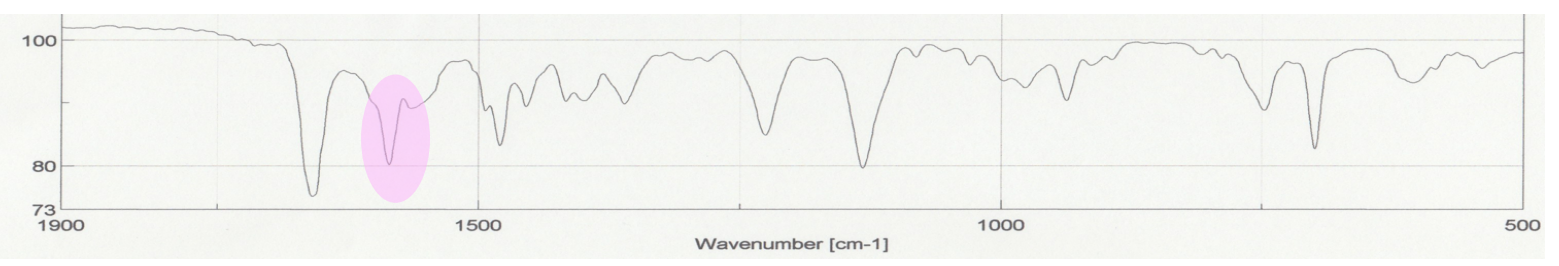

Figure S1. IR Analysis of Copper Complexes. 


\section{Relationship between the Ee of Ph-BOX and That of Product $4 c$}

The $\mathrm{CuCl}_{2} / \mathrm{AgOPiv} / \mathrm{Ph}-\mathrm{BOX}$-catalyzed reaction of dibenzyl meso-tartrate with pyridyl ester $1 \mathrm{c}$ was investigated using Ph-BOX of $36 \%$ and $62 \%$ ee $(S, S)$. Product $4 \mathbf{c}$ was obtained with $39 \%$ and $54 \%$ ee, respectively. Therefore, almost linear relationship between the ee of Ph-BOX and that of the product was observed (Figure S2).

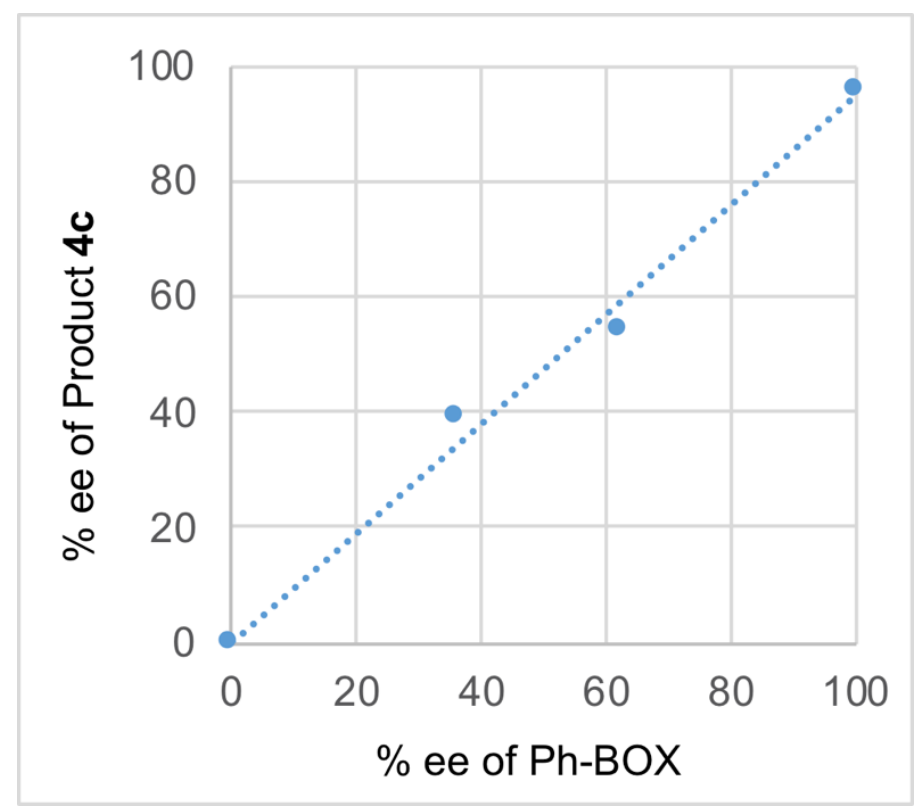

Figure S2. Relationship between the Ee of Ph-BOX and That of Product 4c.

\section{Possible Models to Rationalize the Asymmetric Induction}

Based on the above IR studies and linear relationship, we speculate that a mononuclear copper(II) monochloride monocarboxylate species having one Ph-BOX imparts asymmetric induction. Figure S3 shows possible models of the asymmetric induction in the enantio-determining acylation step. A twisted square pyramidal geometry of the copper and coordination of the pyridyl ester to the copper are assumed according to literatures. ${ }^{2-4}$ Because of the Jahn-Teller effect, the chloride anion dissociates to generate cationic metal center and the electrophile (pyridyl ester) strongly binds to cis-oriented coordinating sites in the ligand plane. The pivalate anion occupies a weakly coordinating site perpendicular to the ligand plane and acts as a base. Benzyl meso-tartrate attacks the pyridyl ester from the side of the pivalate anion, so that the pivalate abstracts one of the hydroxy groups of the tartrate, which is activated by intramolecular hydrogen bond. TS1 is more sterically favored than TS2, because the meso-tartrate repel one of the phenyl groups of Ph-BOX in TS2. Similarly, TS3 is more sterically favored than TS4-TS6 in the kinetic resolution of dibenzyl $d l$-tartrate (Figure S4). 


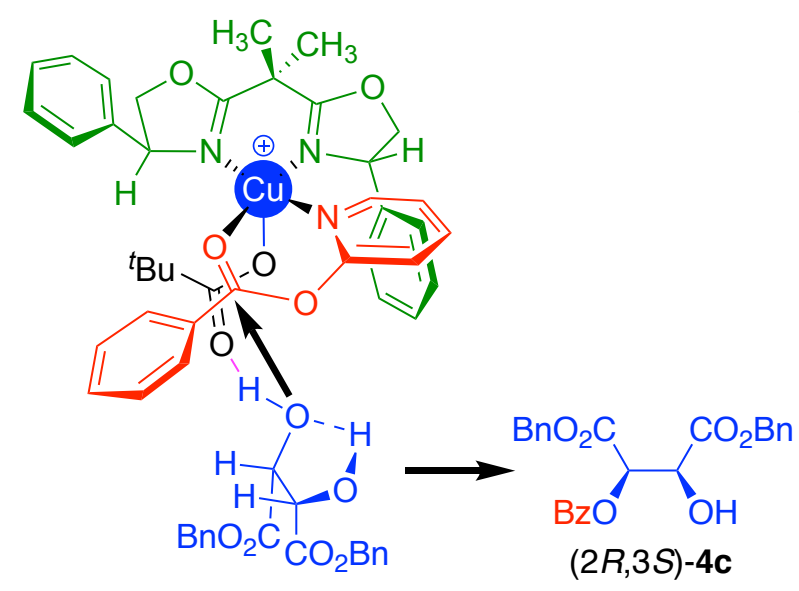

TS1 (favored)

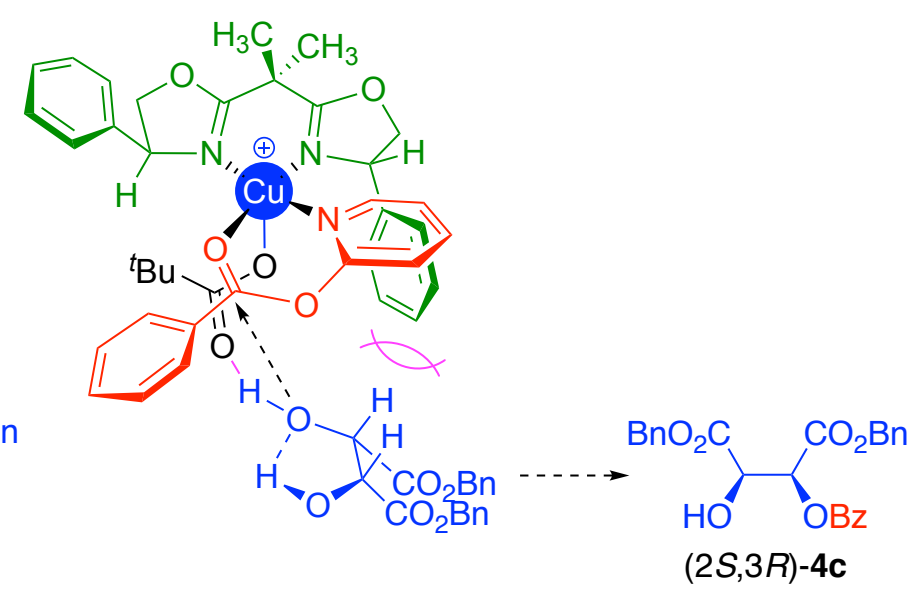

TS2 (disfavored)

Figure S3. Models for Desymmetrization of Dibenzyl meso-Tartrate.

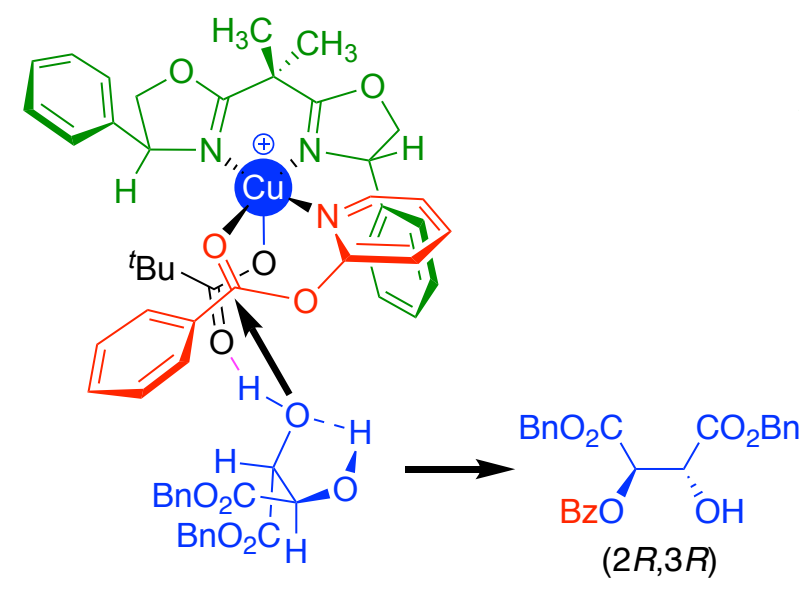

TS3 (favored)

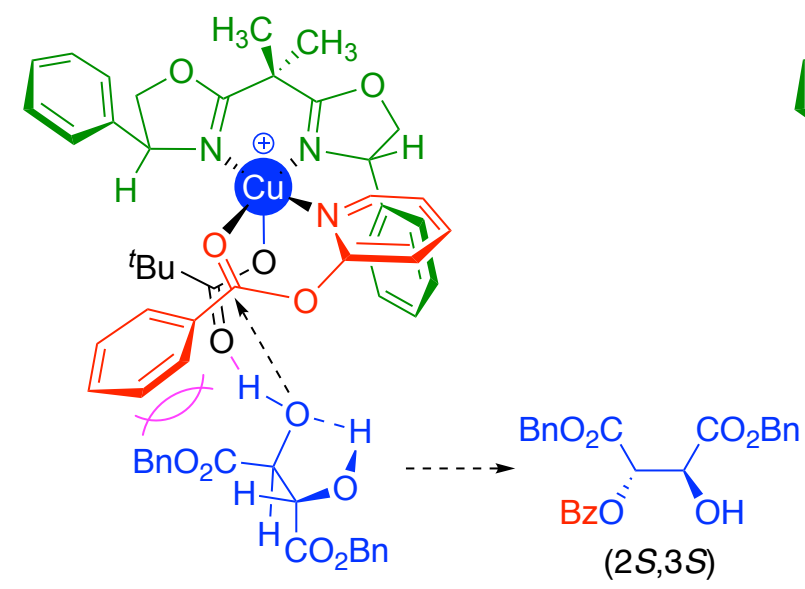

TS5 (disfavored)

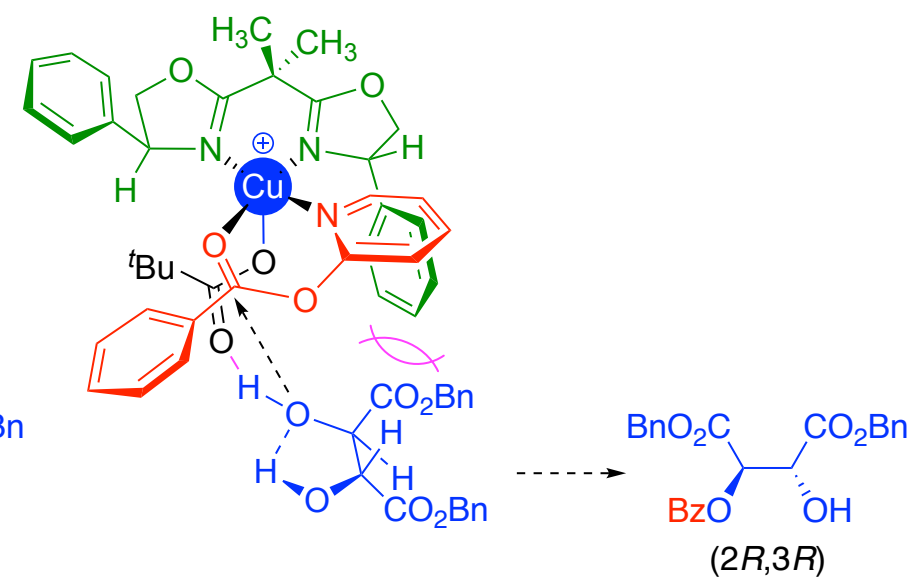

TS4 (disfavored)

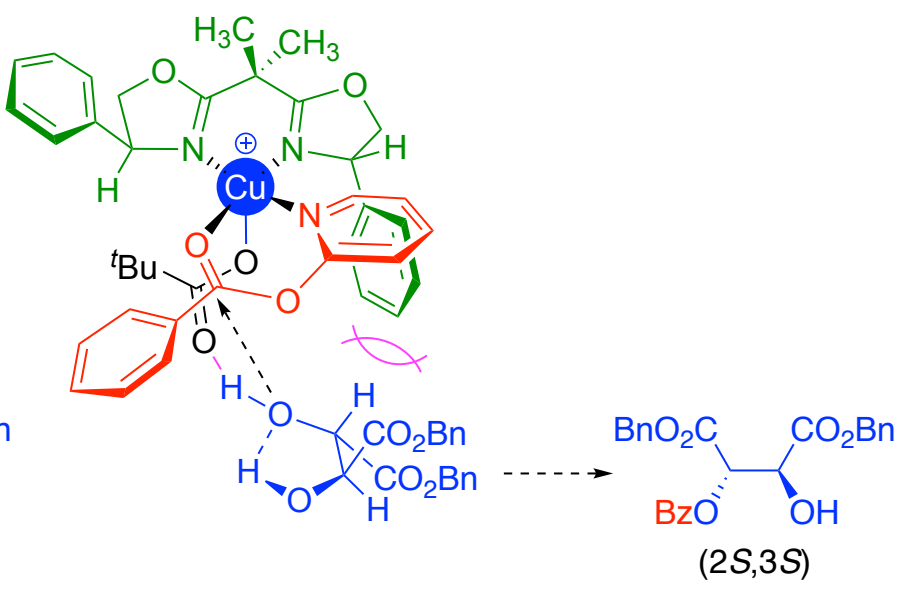

TS6 (disfavored)

Figure S4. Models for Kinetic Resolution of Dibenzyl dl-Tartrate. 


\section{References}

(1) (a) Freudénberg, K.; Brauns, F. Die Konfiguration der einfachen $\alpha$-Oxy-säuren. Ber. Dtsch. Chem. Ges. 1922, 55, 1339-1351. (b) Hungerbühler, E.; Seebach, D.; Wasmuth, D. Doppelt und dreifach funktionalisierte, enantiomerenreine $C_{4}$-Synthesebausteine aus $\beta$-Hydroxybuttersäure, Äpfelsäure und Weinsäure. Helvetica Chimica Acta 1981, 64, 1467-1487.

(2) Evans, D. A.; Seidel, D.; Rueping, M.; Lam, H. W.; Shaw, J. T.; Downey, C. W. A New Copper AcetateBis(oxazoline)-Catalyzed, Enantioselective Henry Reaction. J. Am. Chem. Soc. 2003, 125, 12692-12693.

(3) Desimoni, G.; Faita, G.; Jørgensen, K. A. $C_{2}$-Symmetric Chiral Bis(oxazoline) Ligands in Asymmetric Catalysis. Chem. Rev. 2011, 111, PR284-PR437.

(4) Nakamura, S.; Nakashima, H.; Sugimoto, H.; Sano, H.; Hattori, M.; Shibata, N.; Toru, T. Enantioselective CC Bond Formation to Sulfonylimines through Use of the 2-Pyridinesulfonyl Group as a Novel Stereocontroller. Chem. Eur. J. 2008, 14, 2145-2152. 
${ }^{1}$ H and ${ }^{13}$ C NMR Spectra of New Compounds; ${ }^{1}$ H NMR Spectra of Known Compounds<smiles></smiles>

Dibenzyl meso-tartrate
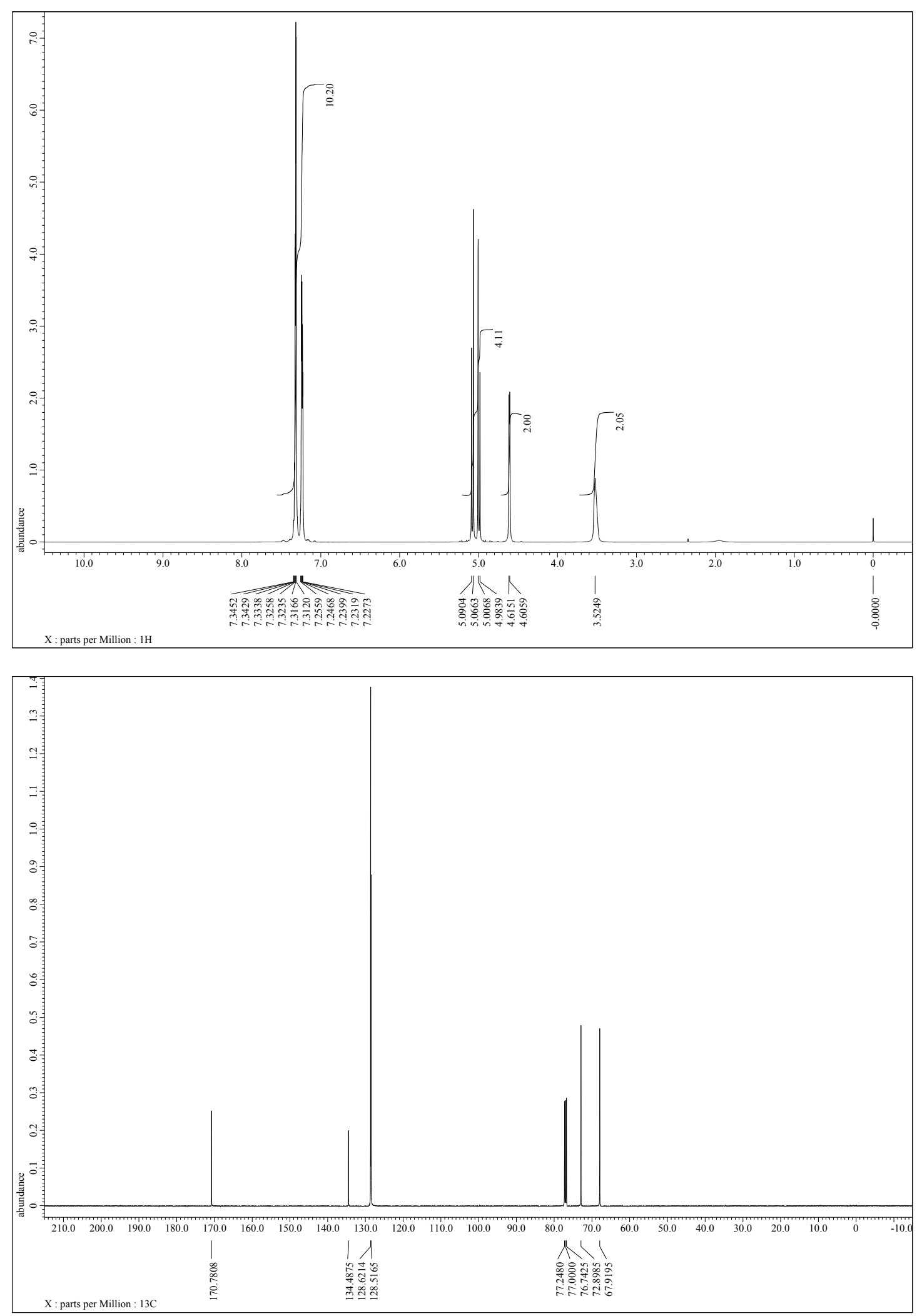

Sq 

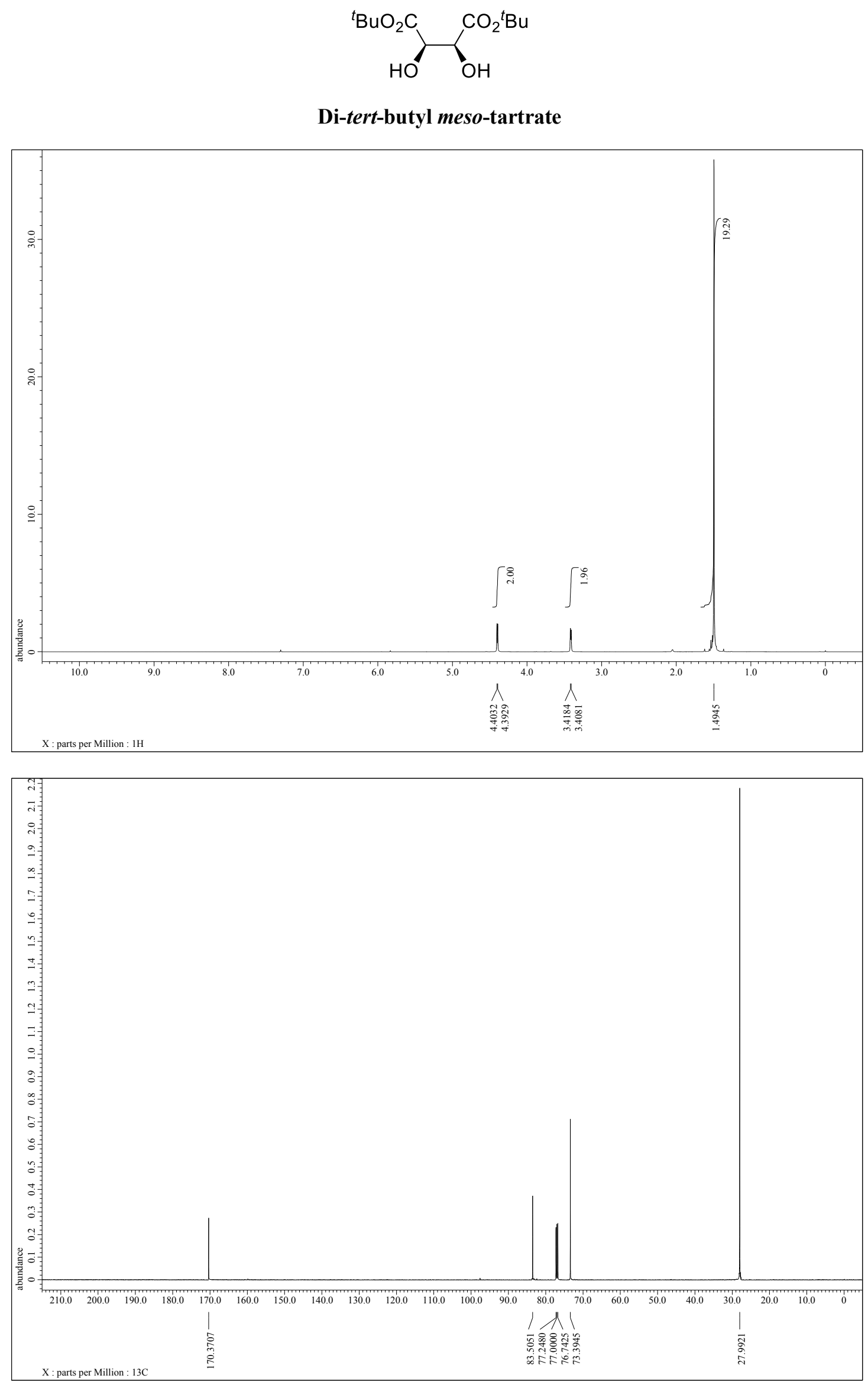

S10 

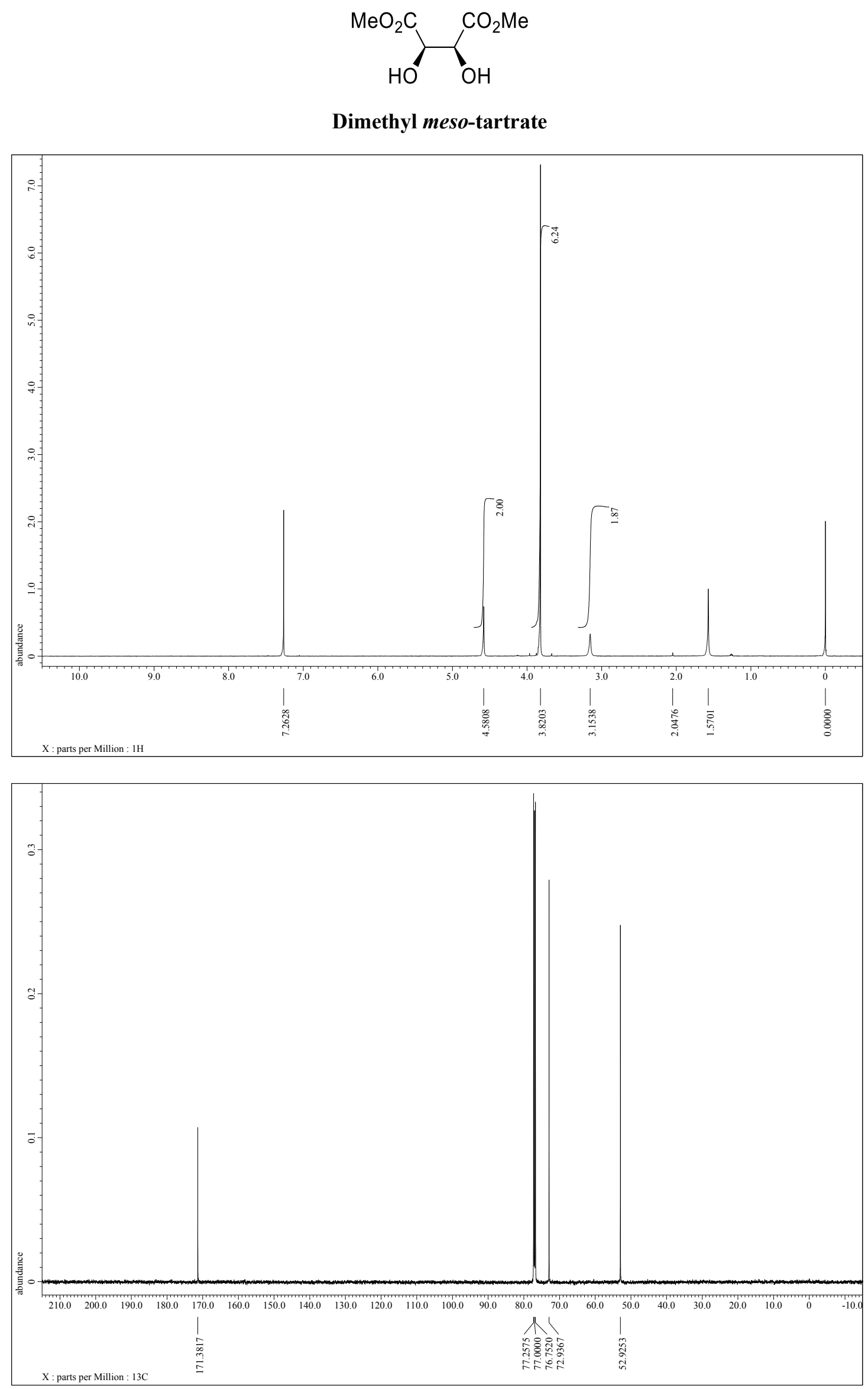

S11 


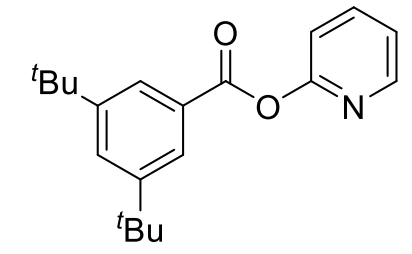

Pyridin-2-yl 3,5-di-tert-butylbenzoate (1a)
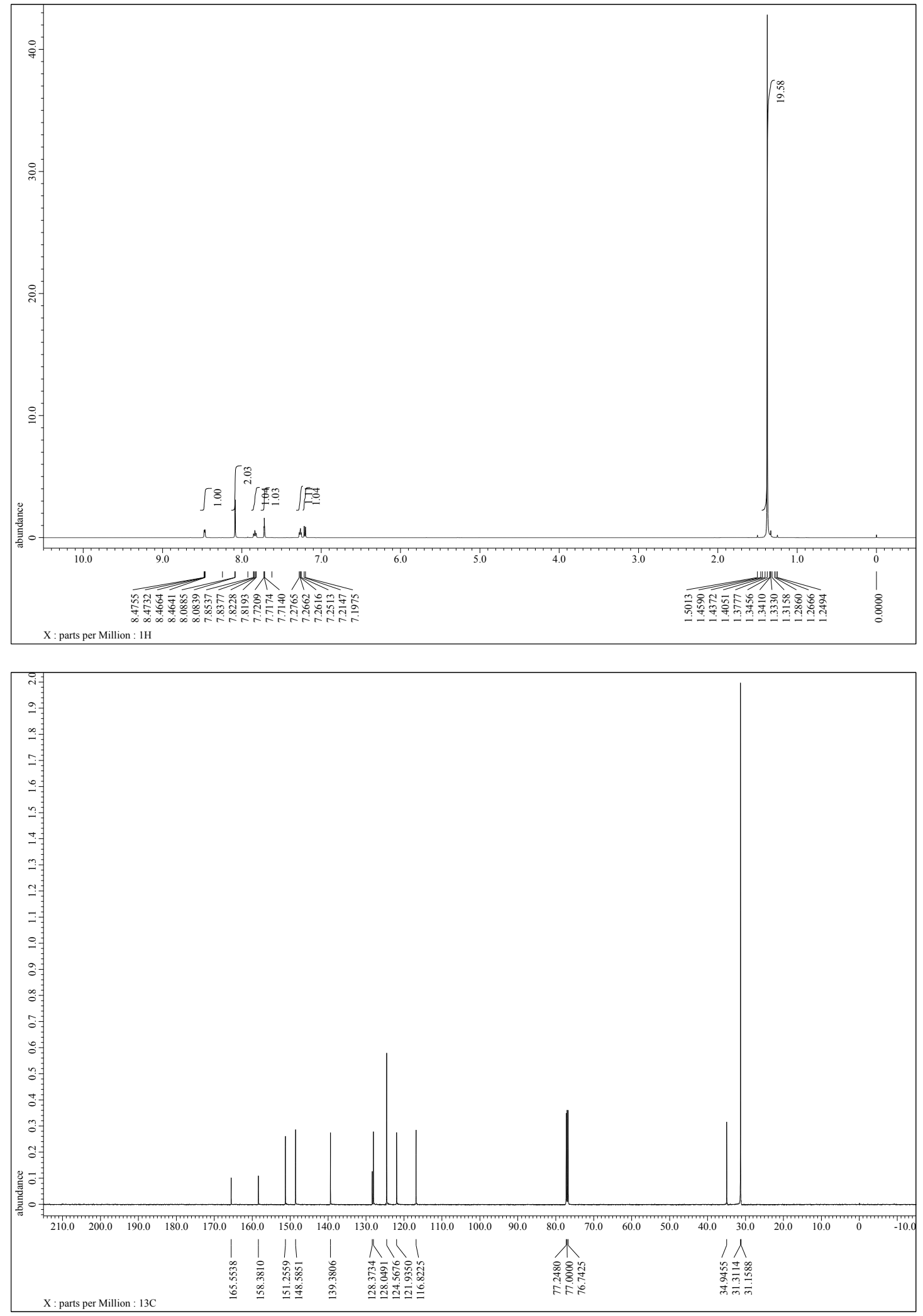


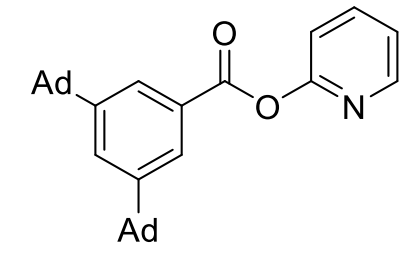

Pyridin-2-yl 3,5-di(1-adamantyl)benzoate (1b)
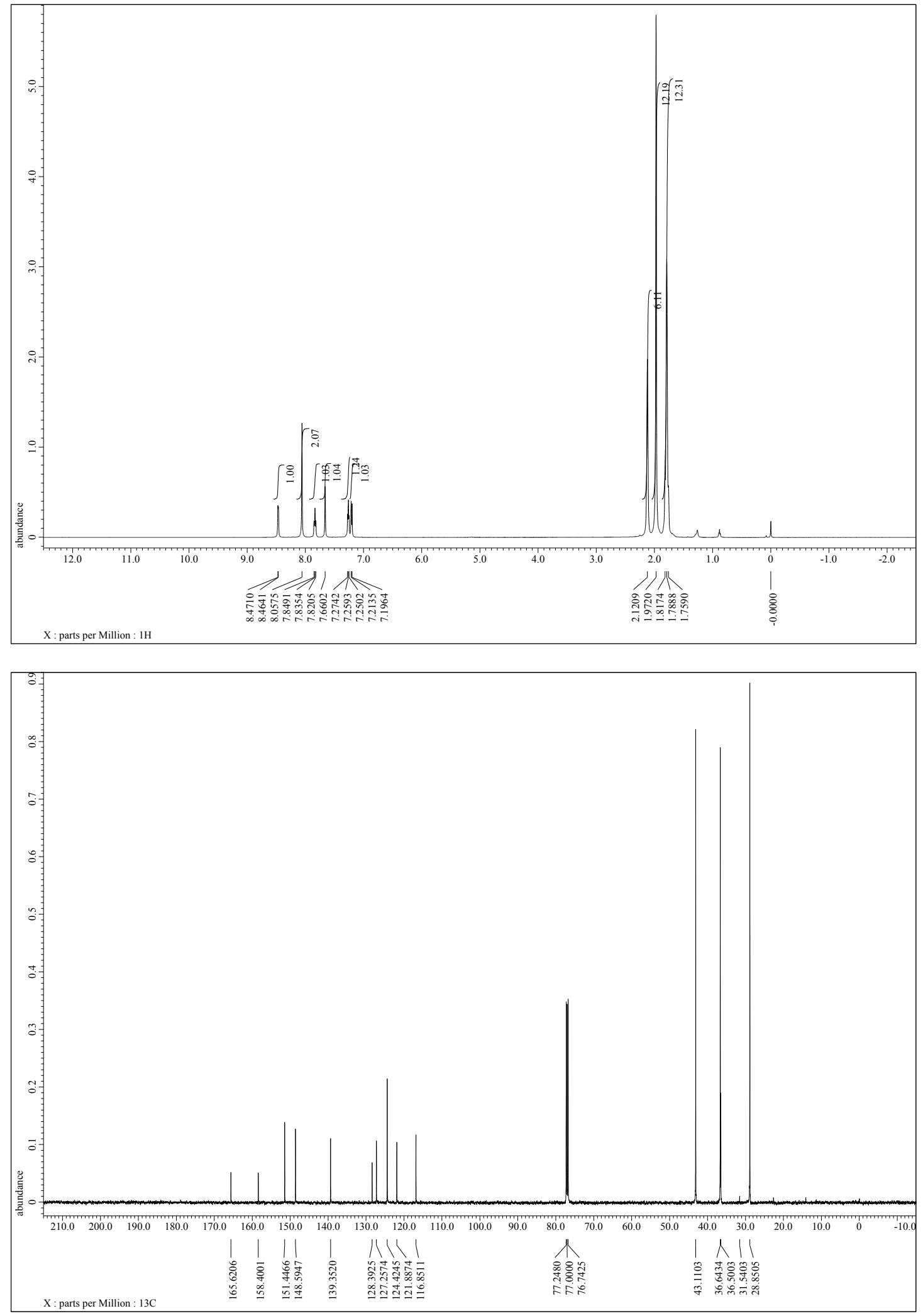
<smiles>O=C(Oc1ccccn1)c1ccccc1</smiles>

Pyridin-2-yl benzoate (1c)

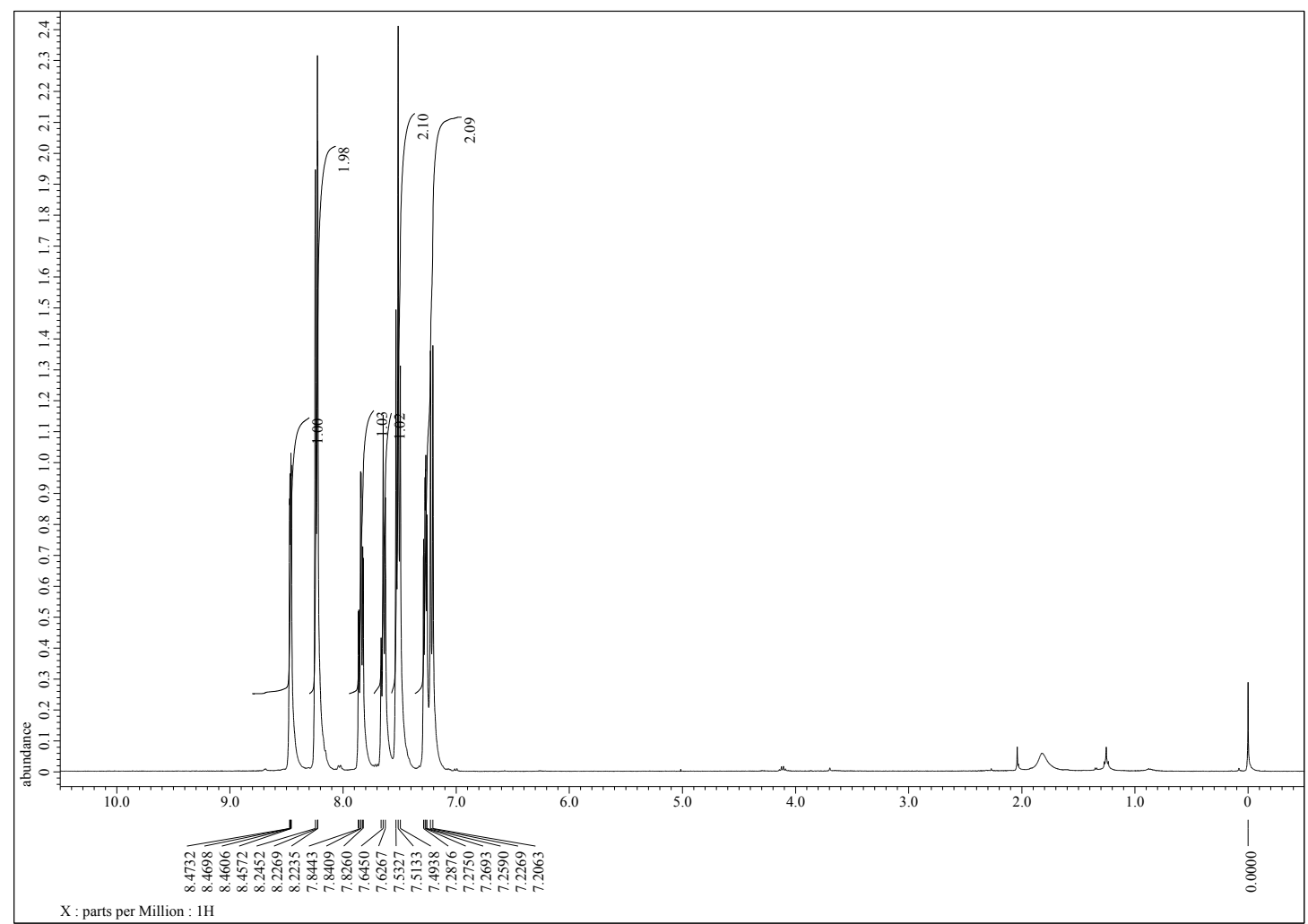




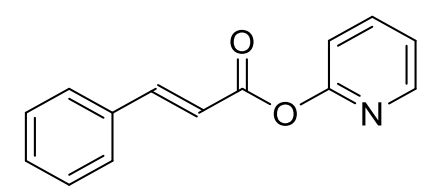

Pyridin-2-yl cinnamate (1d)
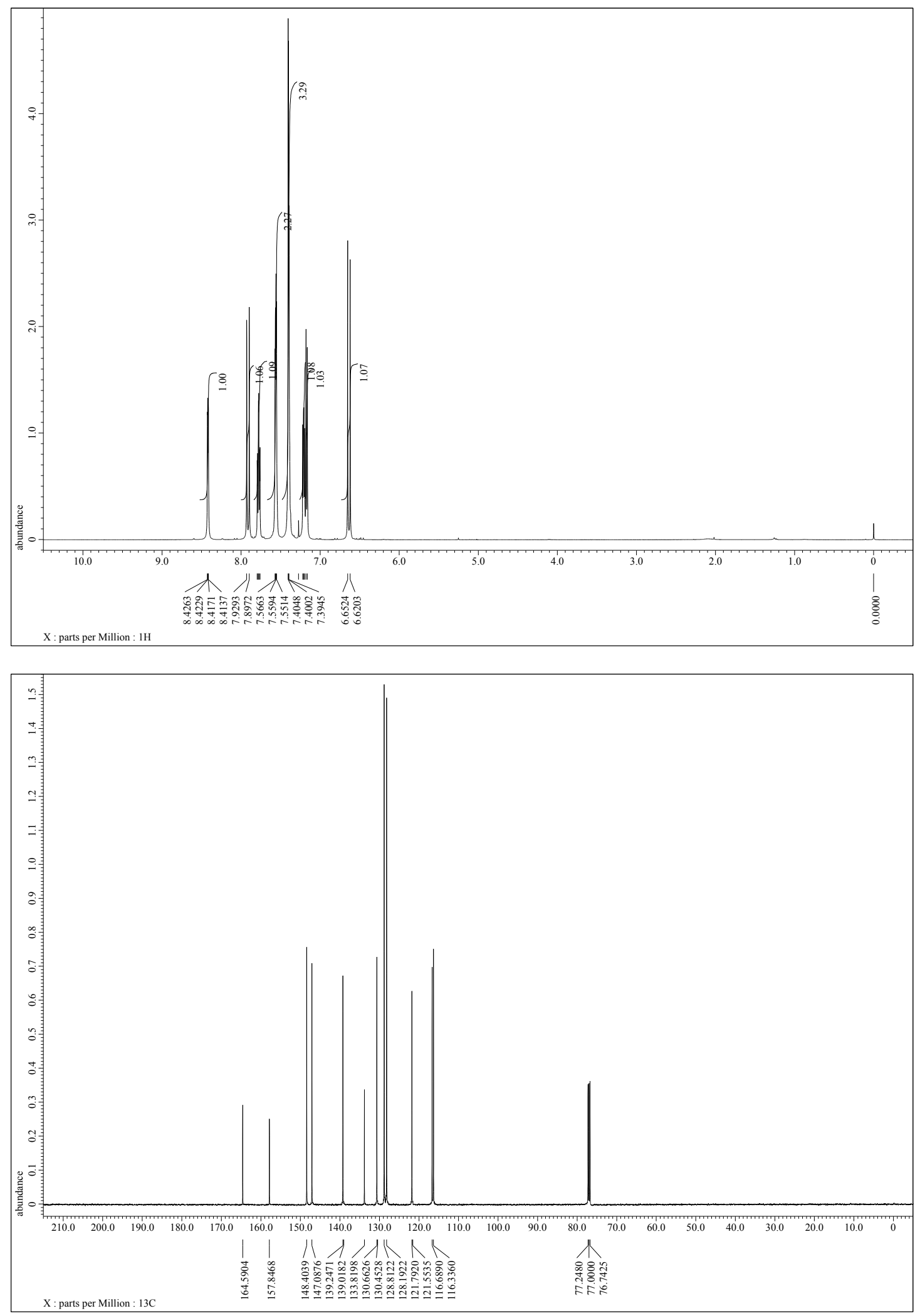
<smiles>O=C(/C=C/c1ccc(OCc2ccccc2)c(OCc2ccccc2)c1)Oc1ccccn1</smiles>

Pyridin-2-yl 3,4-dibenzyloxycinnamate (1e)
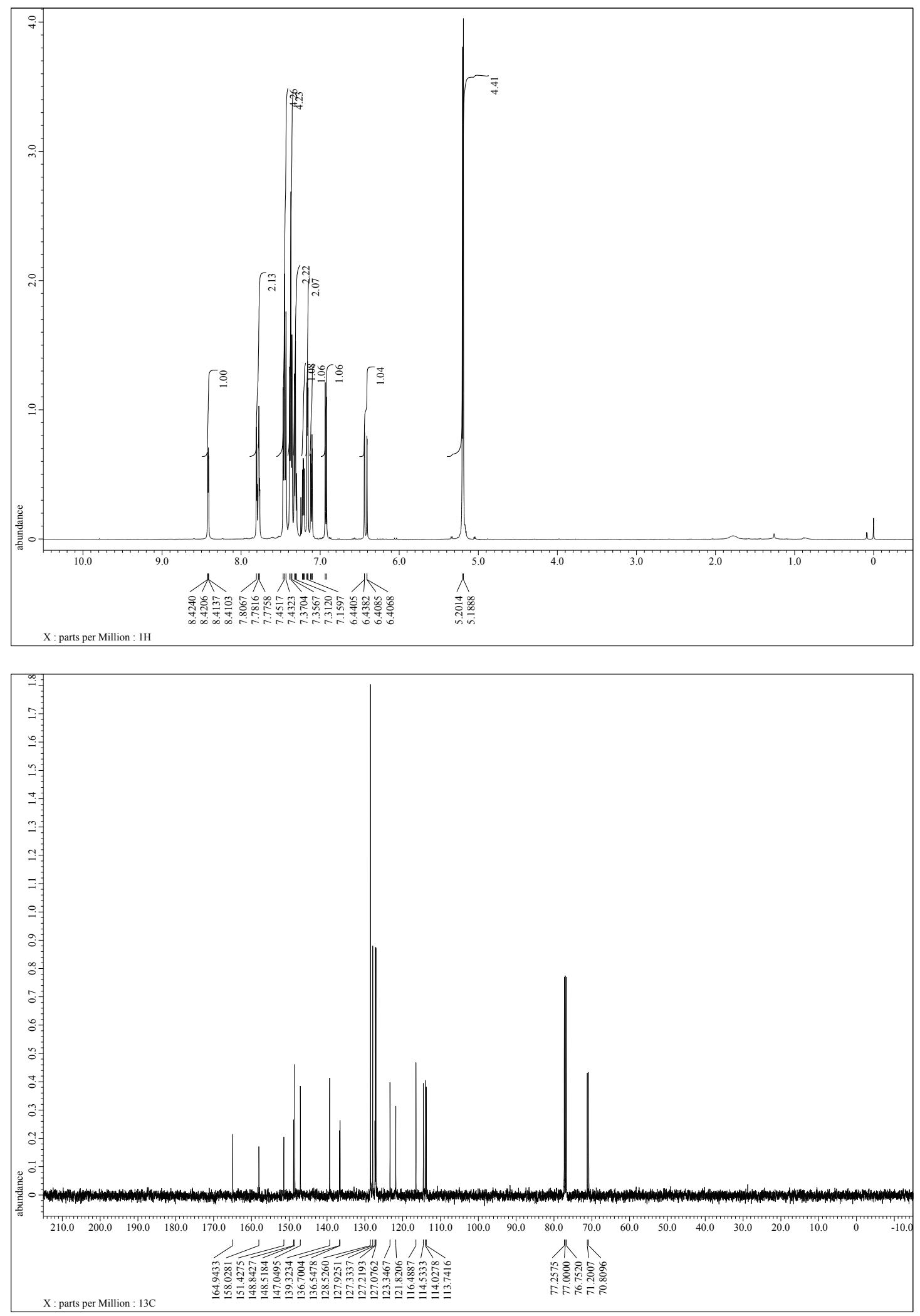
<smiles>C/C=C/C(=O)Oc1ccccn1</smiles>

Pyridin-2-yl crotonate (1f)
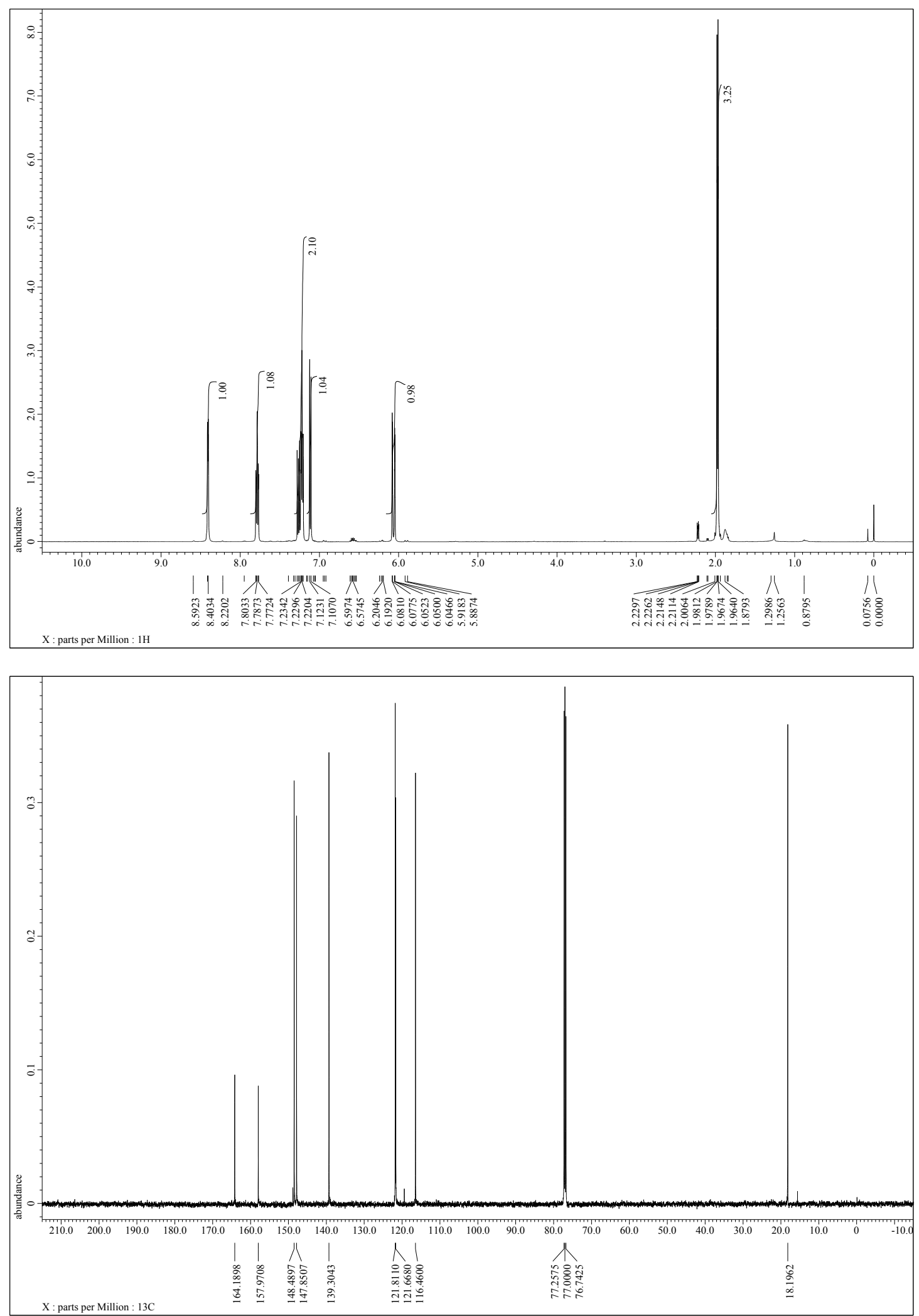


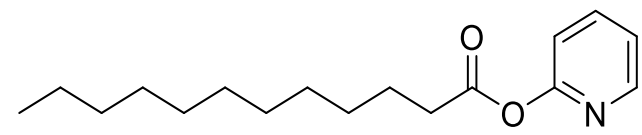

Pyridin-2-yl dodecanoate (1g)
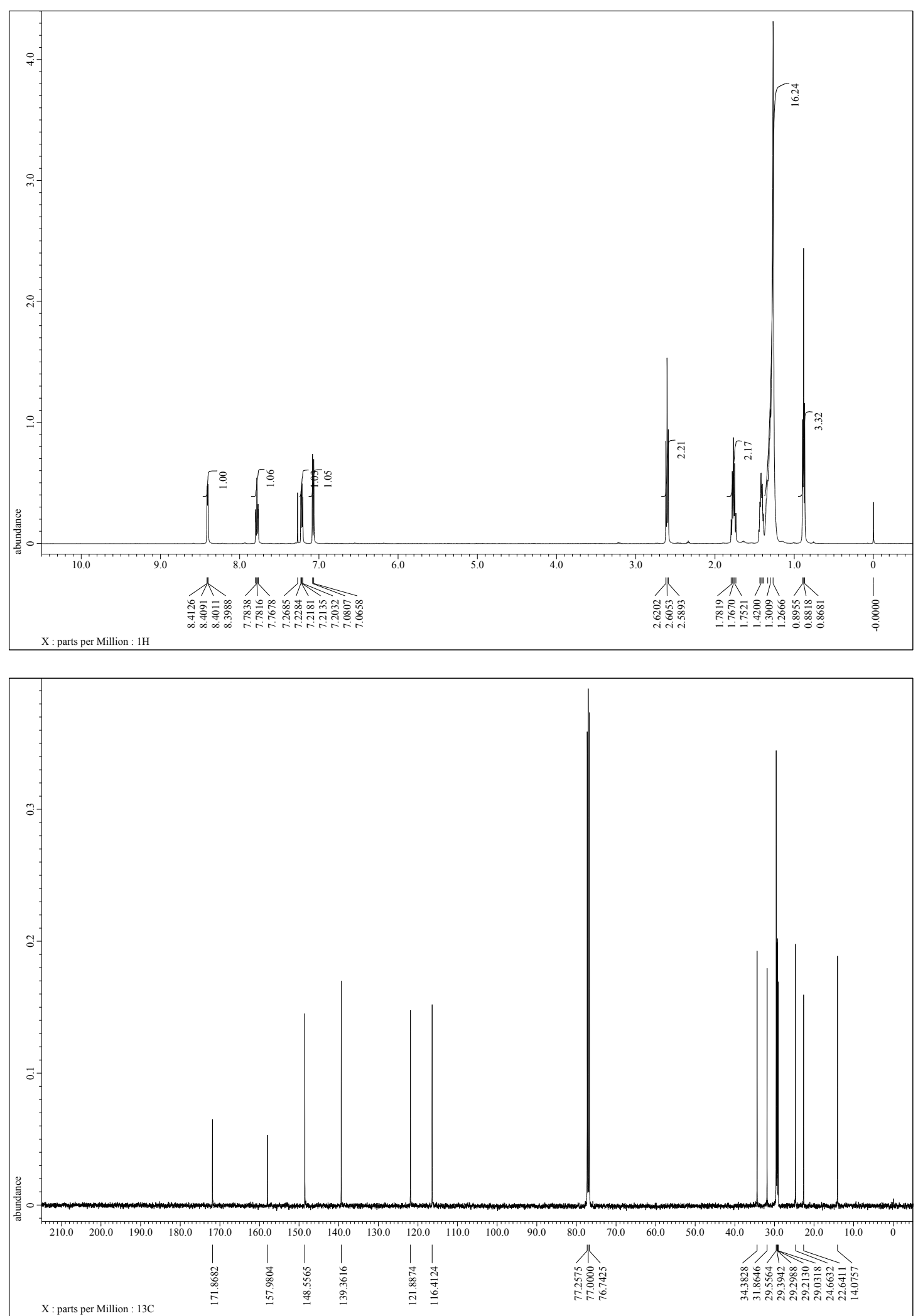
$O-3,5-D i-t e r t-b u t y l b e n z o y l ~ d i b e n z y l ~(2 R, 3 R)$-tartrate (2a)

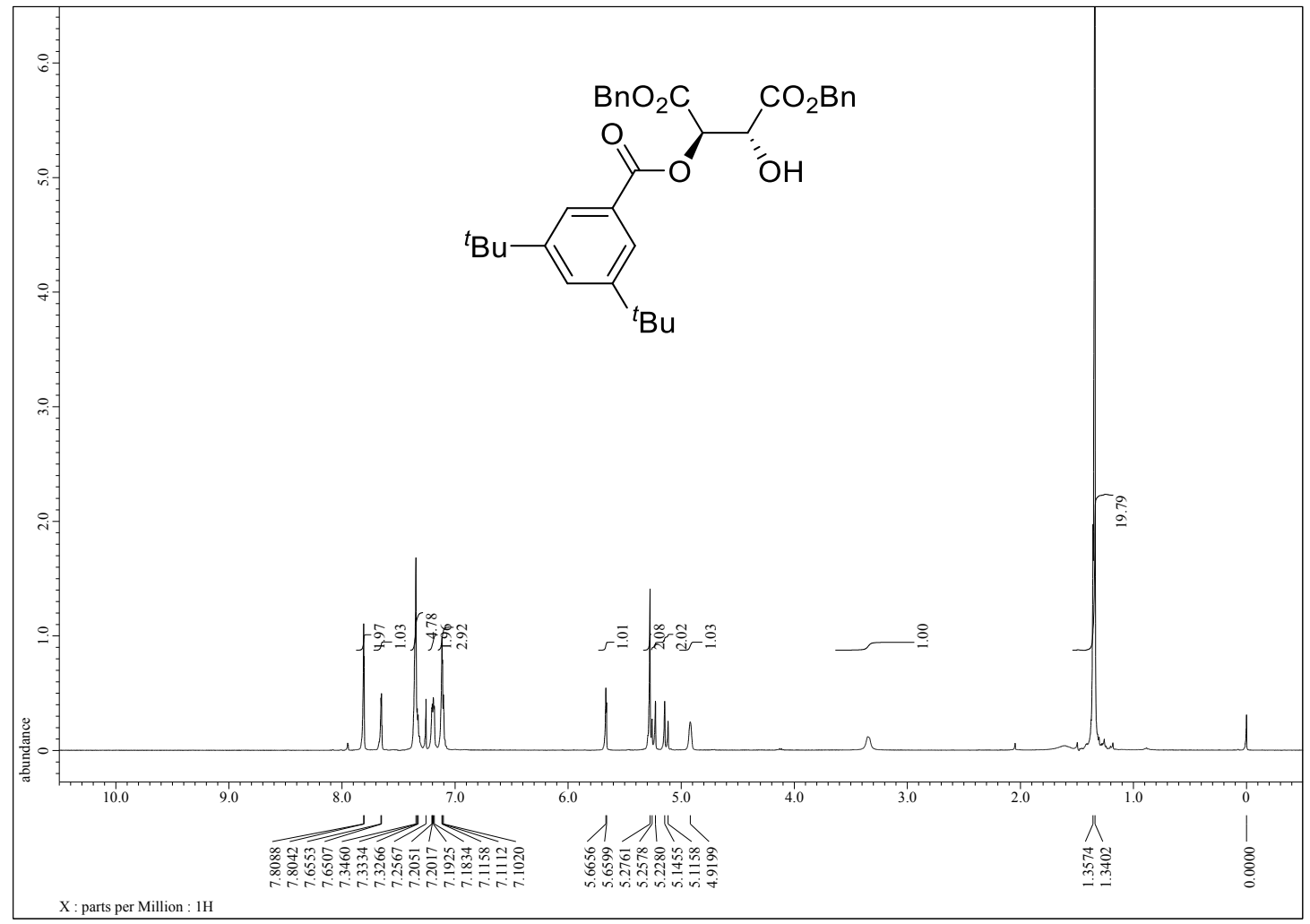

$O, O$ '-Bis(3,5-di-tert-butylbenzoyl) dibenzyl (2R,3R)-tartrate (3a)

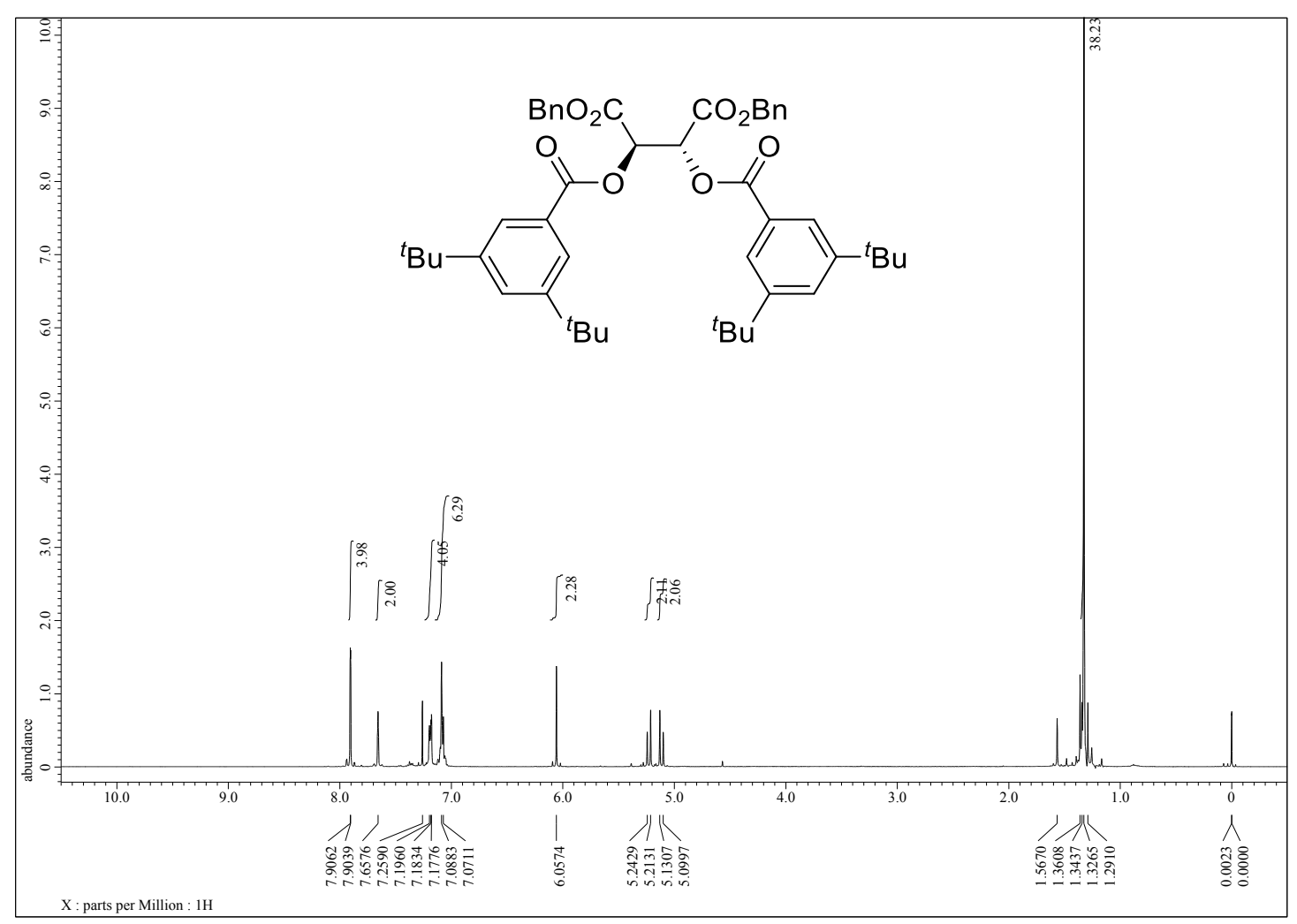


$O-3,5$-Di(1-adamantyl)benzoyl dibenzyl $(2 R, 3 R)$-tartrate (2b)

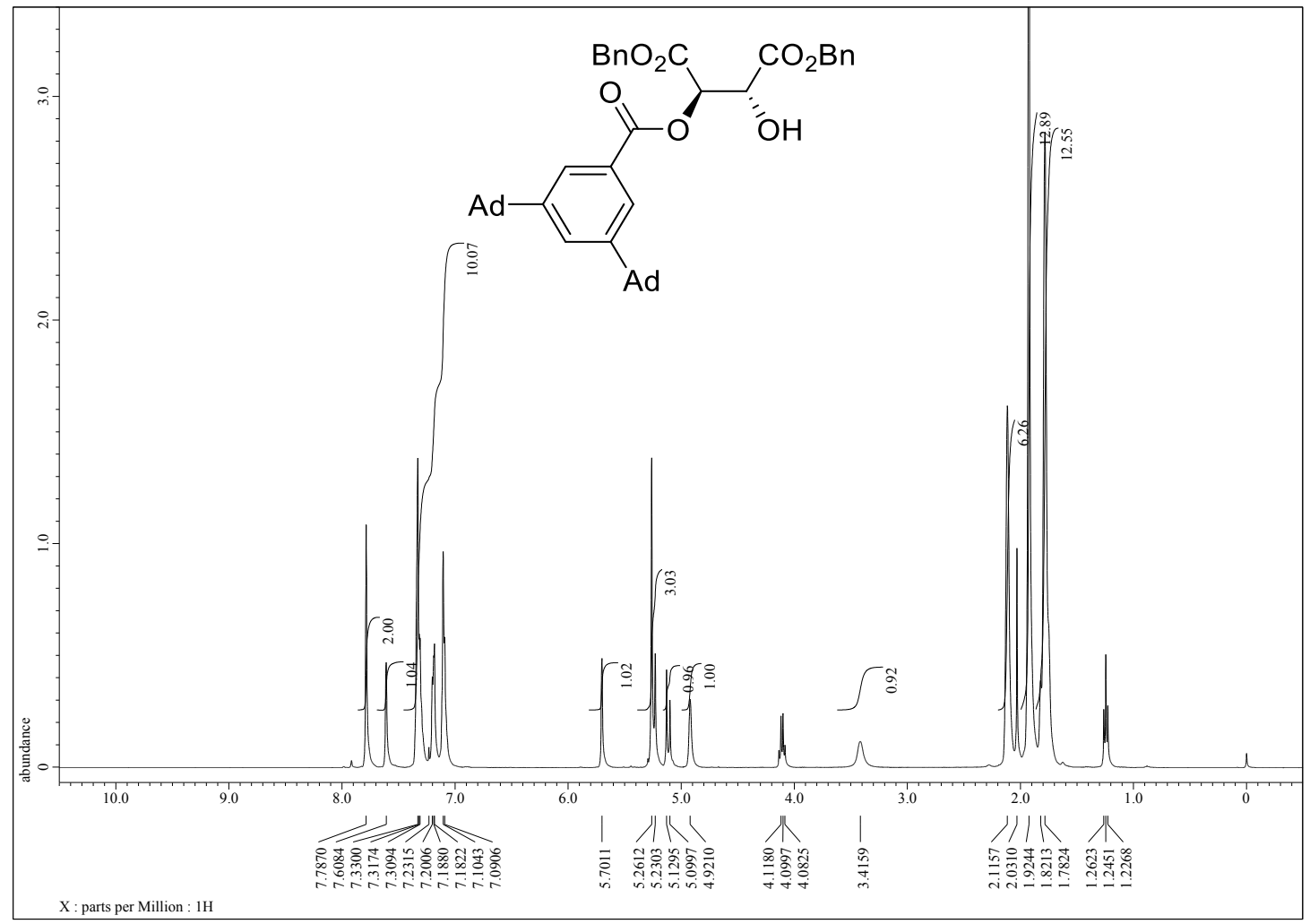

$O$-Benzoyl dibenzyl $(2 R, 3 R)$-tartrate (2c)

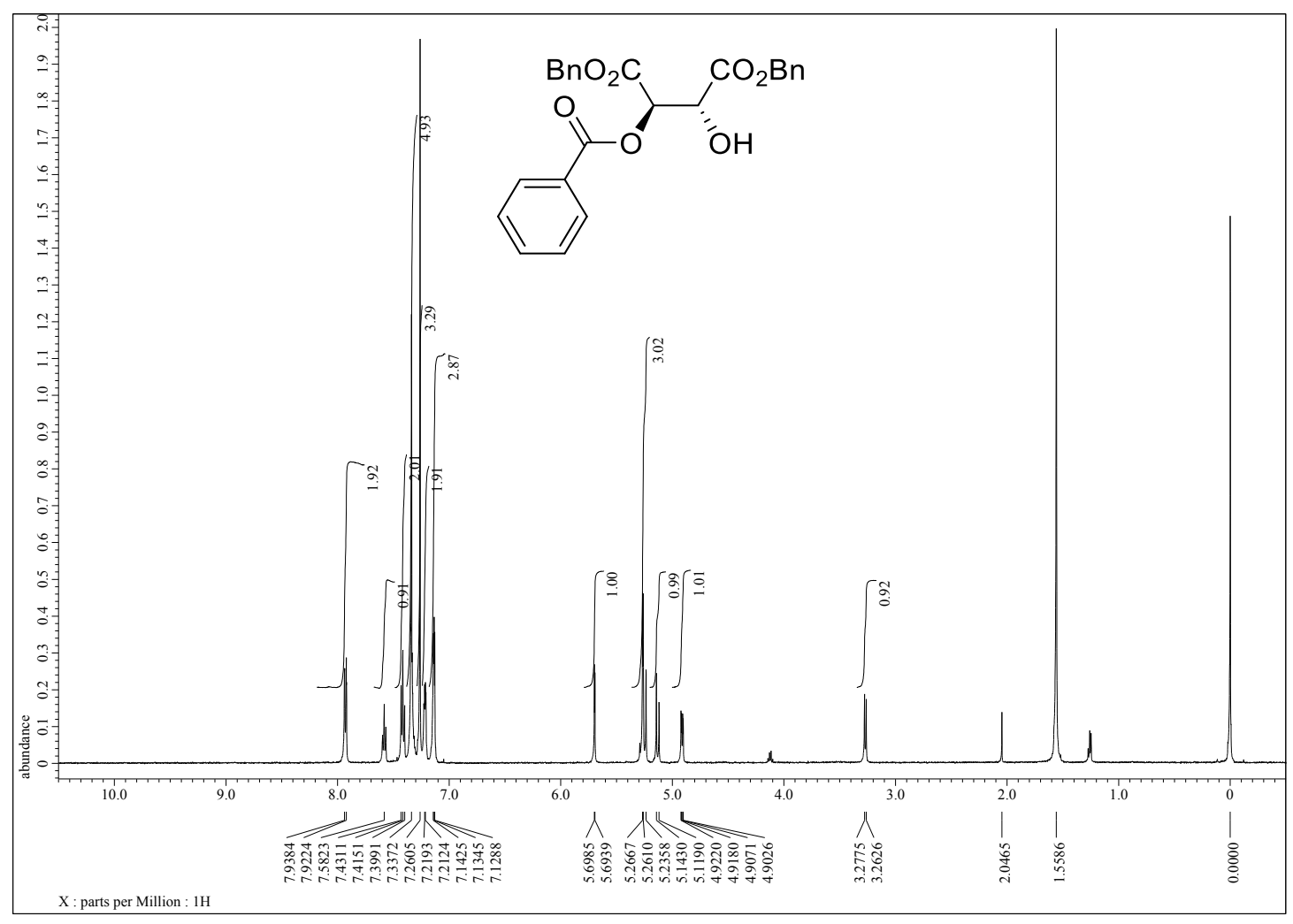




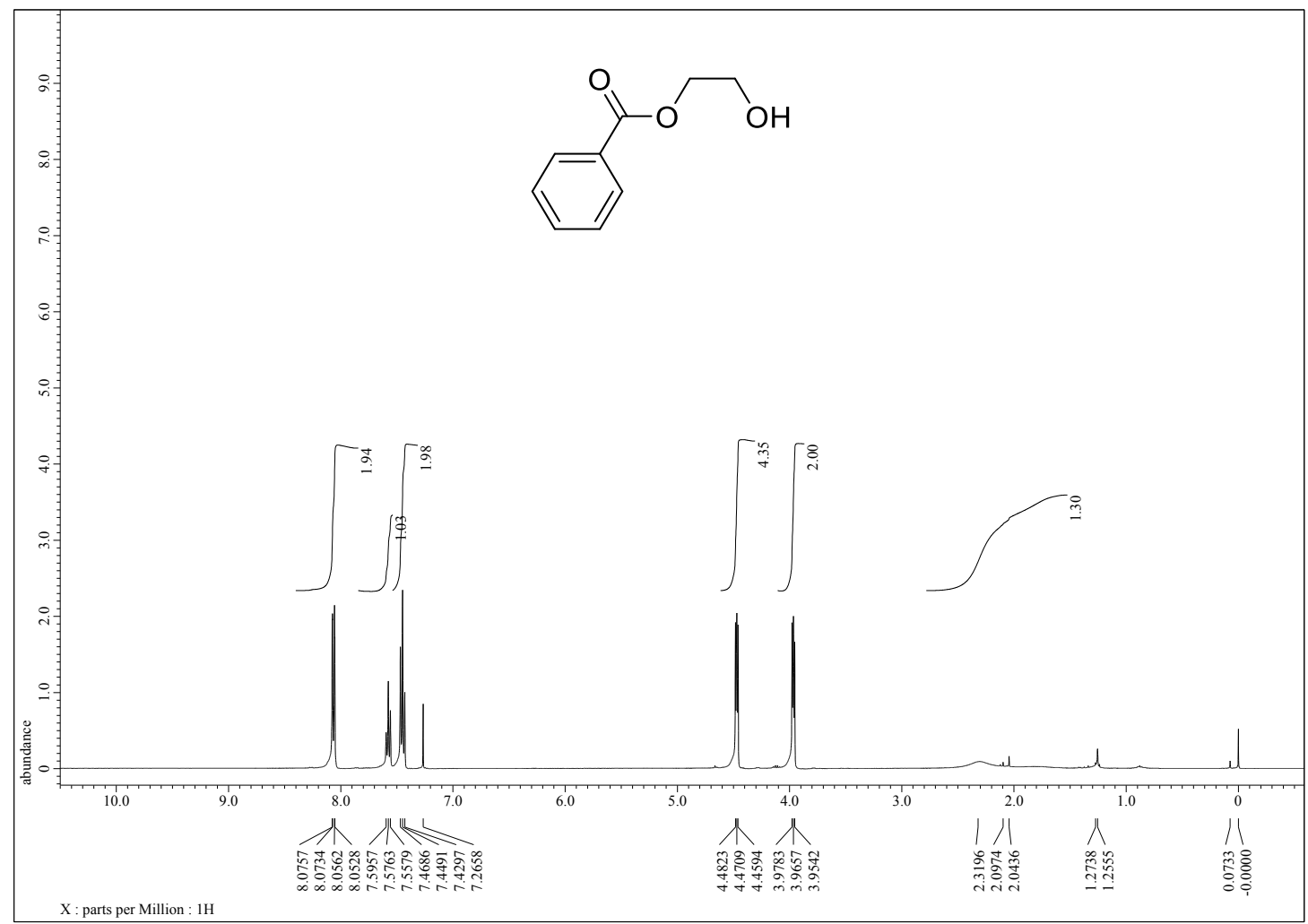

cis-2-Hydroxycyclohexyl benzoate

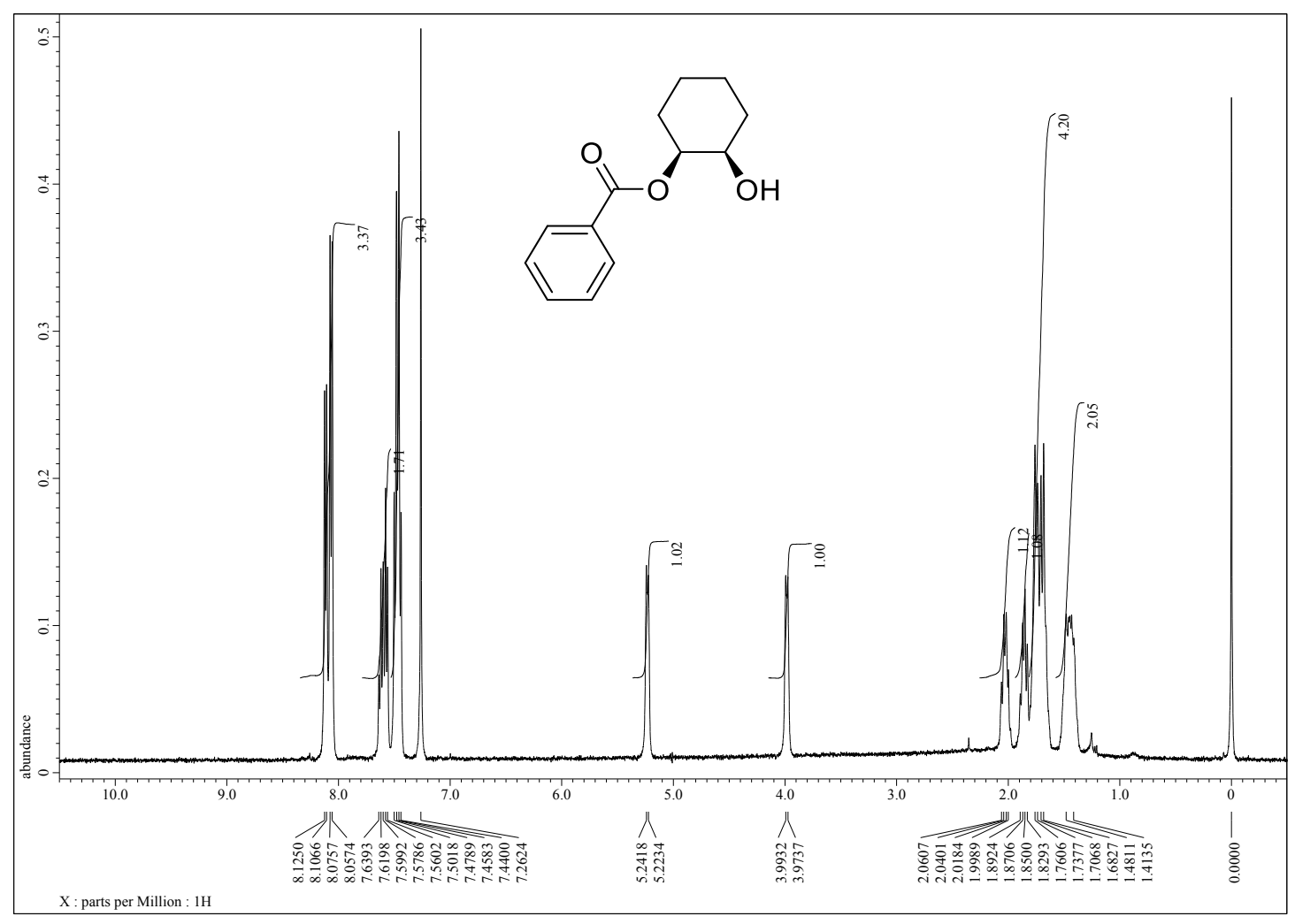


trans-2-Hydroxycyclohexyl benzoate

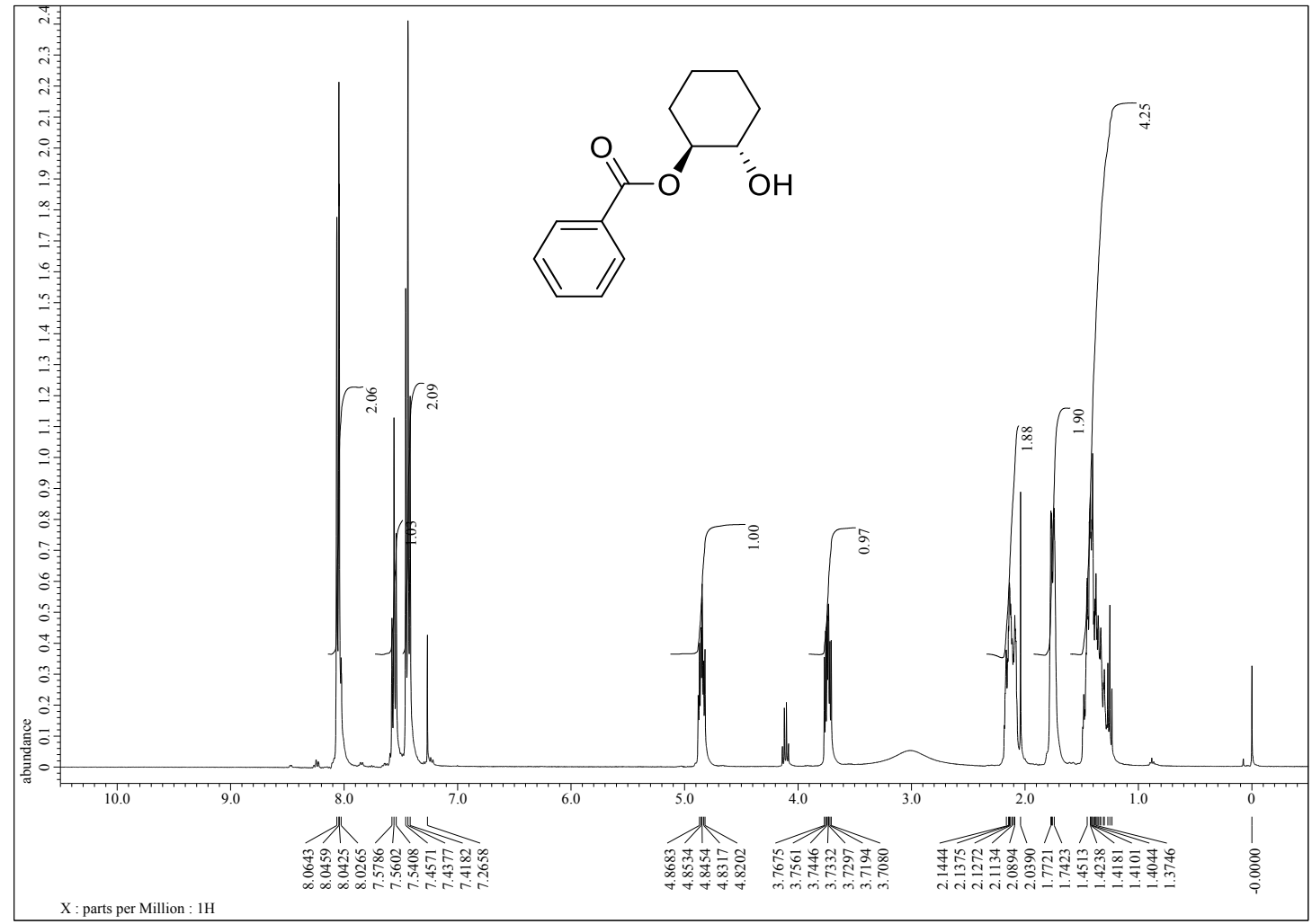

3-Hydroxy-2,2-dimethylpropyl benzoate

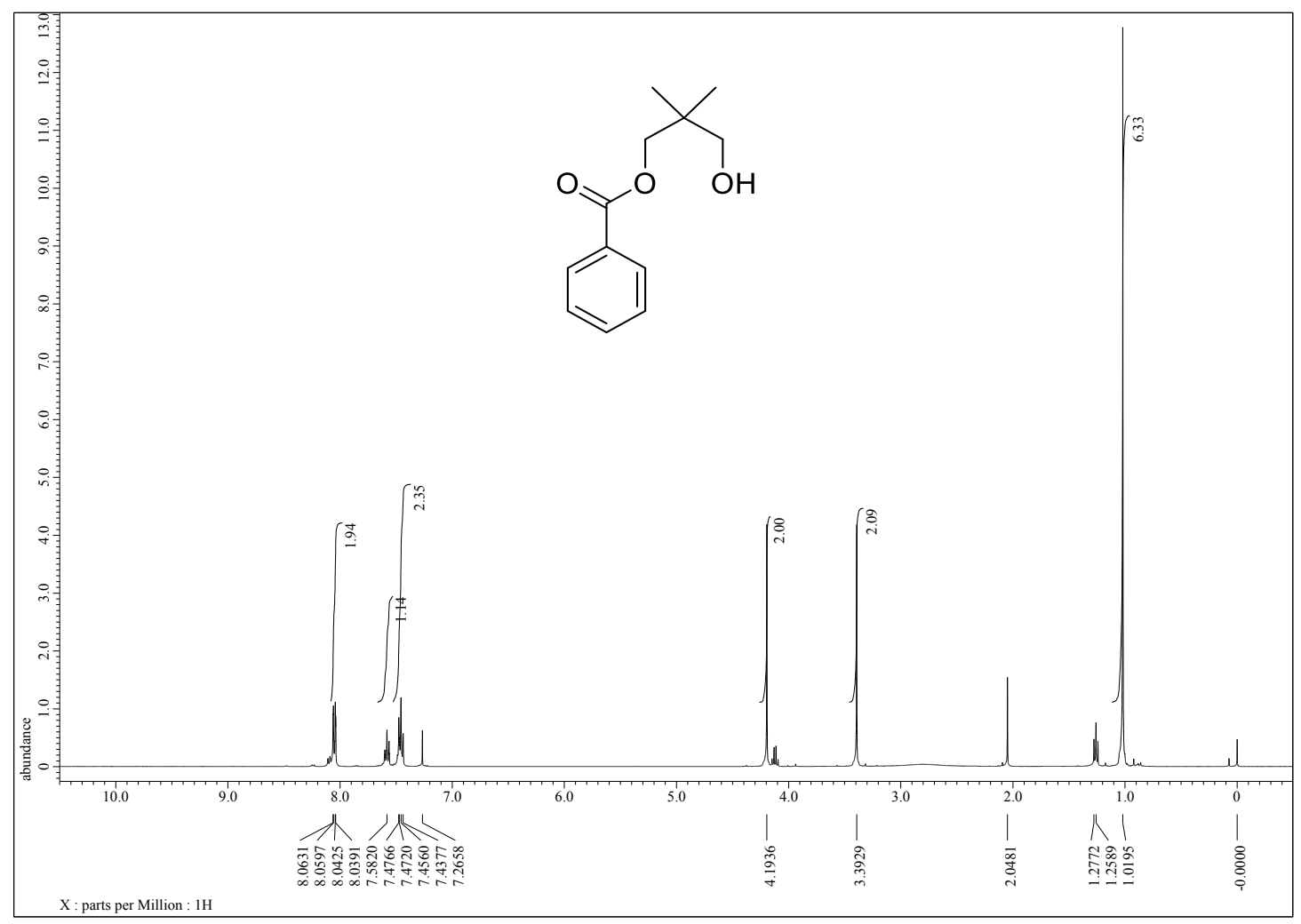




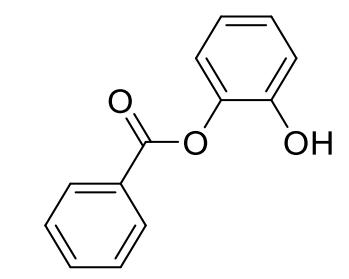

2-Hydroxyphenyl benzoate

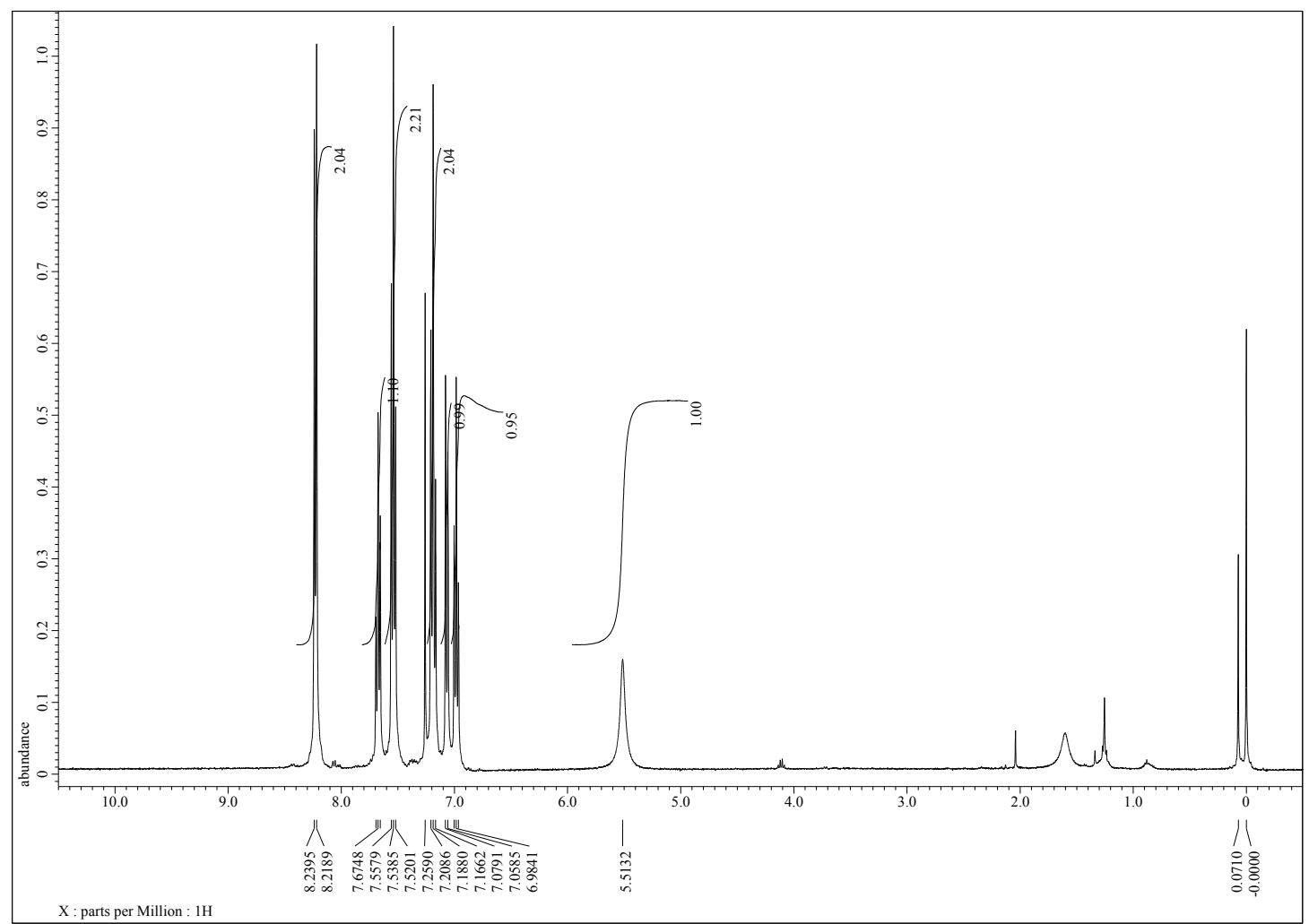




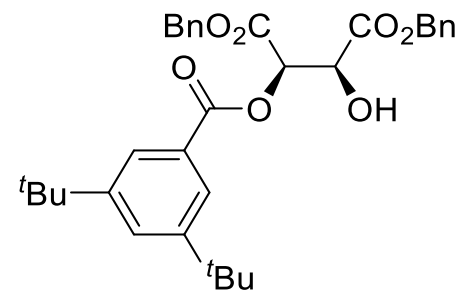

$O$-3,5-Di-tert-butylbenzoyl dibenzyl $(2 R, 3 S)$-tartrate (4a)
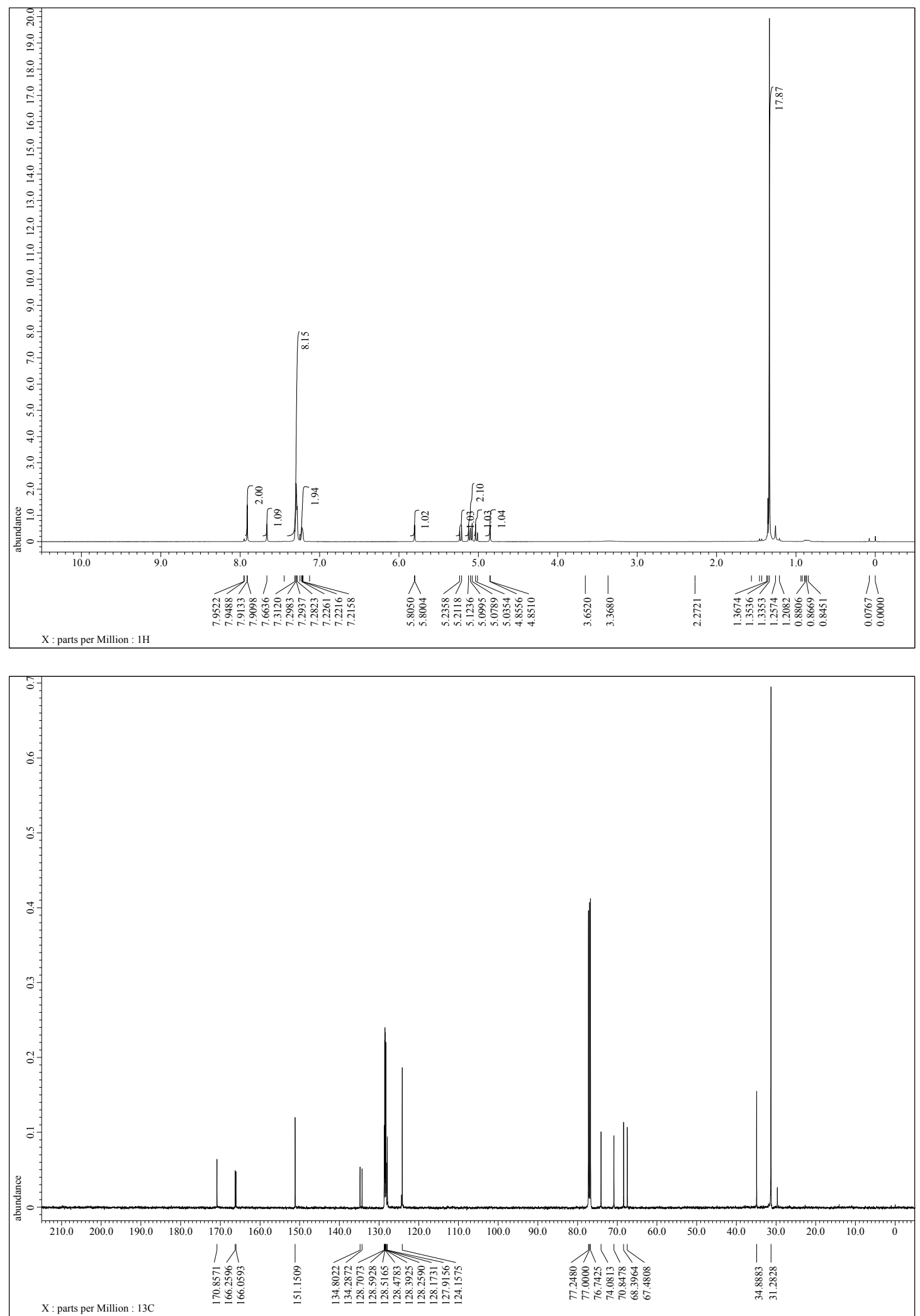

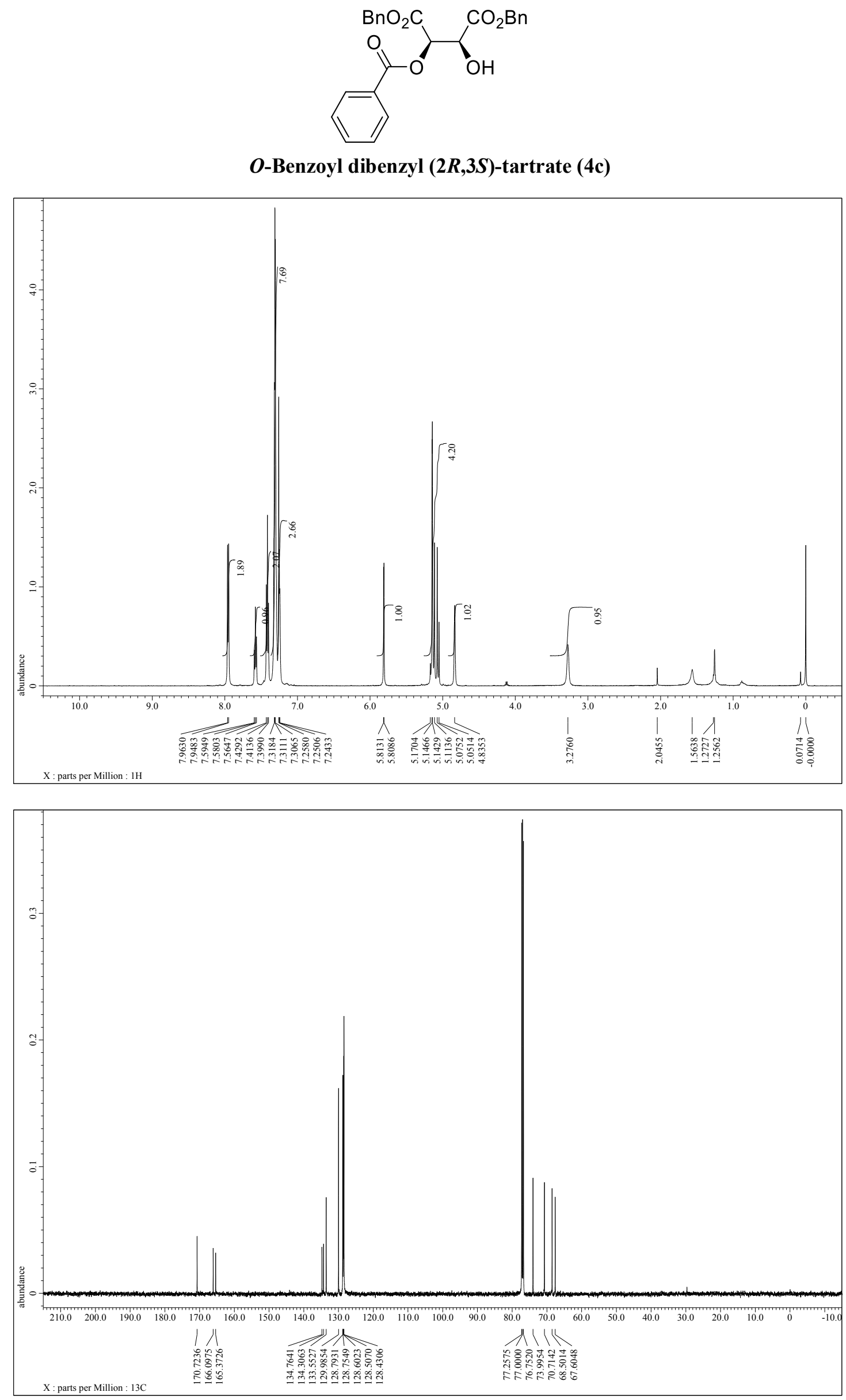

S25 


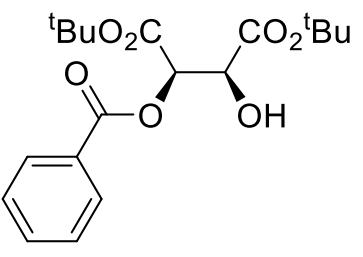

$O$-Benzoyl di-tert-butyl $(2 R, 3 S)$-tartrate $(5 \mathrm{c})$
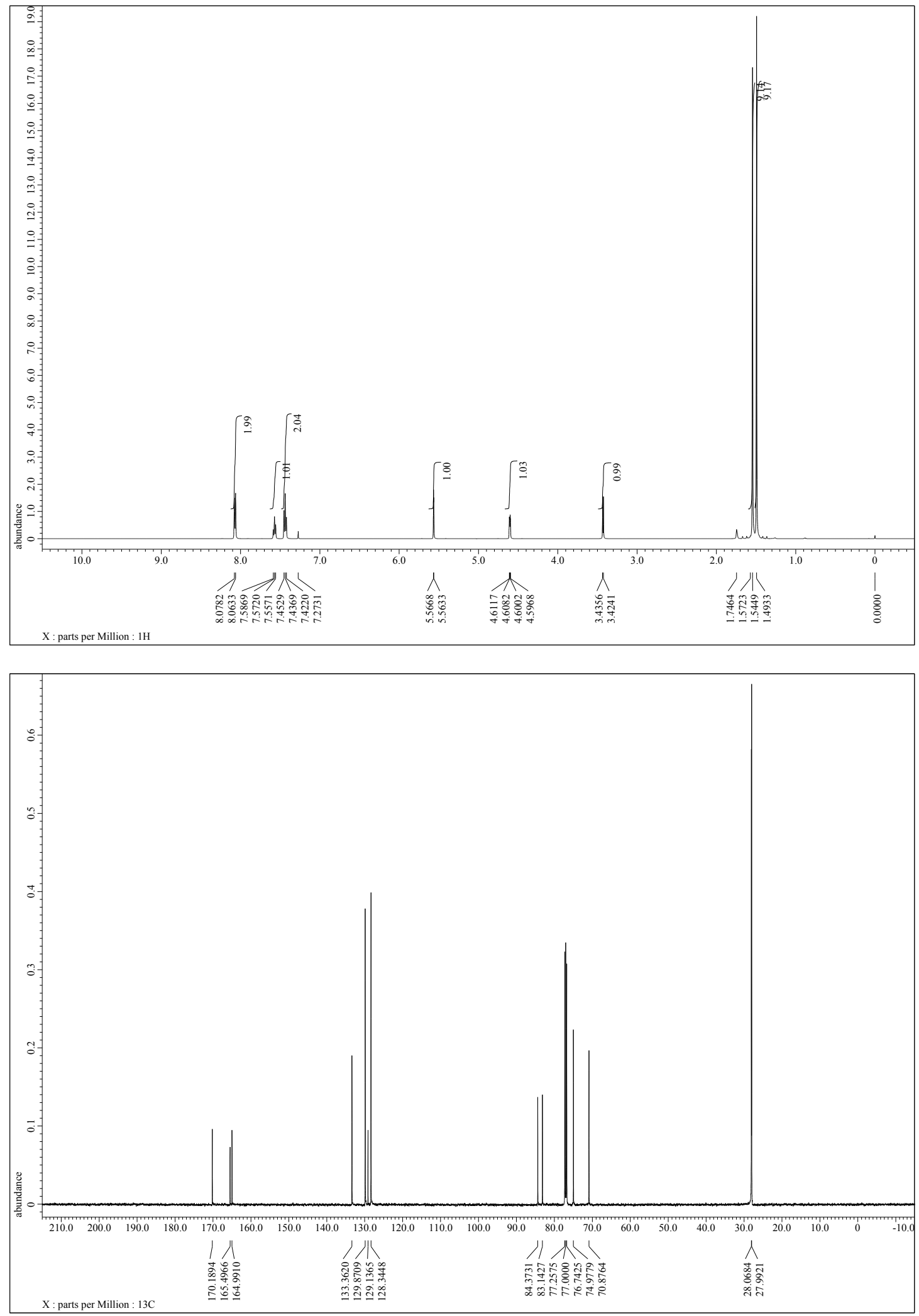
<smiles>COC(=O)[C@H](O)[C@@H](OC(=O)c1ccccc1)C(=O)OC</smiles>
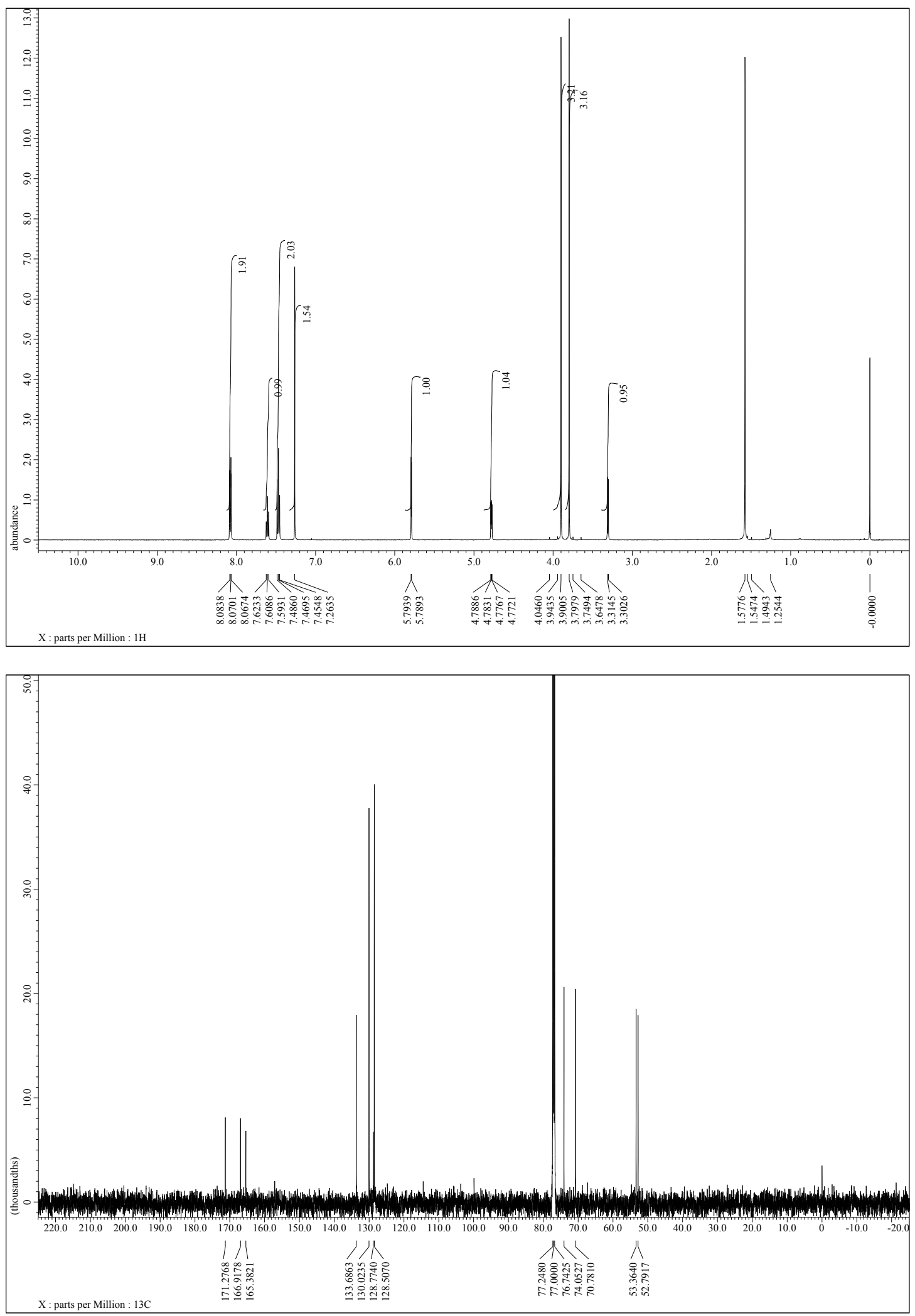

S27 
(1S,2R)-2-Hydroxy-1,2-diphenylethyl benzoate (7c)

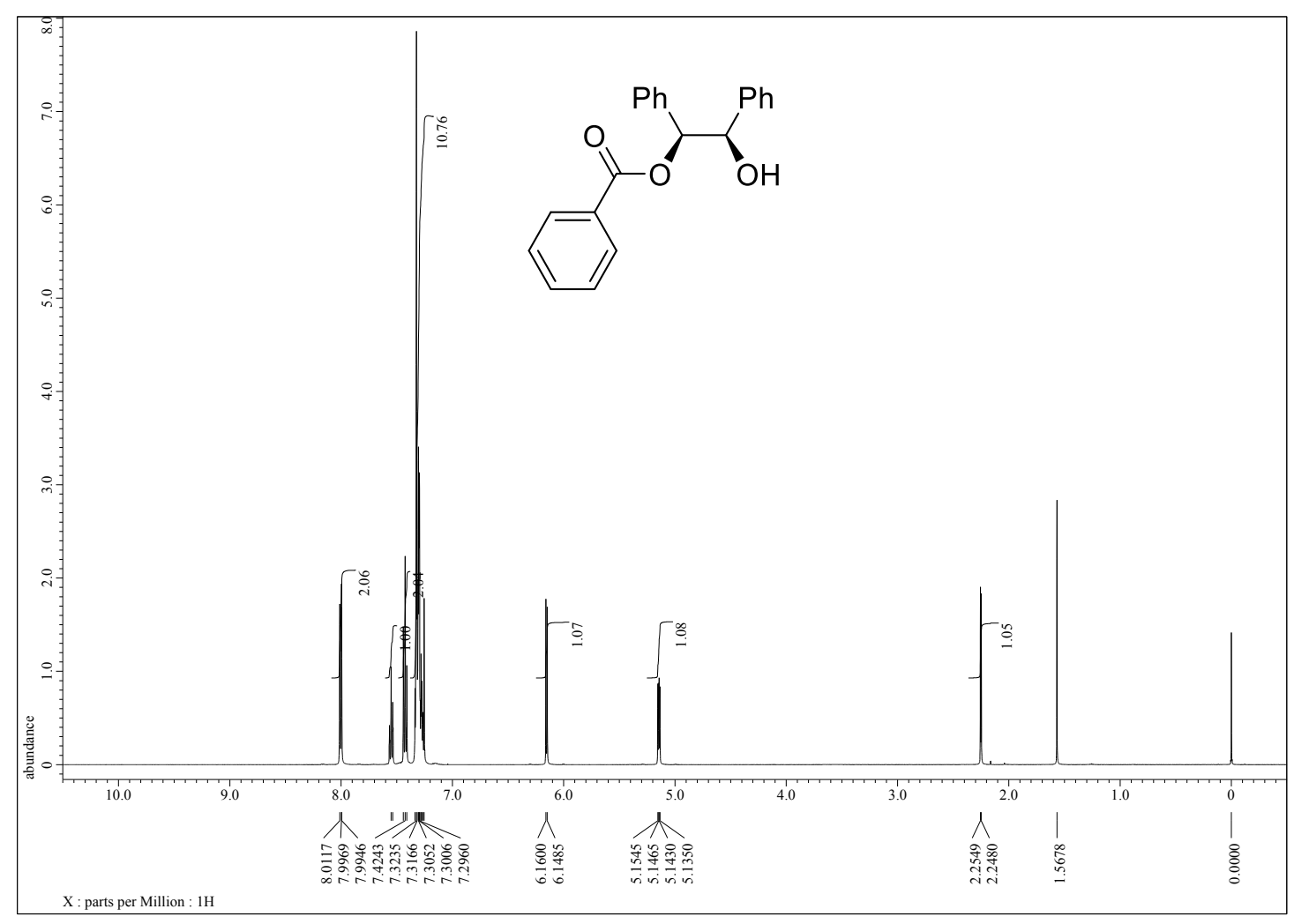

$(1 S, 2 R)$-2-Hydroxycyclohexyl benzoate (8c)

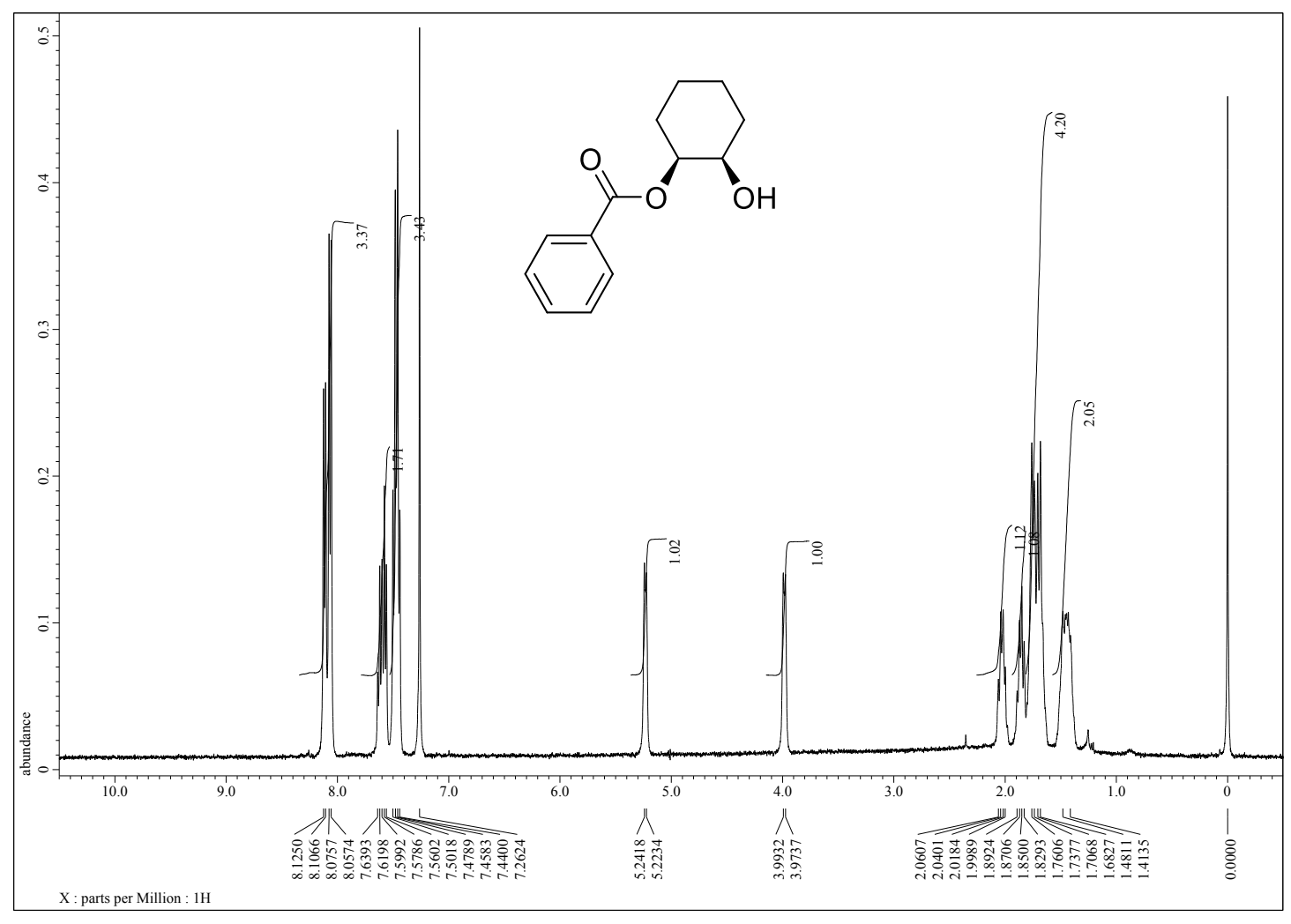

S28 


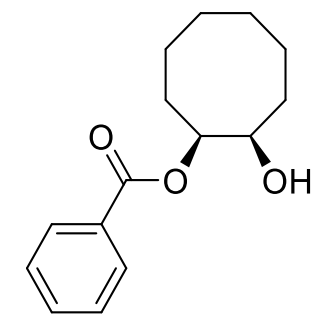

$(1 S, 2 R)$-2-Hydroxycyclooctyl benzoate (9c)

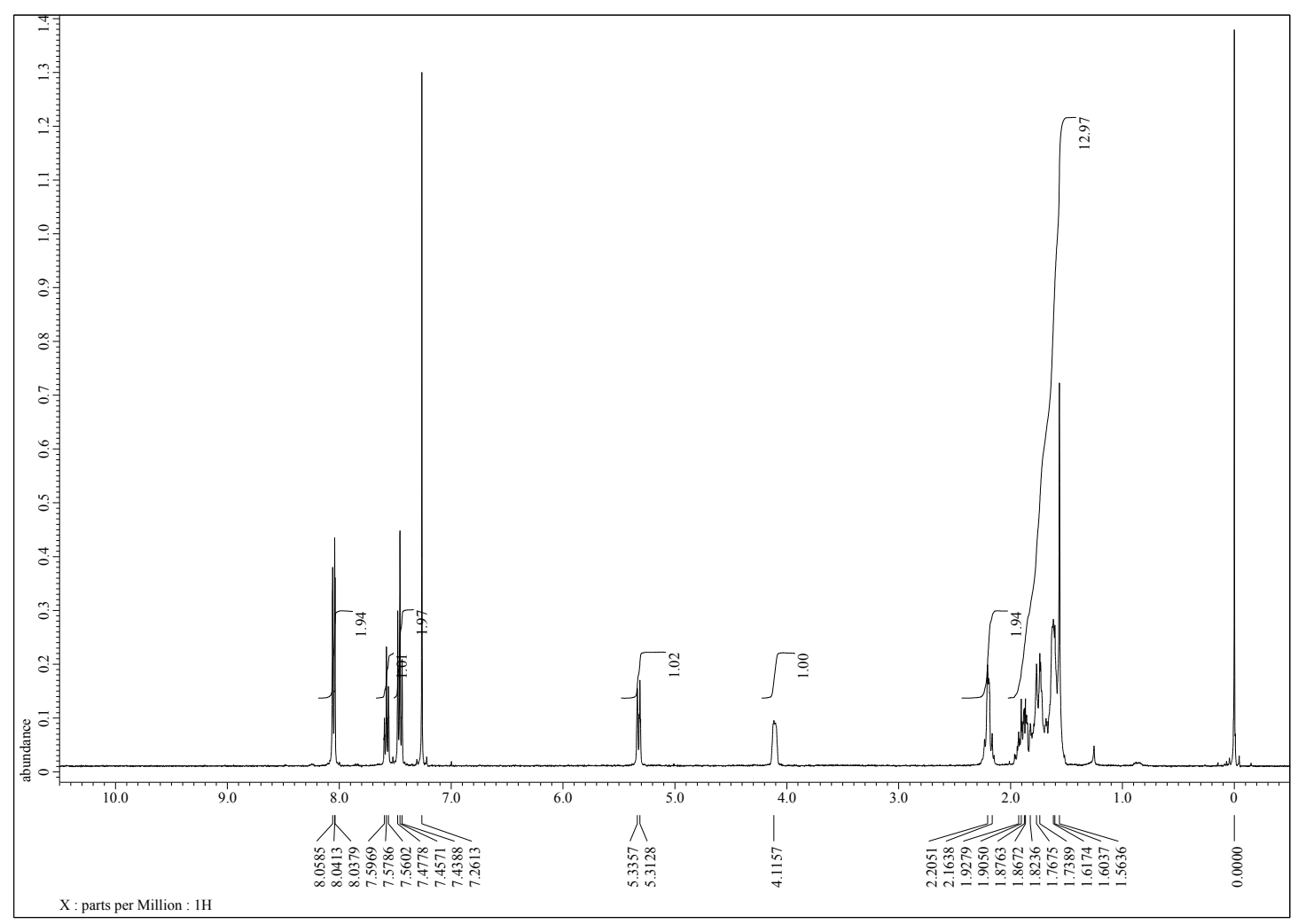




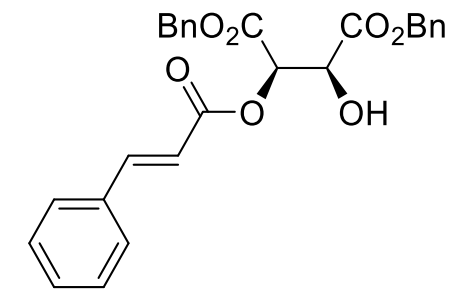

$O$-Cinnamoyl dibenzyl $(2 R, 3 S)$-tartrate (4d)
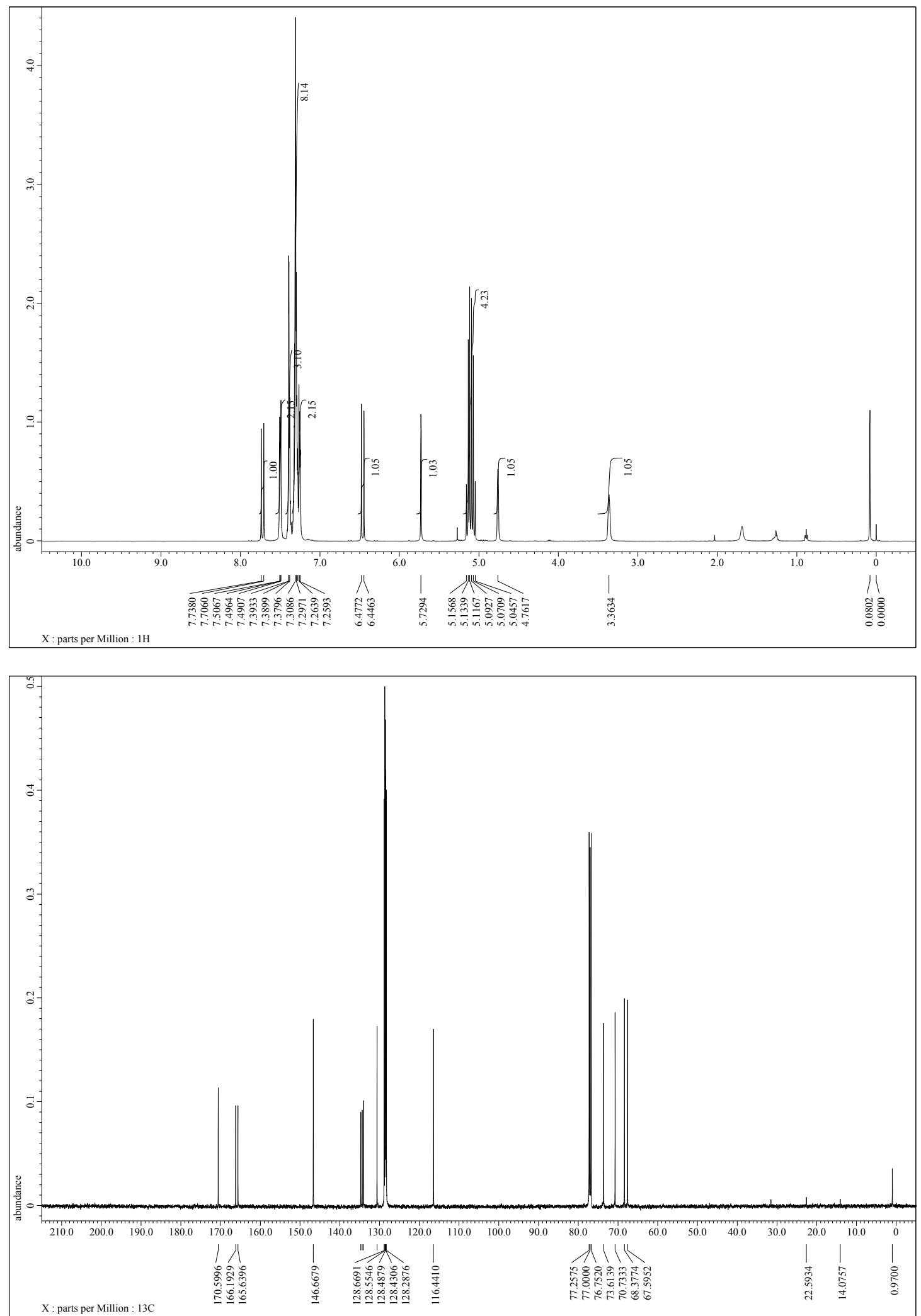


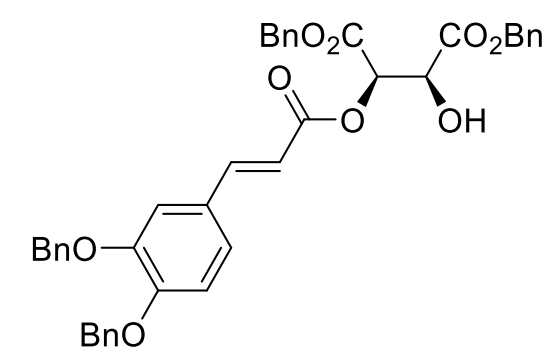

$O-3,4-D i b e n z y l o x y c i n n a m o y l ~ d i b e n z y l ~(2 R, 3 S)$-tartrate (4e)
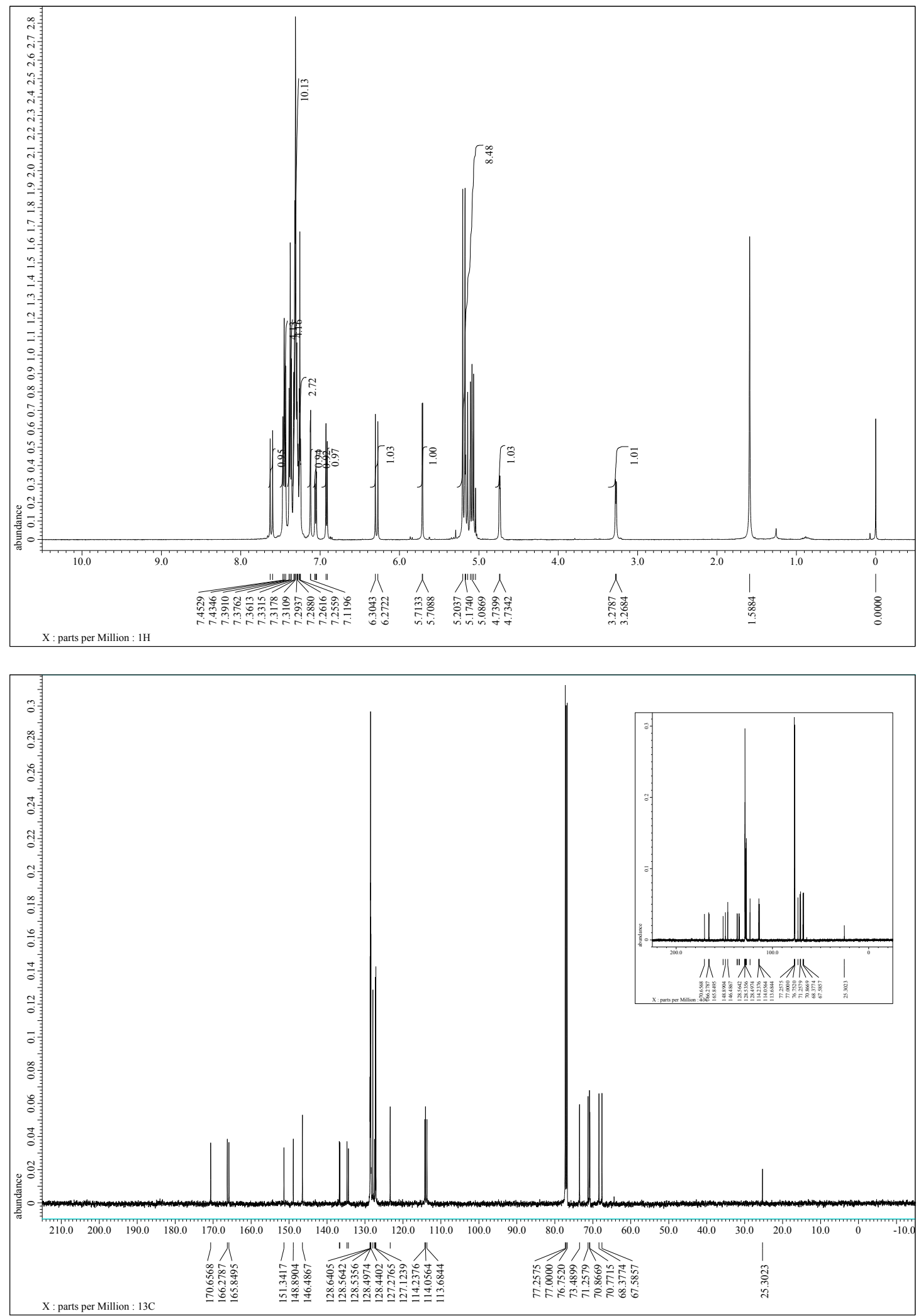


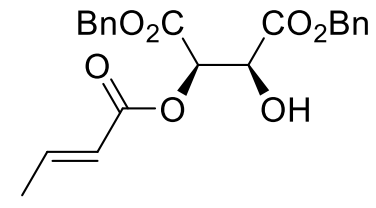

$O$-Crotonoyl dibenzyl $(2 R, 3 S)$-tartrate (4f)
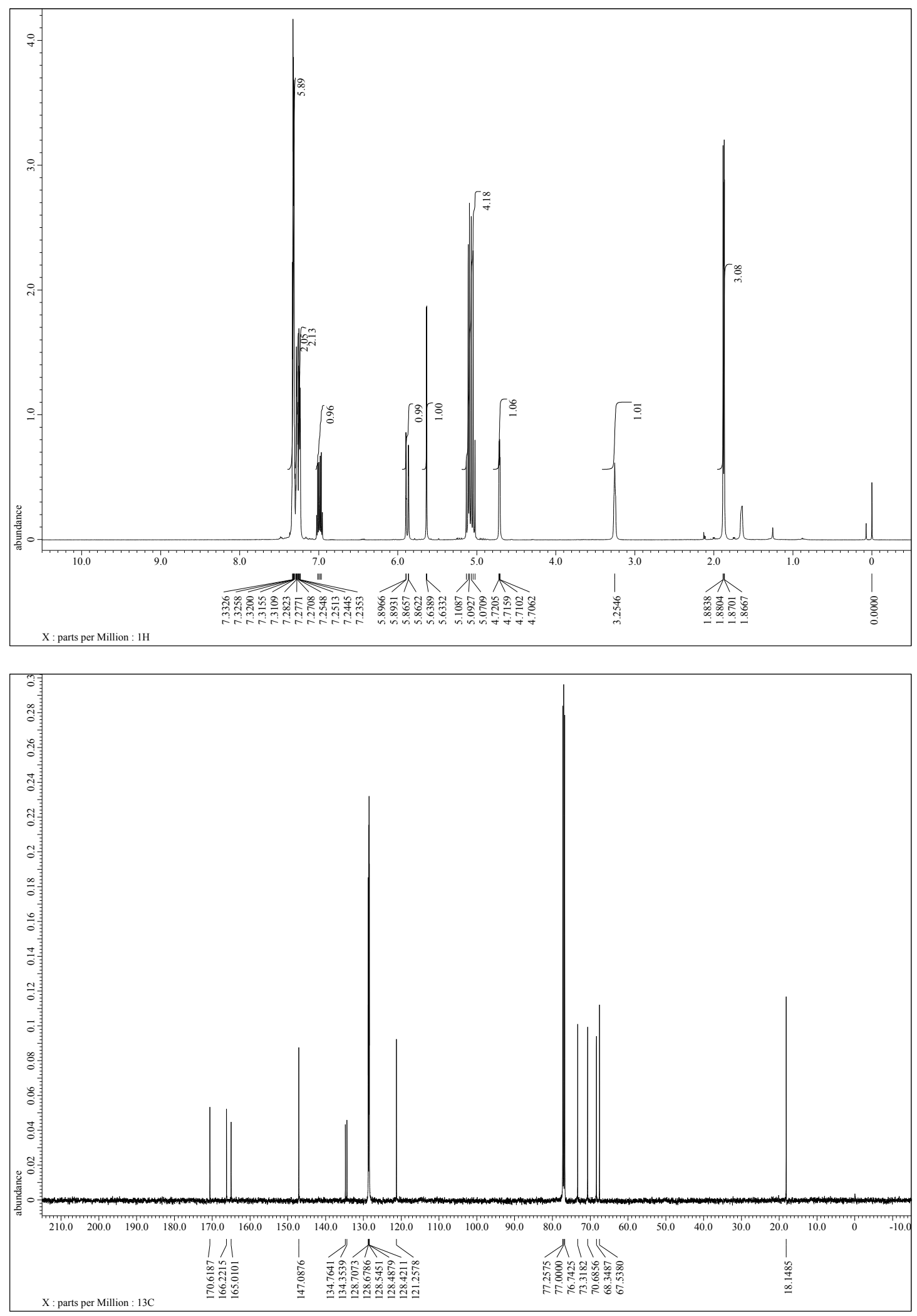


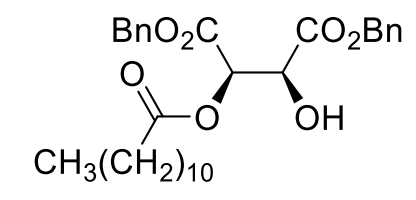

$O$ - Dodecanoyl dibenzyl $(2 R, 3 S)$-tartrate $(4 \mathrm{~g})$
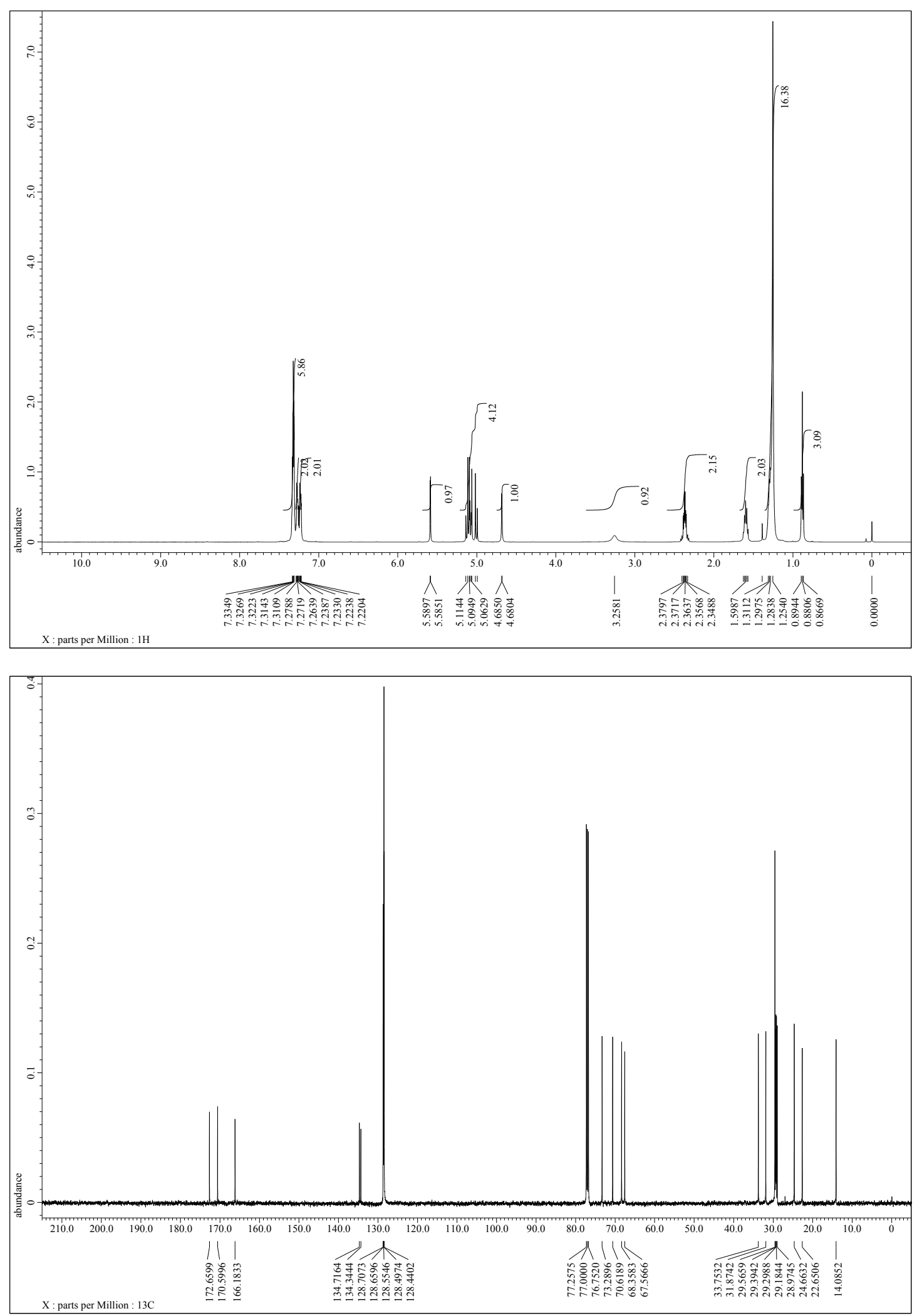


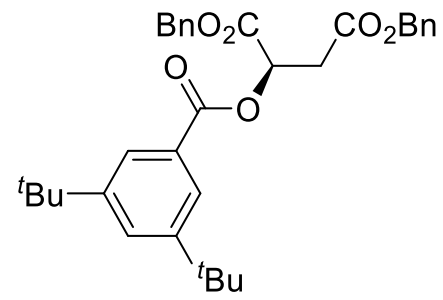

Dibenzyl ( $R)$-2-((3,5-di-tert-butylbenzoyl)oxy)succinate
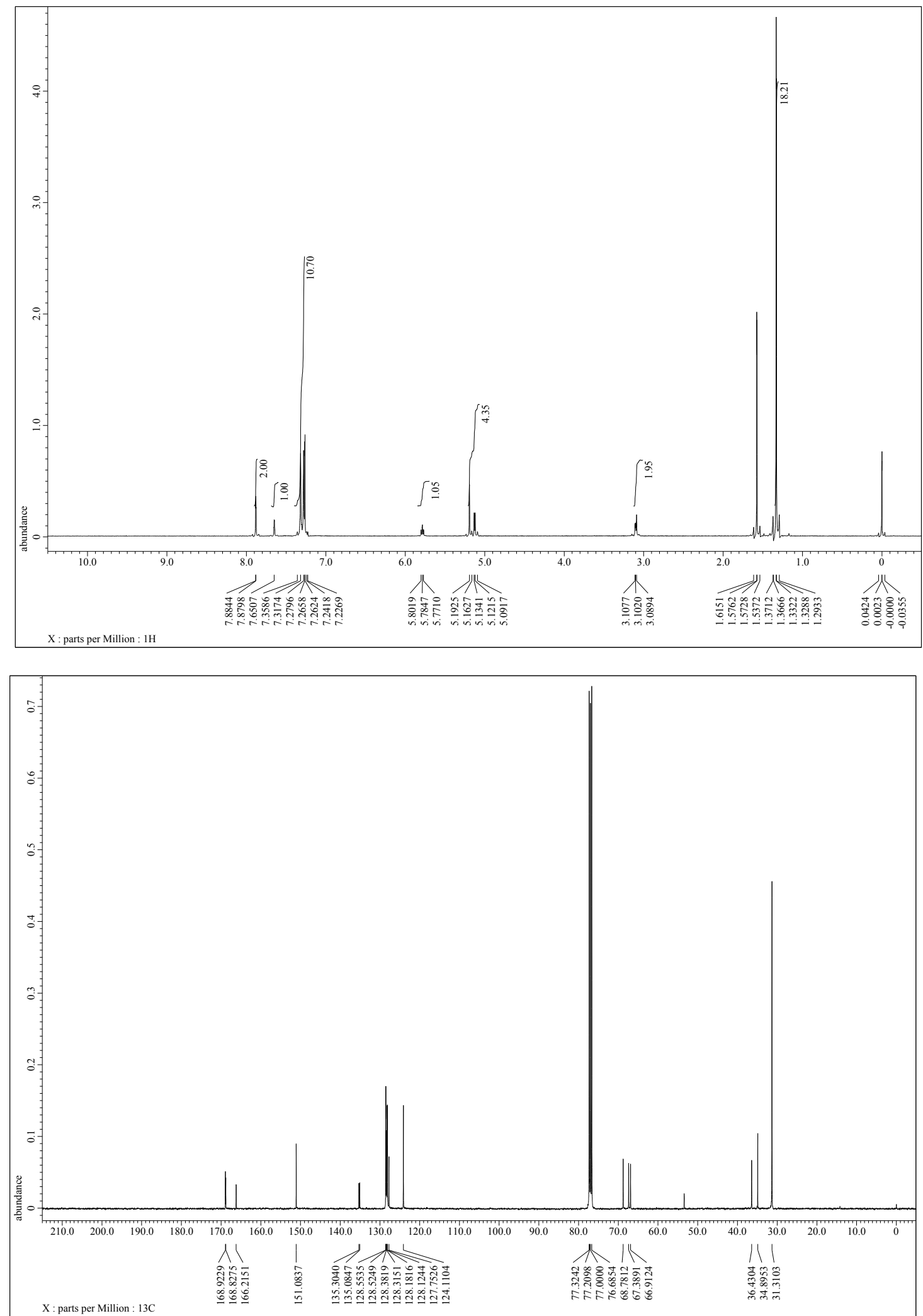


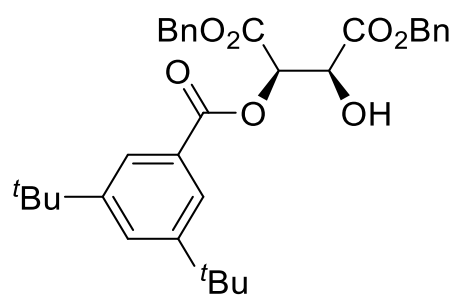

$O$-3,5-Di-tert-butylbenzoyl dibenzyl $(2 R, 3 S)$-tartrate (4a) CHIRALPAK AD-H

$\mathrm{Hex} /{ }^{i} \mathrm{PrOH}=9: 1$

$1.0 \mathrm{~mL} / \mathrm{min}, 254 \mathrm{~nm}$

1. Racemic

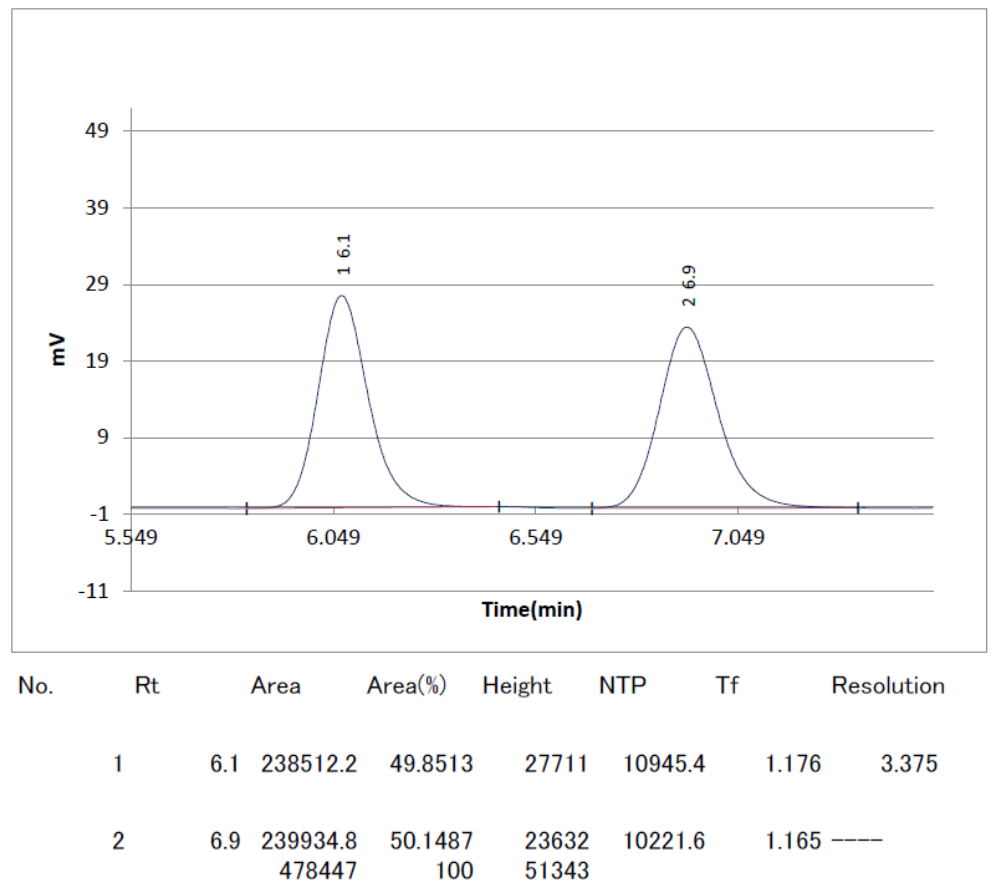

2. Optically active (93\% ee)

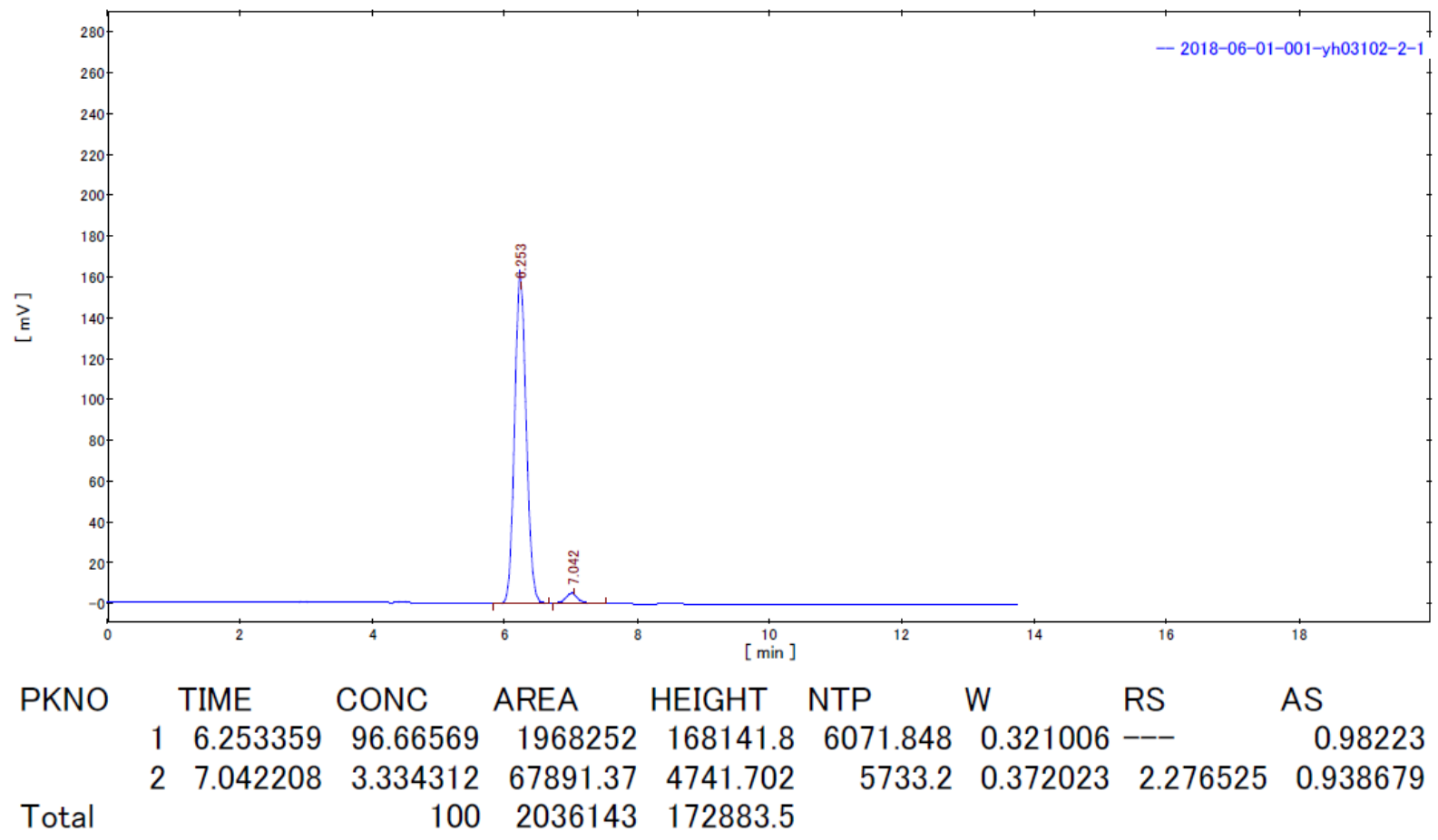




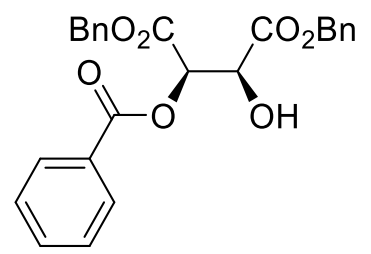

$O$-Benzoyl dibenzyl $(2 R, 3 S)$-tartrate (4c) CHIRALPAK AD-H

$\mathrm{Hex} /{ }^{i} \mathrm{PrOH}=9: 1$

$1.0 \mathrm{~mL} / \mathrm{min}, 254 \mathrm{~nm}$

1. Racemic

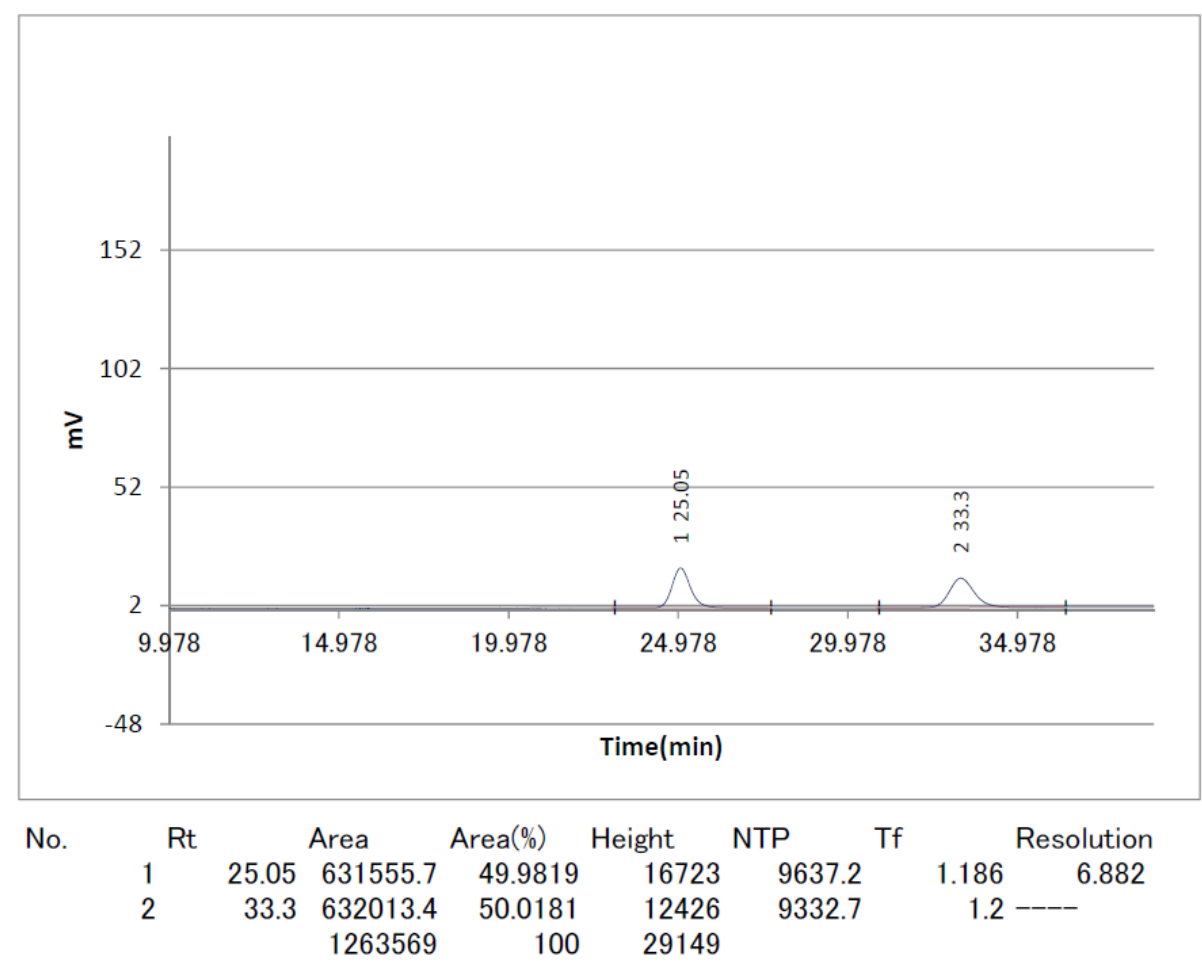

2. Optically active $(96 \%$ ee $)$

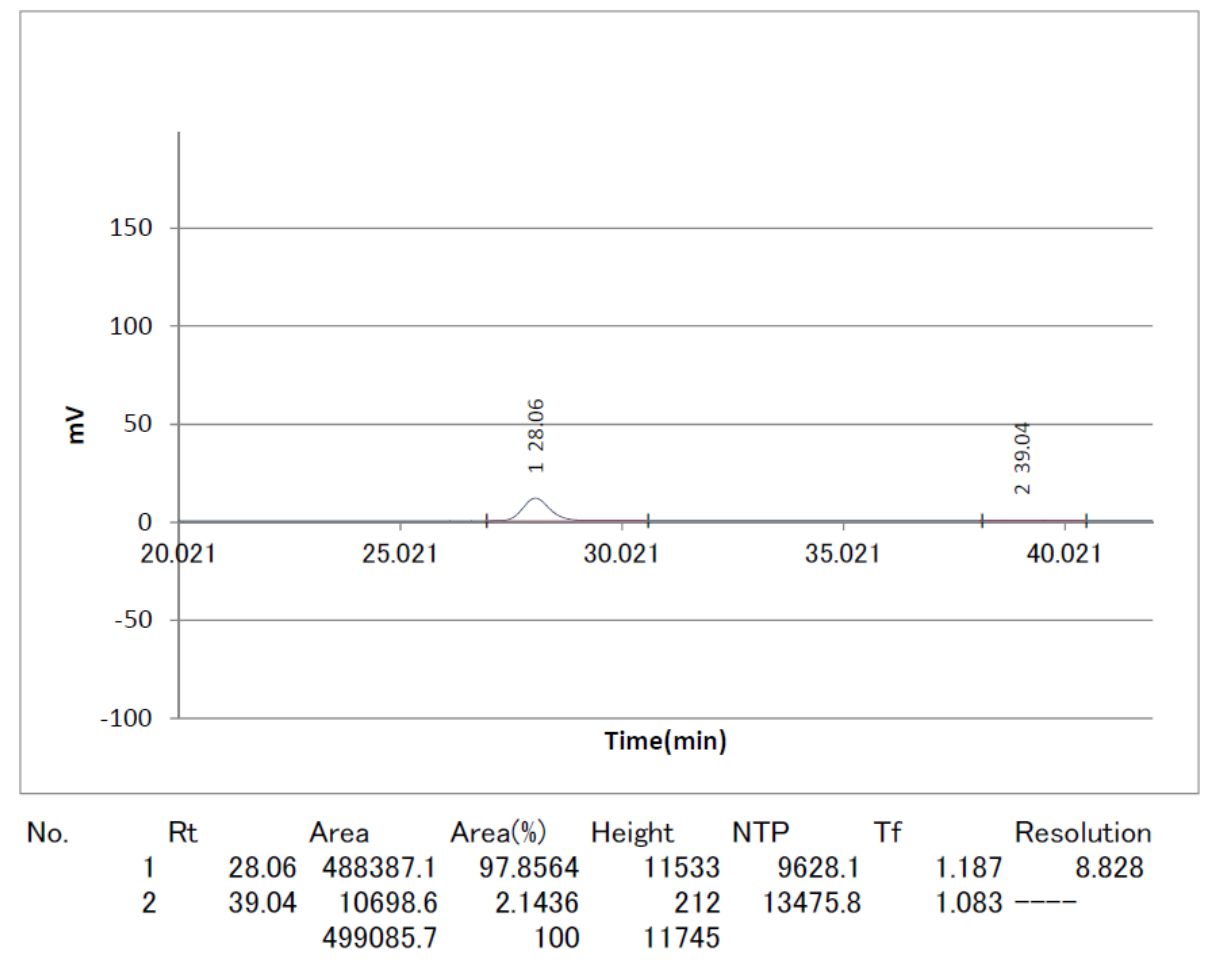




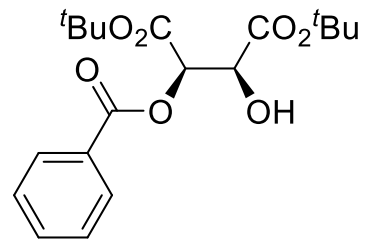

$O$-Benzoyl di-tert-butyl $(2 R, 3 S)$-tartrate (5c)

\section{CHIRALPAK AD}

$\mathrm{Hex} /{ }^{i} \mathrm{PrOH}=9: 1$

$1.0 \mathrm{~mL} / \mathrm{min}, 254 \mathrm{~nm}$

1. Racemic

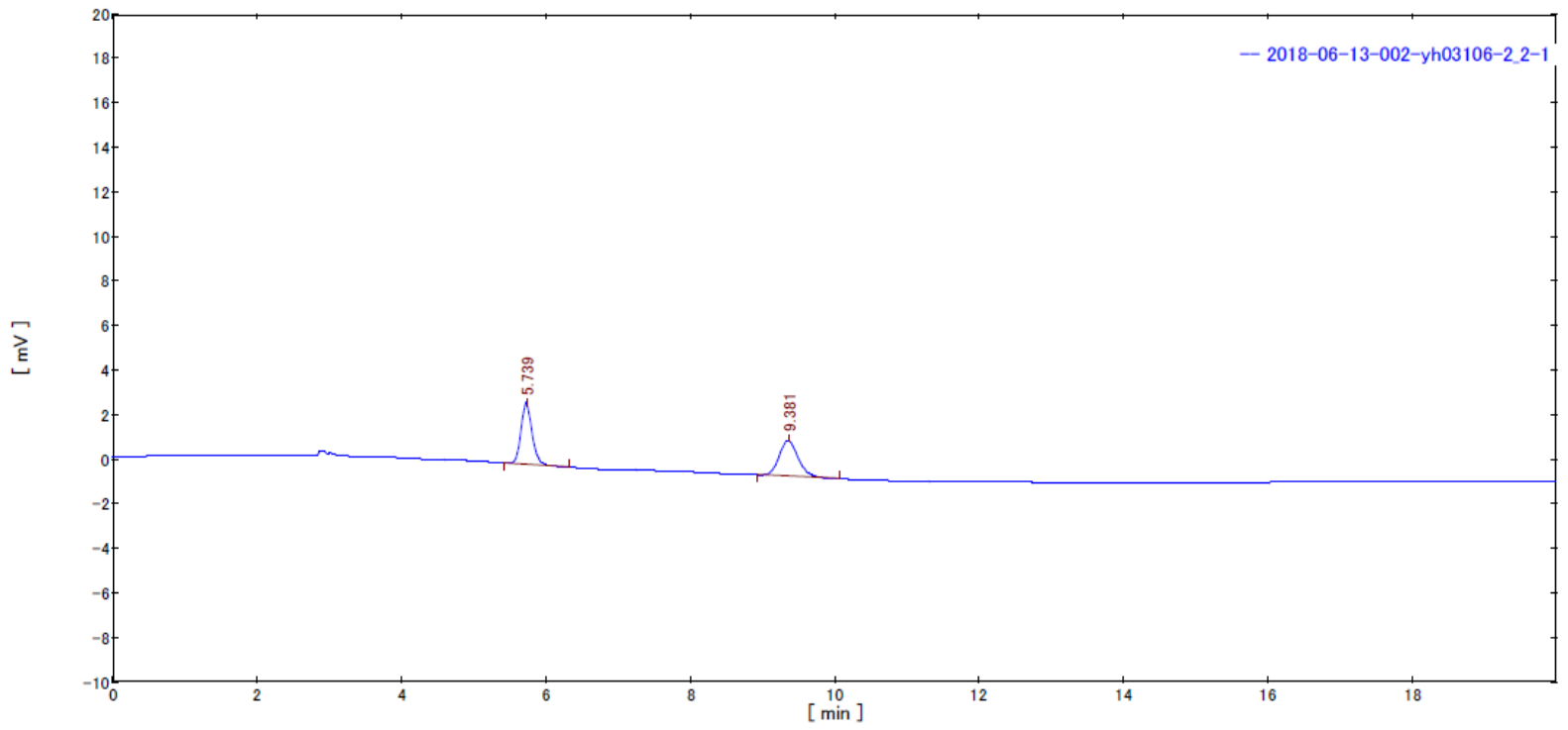

\begin{tabular}{llrlrlllll} 
PKNO & \multicolumn{1}{l}{ TIME } & CONC & AREA & HEIGHT & NTP & W & RS & AS \\
& 1 & 5.739399 & 50.14634 & 29388.71 & 2934.065 & 6315.938 & 0.288873 & --- & 1.090461 \\
& 2 & 9.381152 & 49.85366 & 29217.18 & 1584.692 & 5524.645 & 0.504852 & 9.176355 & 1.071144 \\
Total & & & 100 & 58605.89 & 4518.757 & & & &
\end{tabular}

2. Optically active ( $23 \%$ ee)

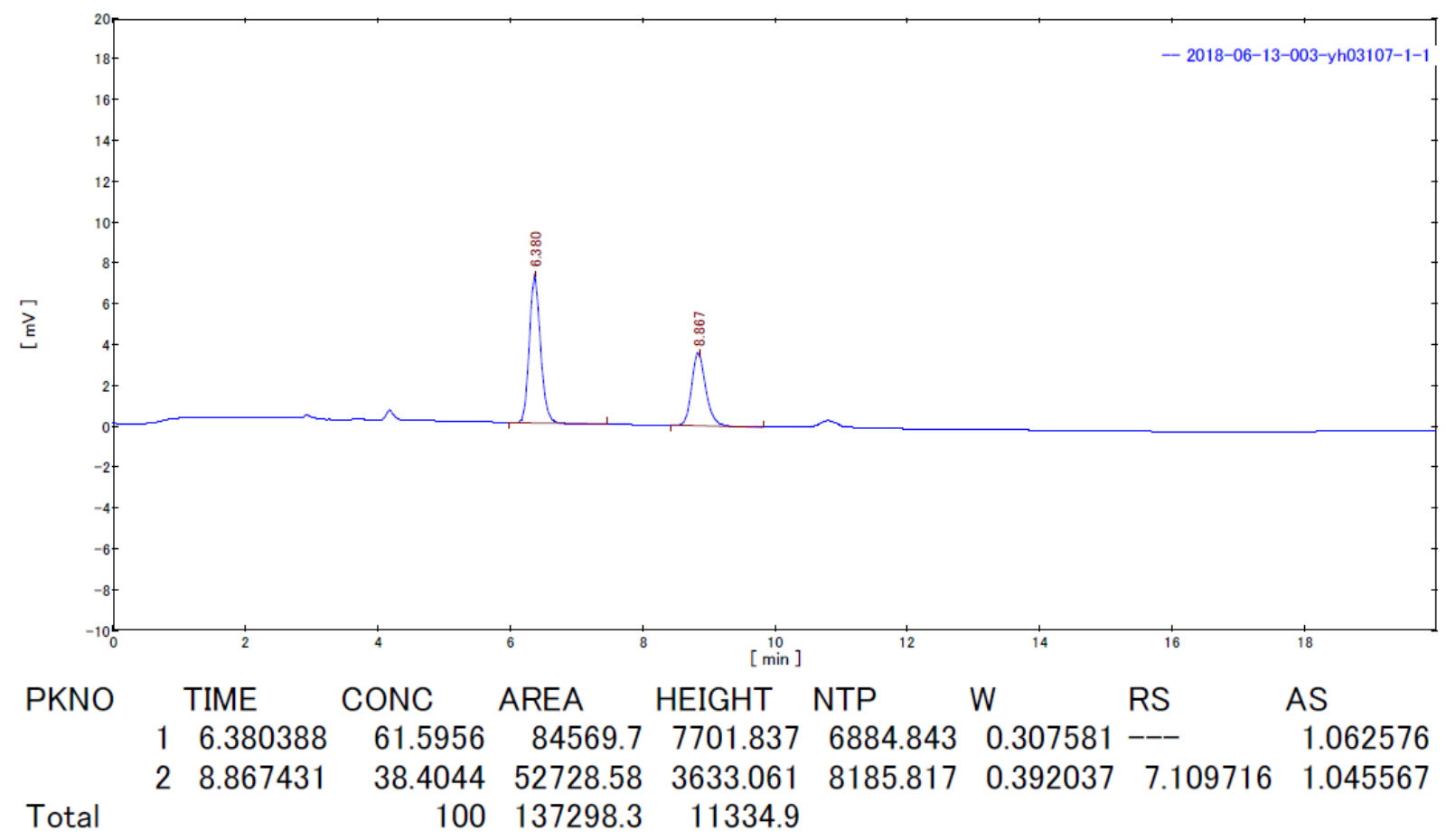




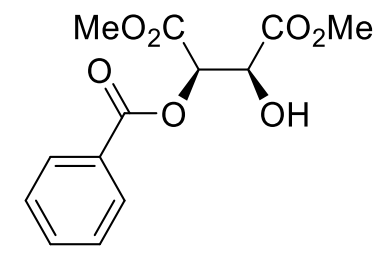

$O$-Benzoyl dimethyl $(2 R, 3 S)$-tartrate (6c)

CHIRALPAK AD

$\mathrm{Hex} /{ }^{i} \mathrm{PrOH}=4: 1$

$1.0 \mathrm{~mL} / \mathrm{min}, 254 \mathrm{~nm}$

1. Racemic

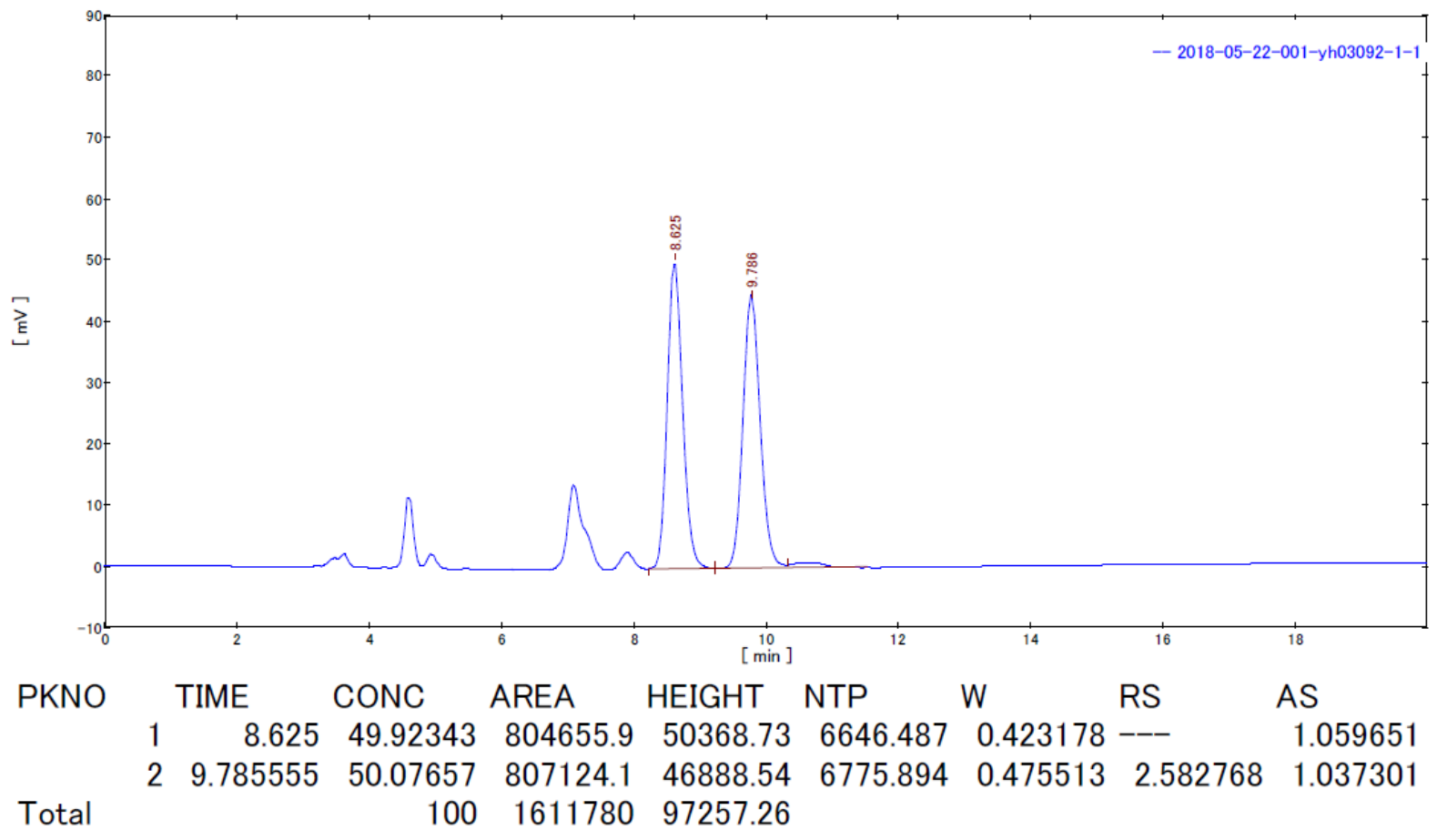

2. Optically active ( $82 \%$ ee)

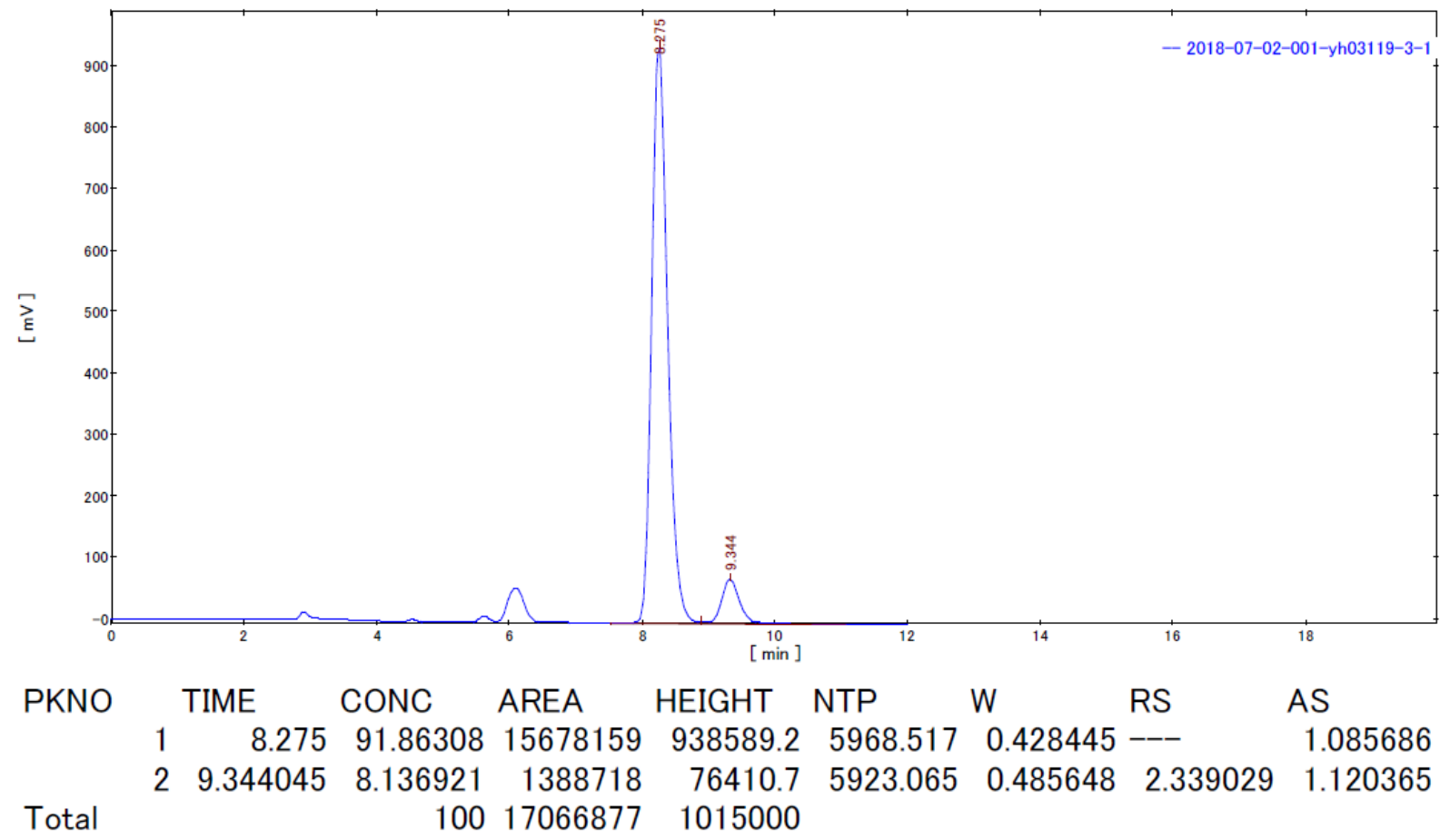




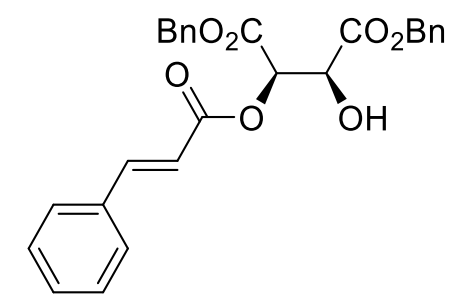

$O$-Cinnamoyl dibenzyl $(2 R, 3 S)$-tartrate (4d)

CHIRALPAK AD

$\mathrm{Hex} /{ }^{i} \mathrm{PrOH}=4: 1$

$1.0 \mathrm{~mL} / \mathrm{min}, 254 \mathrm{~nm}$

1. Racemic
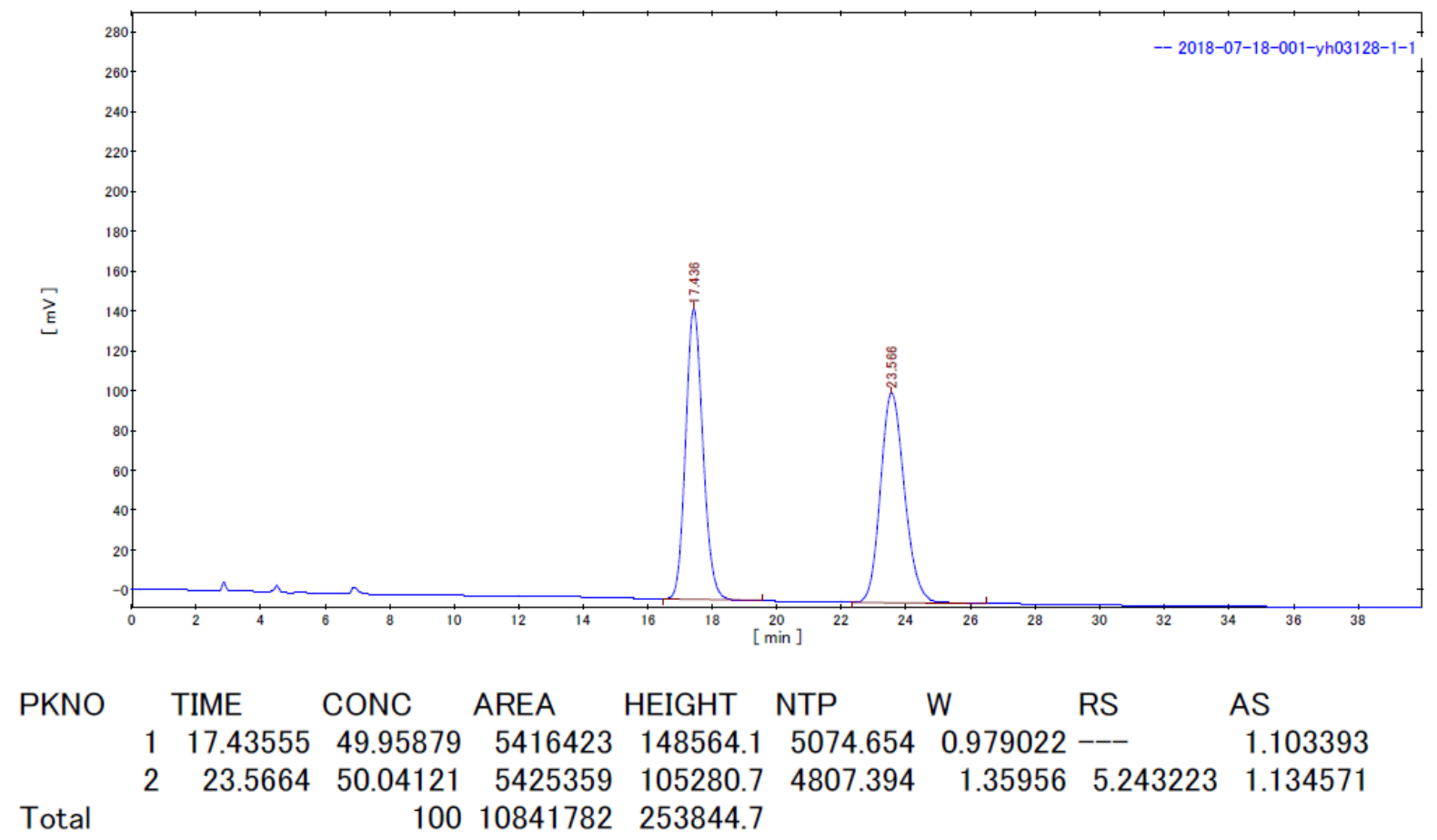

2. Optically active ( $82 \%$ ee)

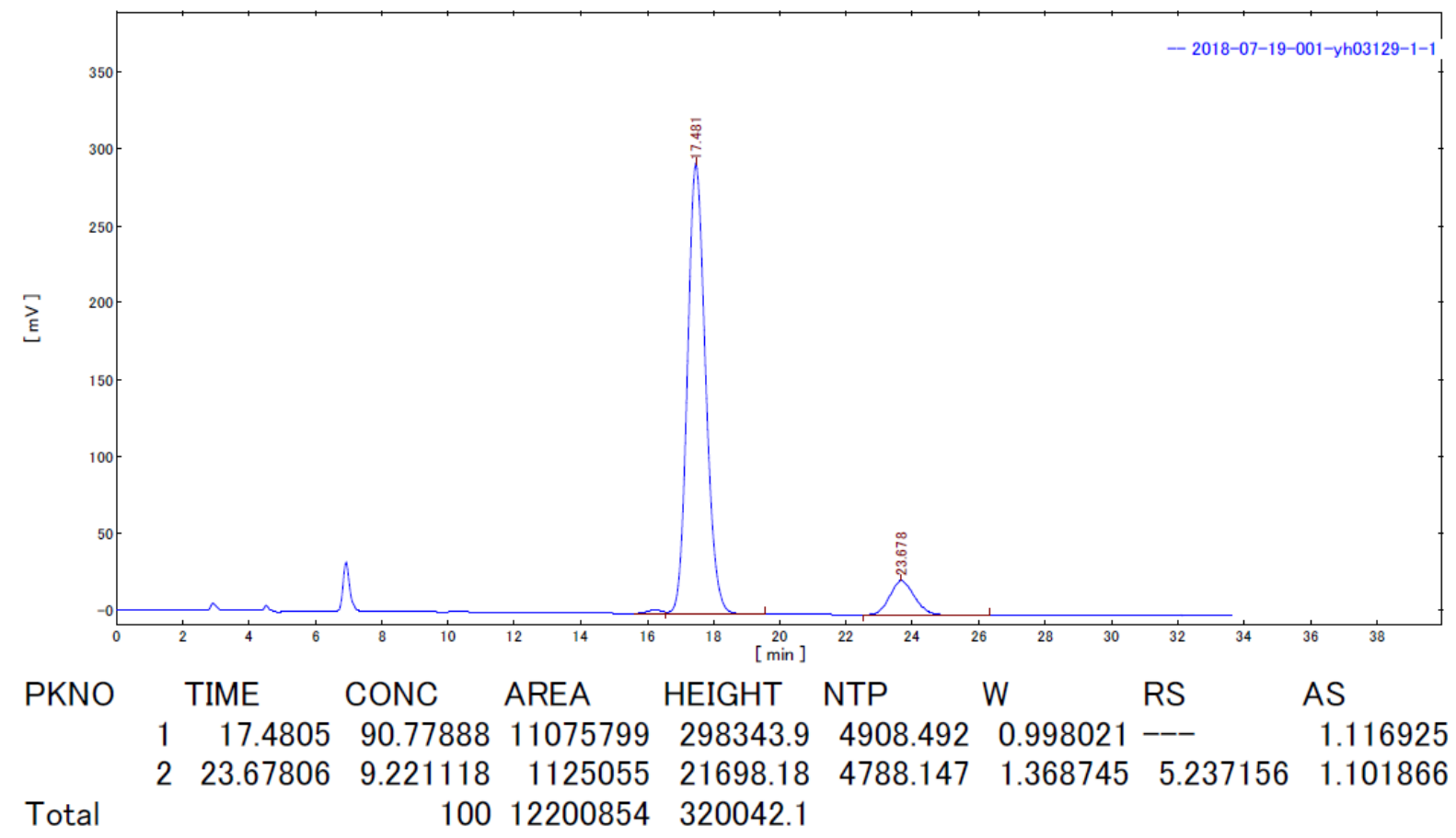




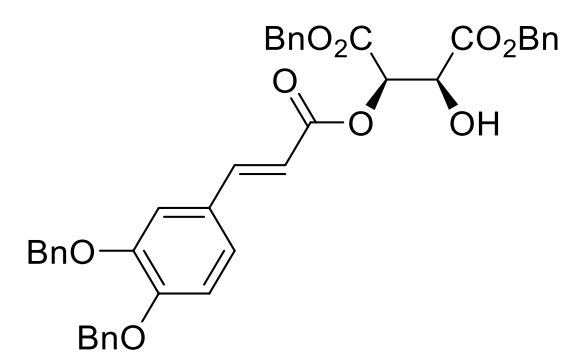

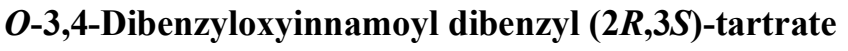

(4e)

CHIRALPAK AS-H

$\mathrm{Hex} /{ }^{i} \mathrm{PrOH}=1: 2$

$0.6 \mathrm{~mL} / \mathrm{min}, 254 \mathrm{~nm}$

1. Racemic

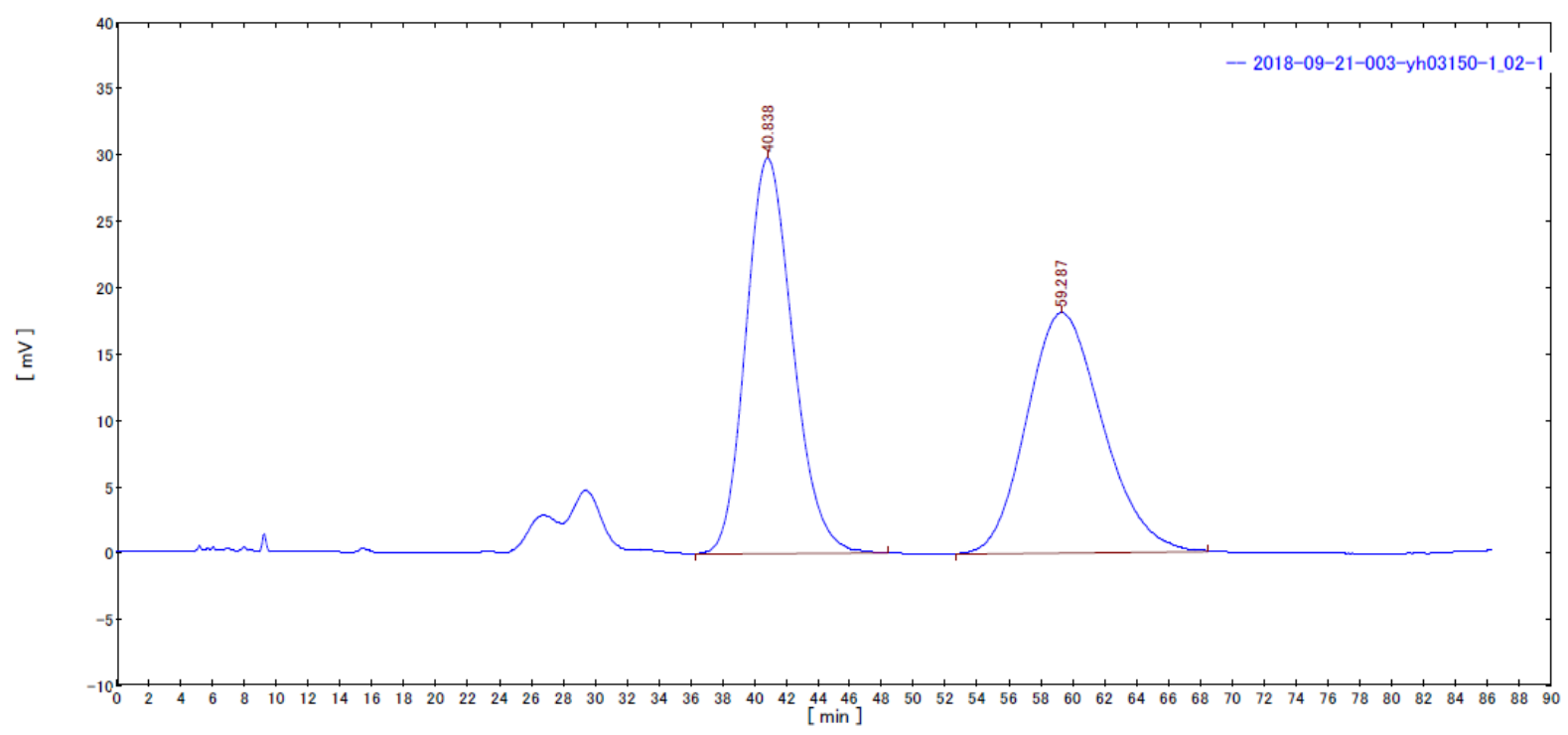

\begin{tabular}{|c|c|c|c|c|c|c|c|c|c|}
\hline PKNO & & TIME & CONC & AREA & HEIGHT & NTP & W & RS & AS \\
\hline & 1 & 40.83781 & 50.51881 & 6104174 & 29820.81 & 917.7685 & 5.392074 & --- & 1.14248 \\
\hline & 2 & 59.28676 & 49.48119 & 5978800 & 18084.81 & 727.1992 & 8.794093 & 2.600978 & 1.137018 \\
\hline Total & & & 100 & 12082975 & 47905.62 & & & & \\
\hline
\end{tabular}

2. Optically active ( $89 \%$ ee)

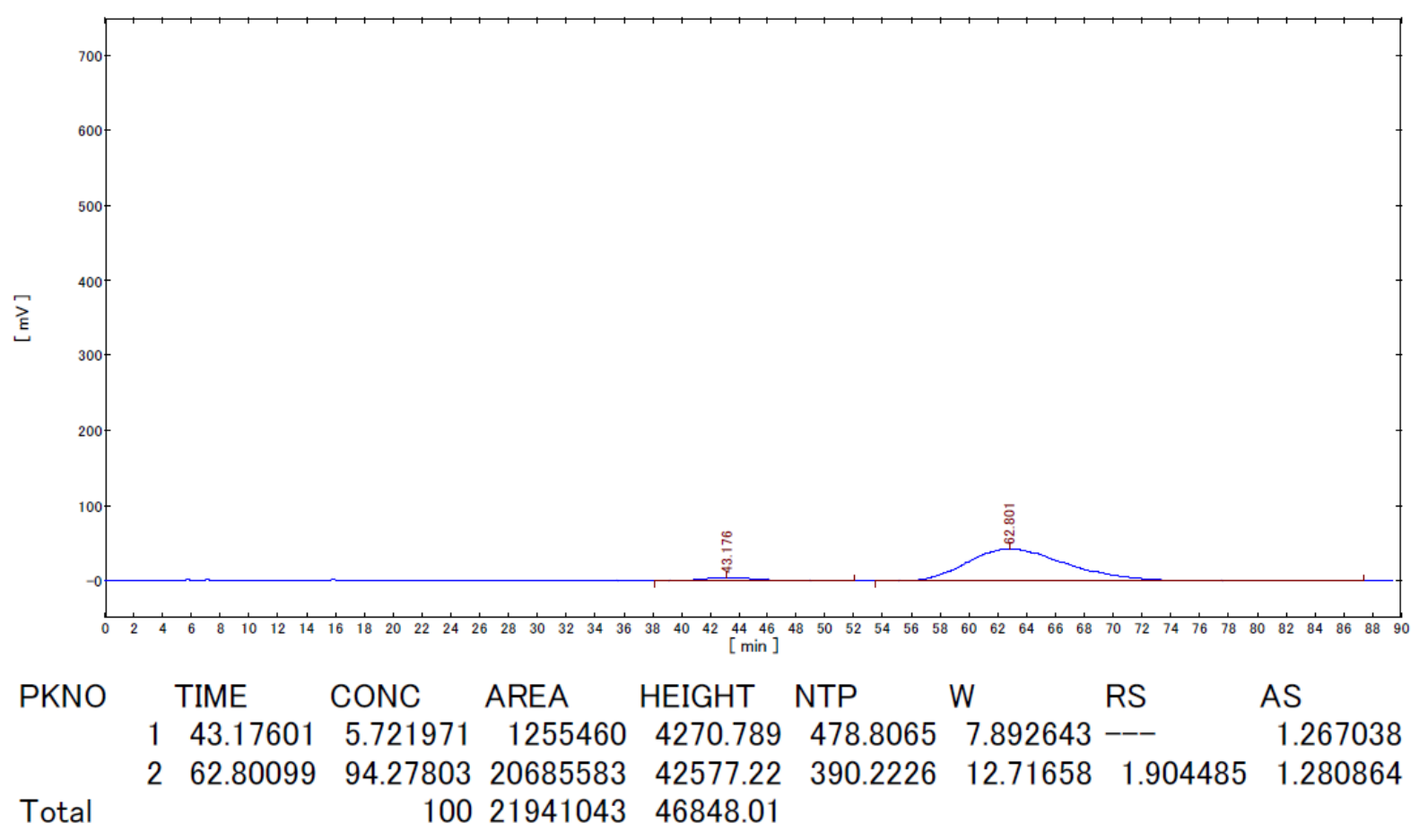




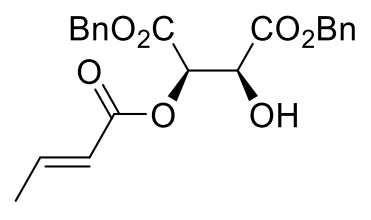

$O$-Crotonoyl dibenzyl $(2 R, 3 S)$-tartrate (4f)

CHIRALPAK AD

$\mathrm{Hex} /{ }^{i} \mathrm{PrOH}=4: 1$

$1.0 \mathrm{~mL} / \mathrm{min}, 254 \mathrm{~nm}$

1. Racemic

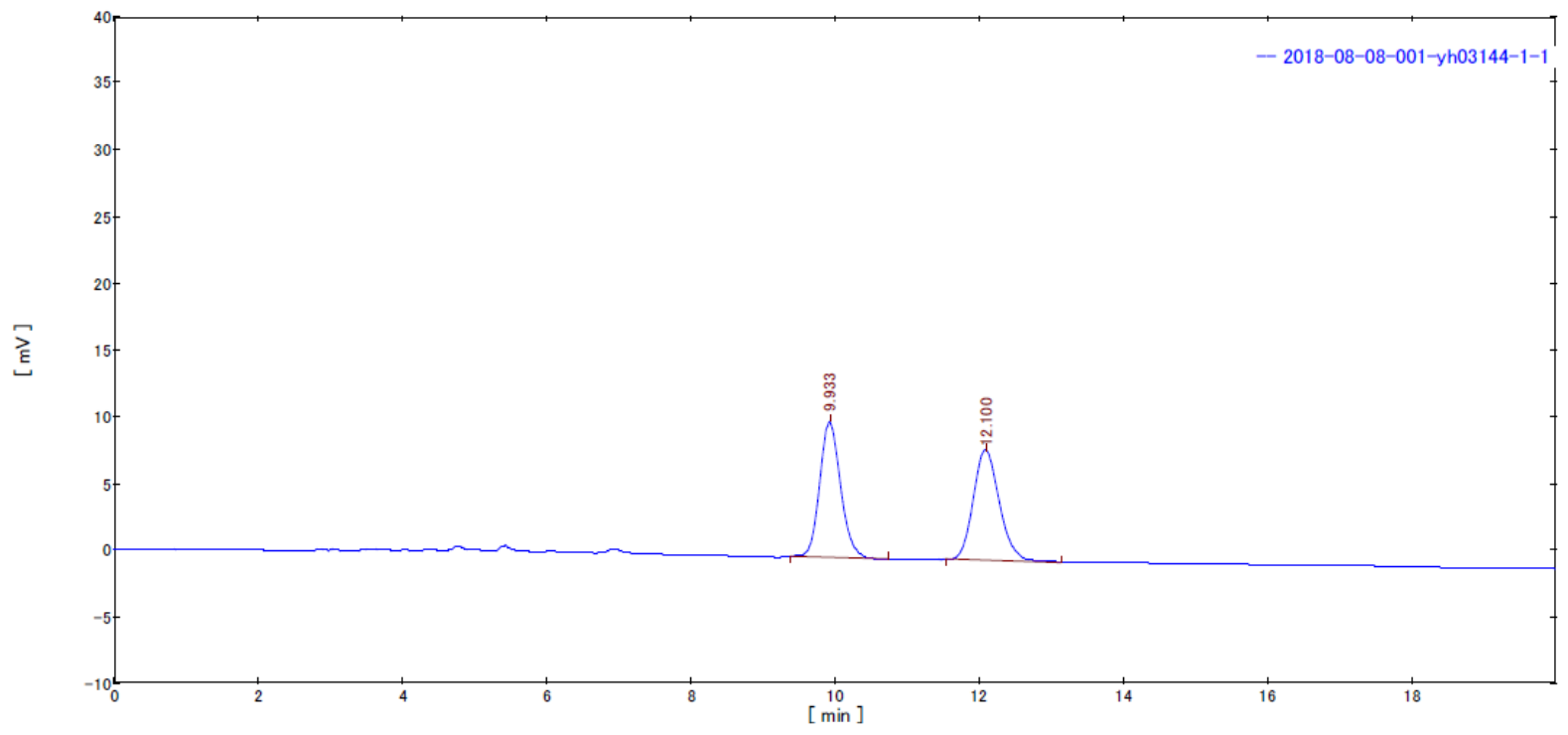

\begin{tabular}{|c|c|c|c|c|c|c|c|c|c|}
\hline PKNO & & ГIME & CONC & AREA & HEIGHT & NTP & W & RS & AS \\
\hline & 1 & 9.933421 & 49.57242 & 204060.4 & 10689.26 & 5693.859 & 0.526569 & & 1.095823 \\
\hline & 2 & 12.09963 & 50.42758 & 207580.6 & 8503.941 & 5314.38 & 0.663905 & 3.639245 & 1.103026 \\
\hline Total & & & 100 & 411641 & 19193.2 & & & & \\
\hline
\end{tabular}

2. Optically active ( $31 \%$ ee)

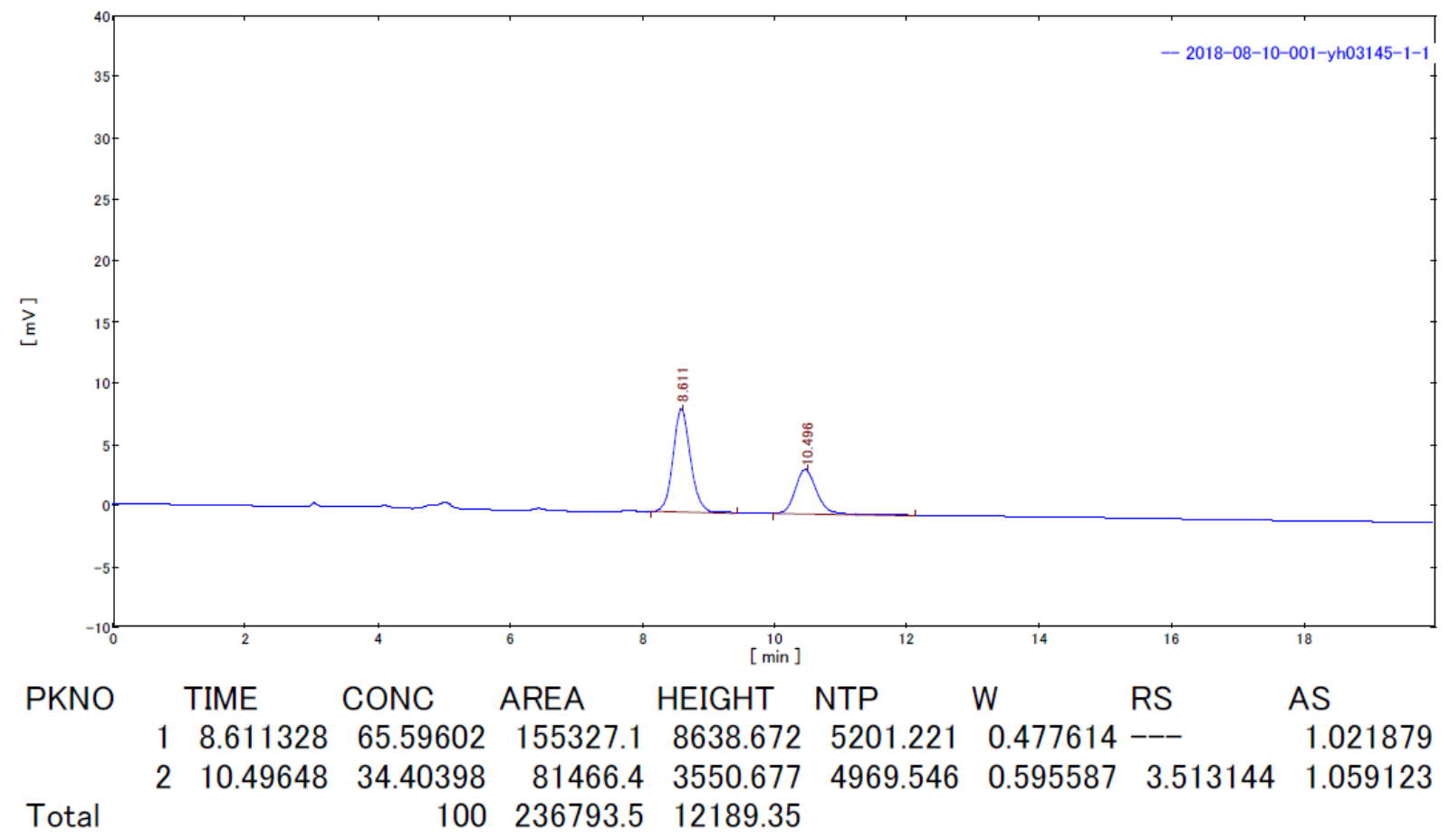




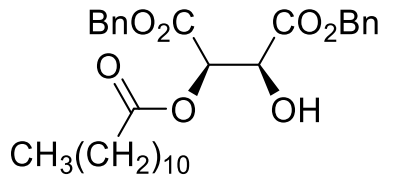

$\mathrm{BnO}_{2} \mathrm{C} \quad \mathrm{CO}_{2} \mathrm{Bn}$

$\mathrm{CH}_{3}\left(\mathrm{CH}_{2}\right)_{10}$
$O$ - Dodecanoyl dibenzyl (2R,3S)-tartrate (4g) CHIRALPAK AD

$\mathrm{Hex} / \mathrm{PrOH}=9: 1$

$1.0 \mathrm{~mL} / \mathrm{min}, 220 \mathrm{~nm}$

1. Racemic

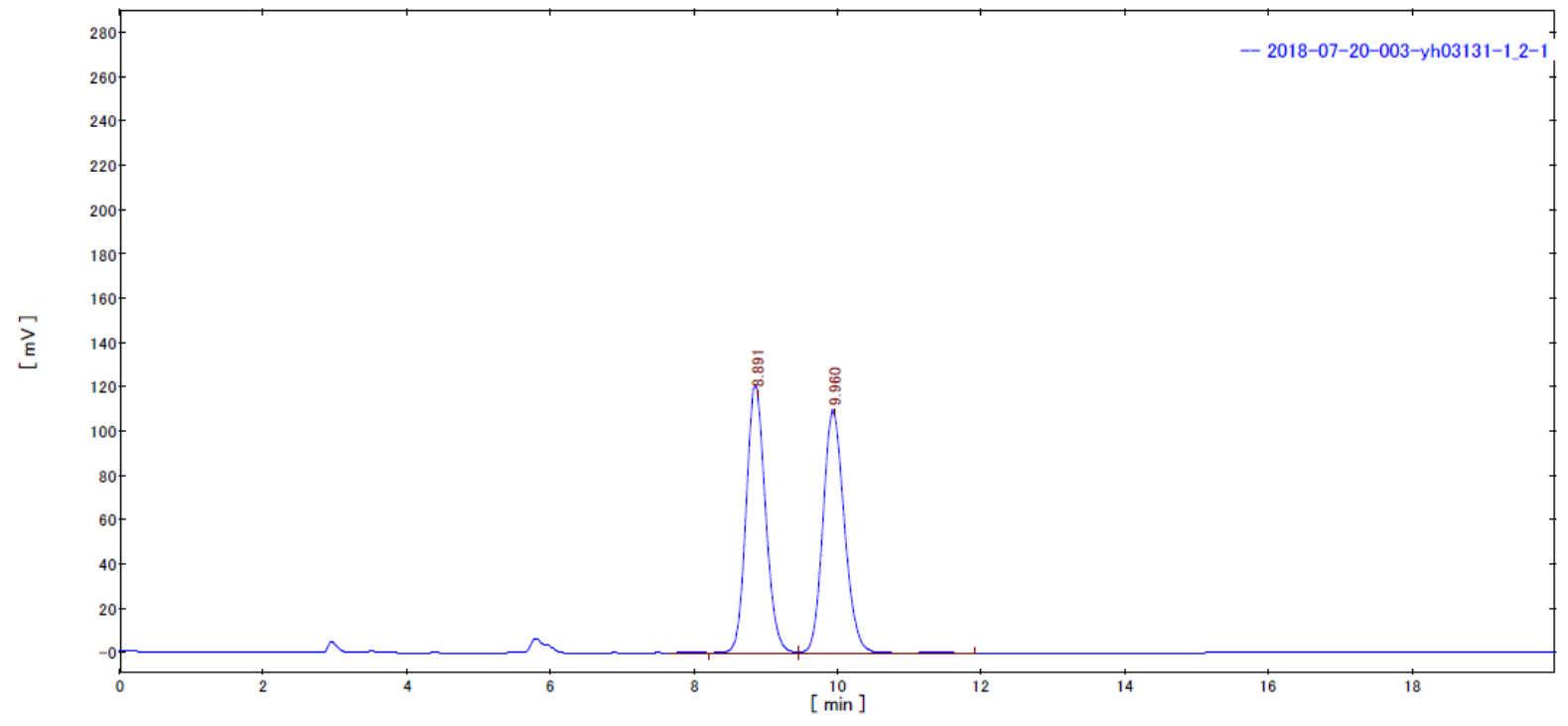

\begin{tabular}{|c|c|c|c|c|c|c|c|c|}
\hline PKNO & TIME & CONC & AREA & HEIGHT & NTP & W & RS & AS \\
\hline & 18.890725 & 49.78307 & 2268219 & 119364.5 & 5253.819 & 0.490636 & --- & 0.973249 \\
\hline & 29.960038 & 50.21693 & 2287987 & 111897.8 & 5303.121 & 0.547086 & 2.060886 & 1.049999 \\
\hline Total & & 100 & 4556205 & 231262.3 & & & & \\
\hline
\end{tabular}

2. Optically active (16\% ee)

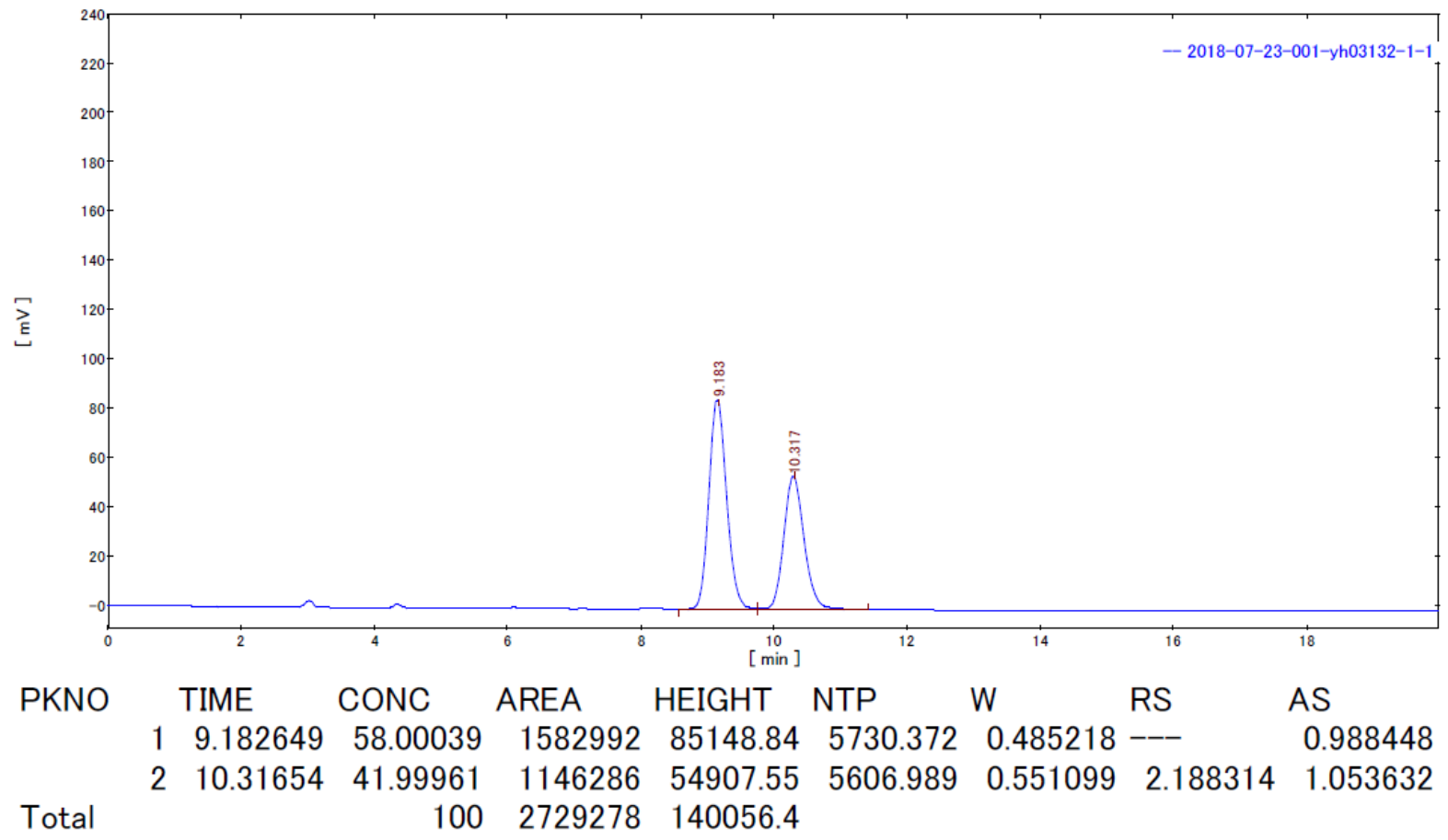




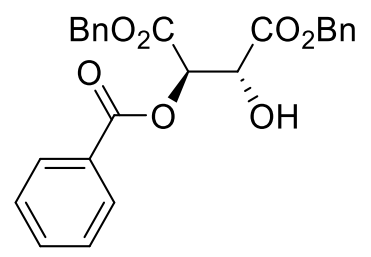

$O$-Benzoyl dibenzyl $(2 R, 3 R)$-tartrate (2c)

CHIRALCEL OD-H

$\mathrm{Hex}^{i} \mathrm{PrOH}=9: 1$

$1.0 \mathrm{~mL} / \mathrm{min}, 254 \mathrm{~nm}$

1. Racemic

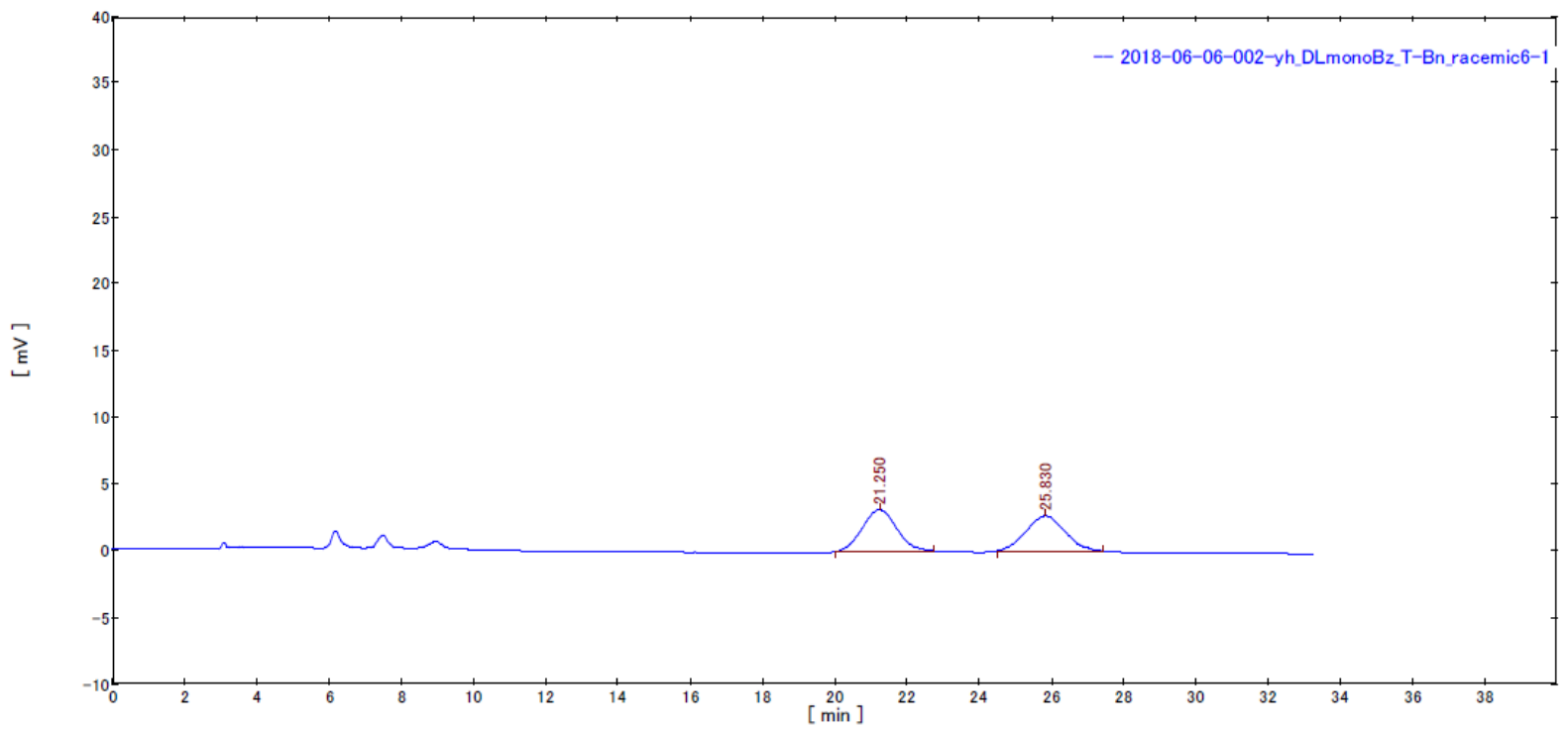

\begin{tabular}{lrrrrrrrrr} 
PKNO & \multicolumn{1}{c}{ TIME } & \multicolumn{1}{c}{ CONC } & AREA & HEIGHT & NTP & W & RS & AS \\
& 1 & 21.25 & 50.98989 & 205836.4 & 3123.034 & 2282.079 & 1.779318 & -- & 1.017417 \\
& 2 & 25.83029 & 49.01011 & 197844.4 & 2620.208 & 2547.91 & 2.046903 & 2.394159 & 1.026537 \\
Total & & & 100 & 403680.8 & 5743.242 & & & &
\end{tabular}

2. Optically active ( $80 \%$ ee, obtained by kinetic resolution of dibenzyl $d l$-tartrate)

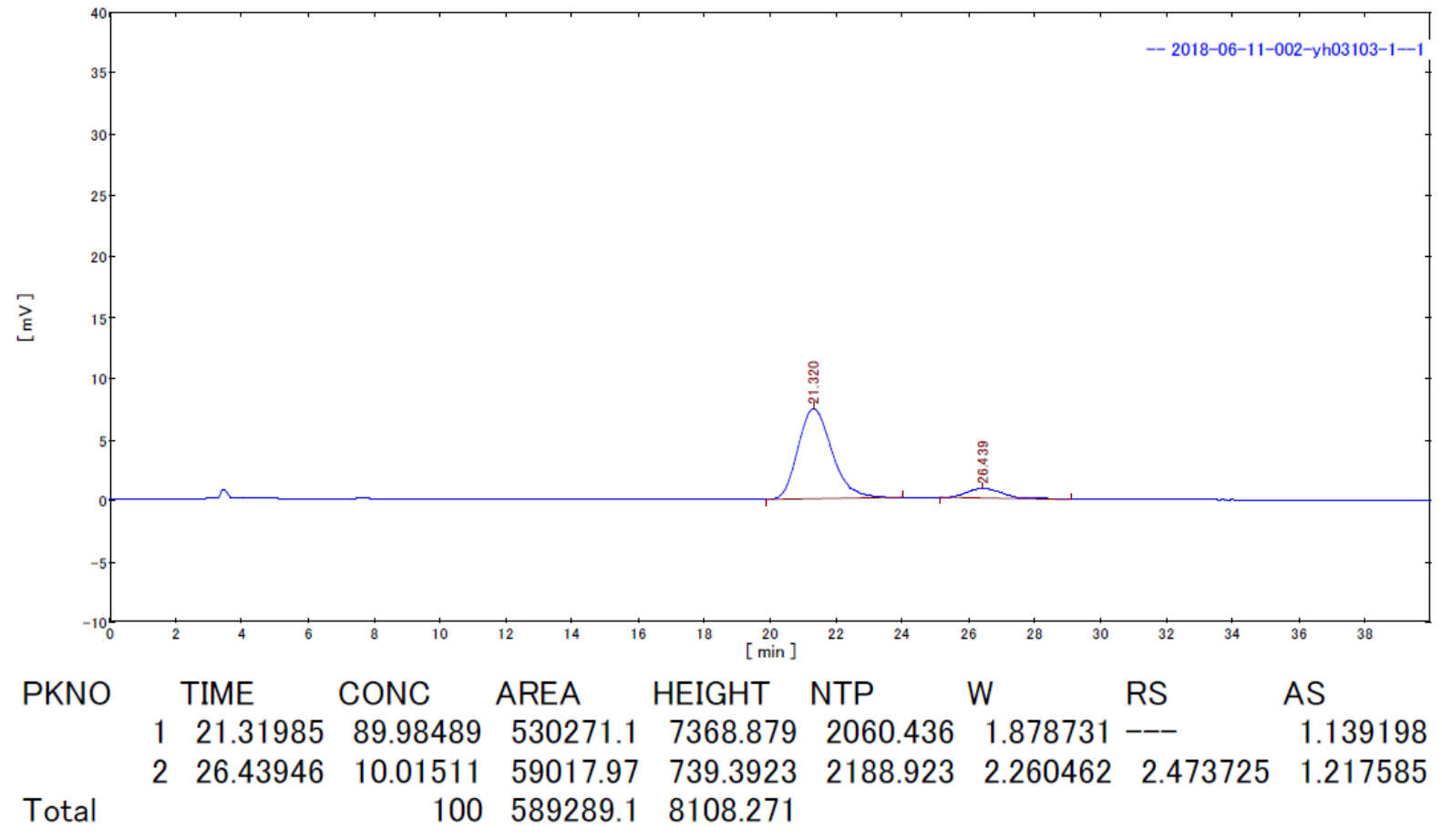




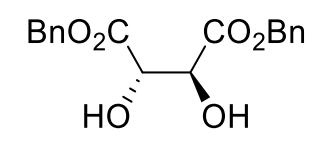

Dibenzyl $(2 S, 3 S)$-tartrate

CHIRALPAK AD

$\mathrm{Hex} /{ }^{i} \mathrm{PrOH}=1: 1$

$1.0 \mathrm{~mL} / \mathrm{min}, 220 \mathrm{~nm}$

1. Racemic
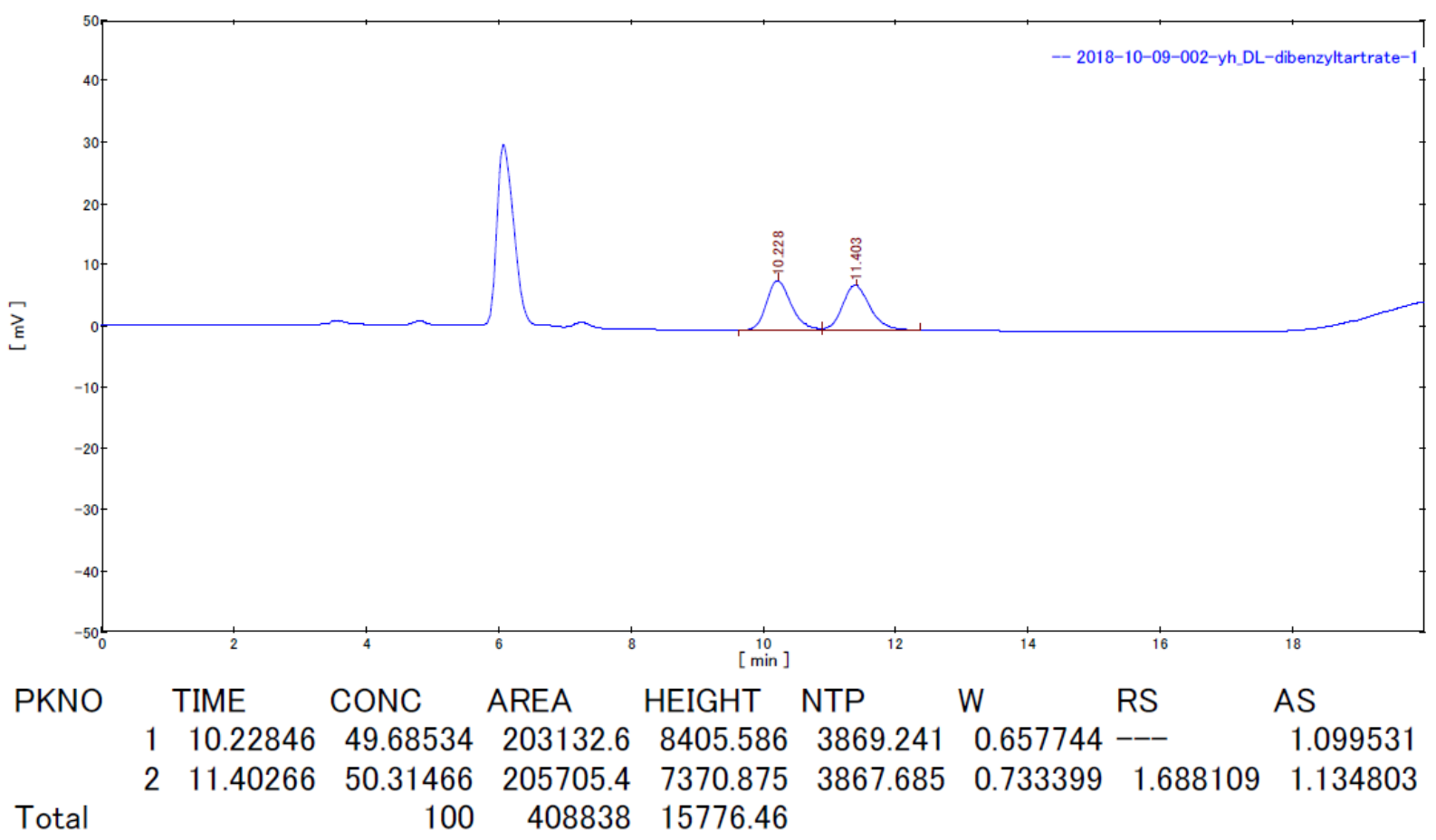

2. Optically active (59\% ee, recovered in kinetic resolution of dibenzyl $d l$-tartrate)

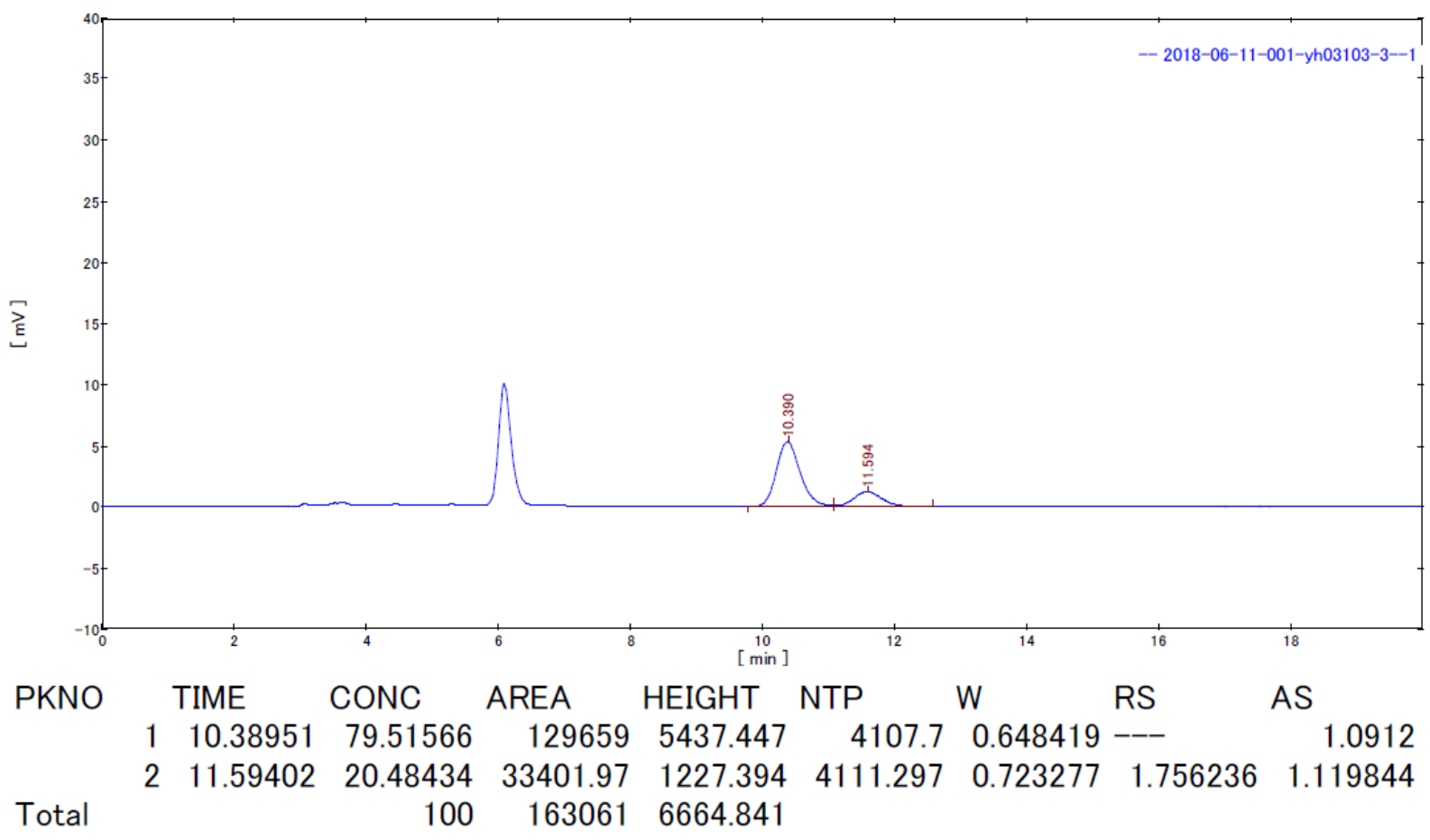




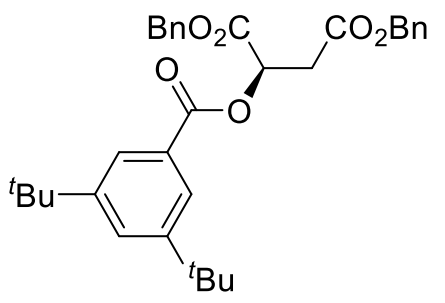

Dibenzyl (R)-2-((3,5-di-tert-butylbenzoyl)oxy)succinate CHIRALPAK AD-H

$\mathrm{Hex} /{ }^{i} \mathrm{PrOH}=19: 1$

$1.0 \mathrm{~mL} / \mathrm{min}, 254 \mathrm{~nm}$

1. Racemic (prepared from $( \pm)$-malic acid)

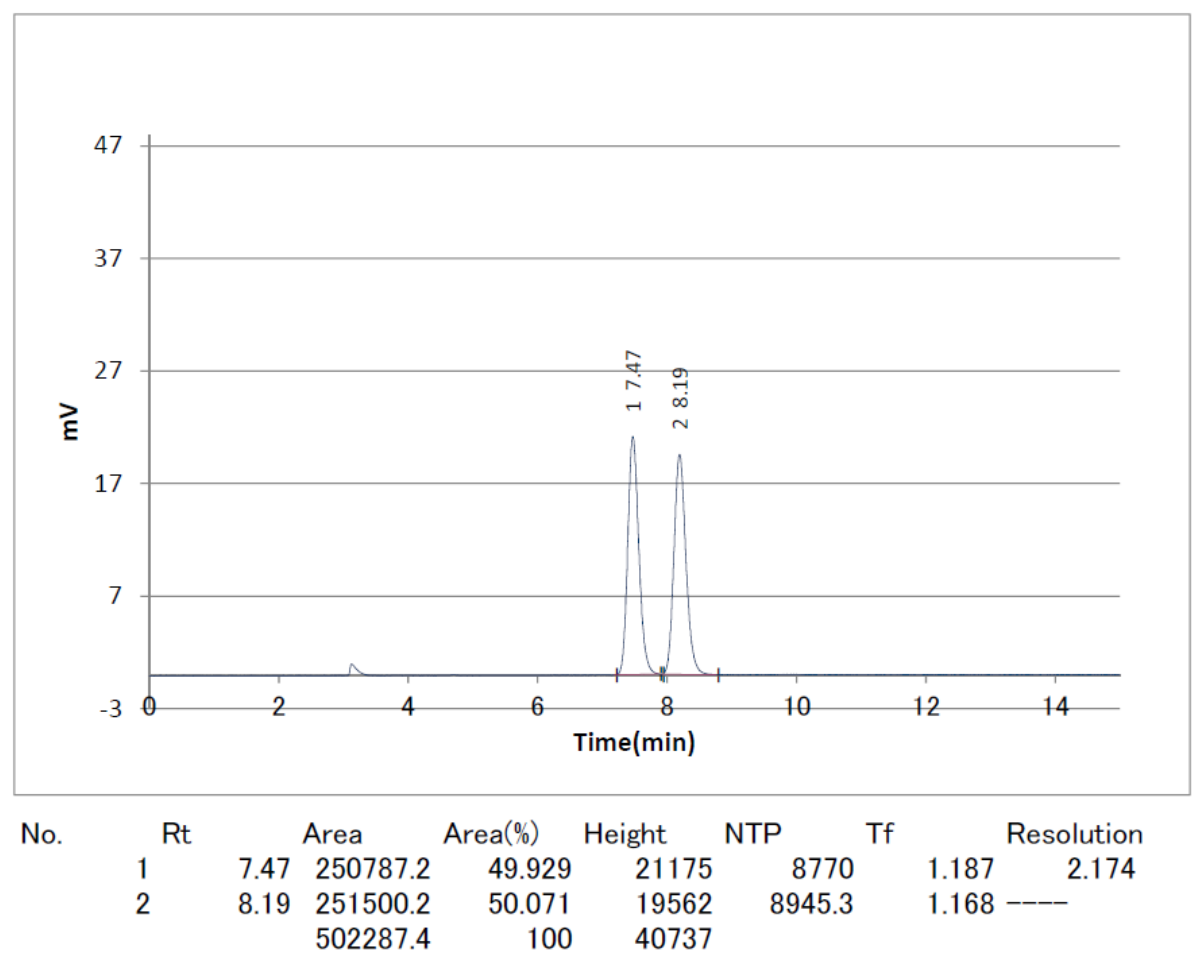

2. Optically active $(48 \%$ ee $(R))$

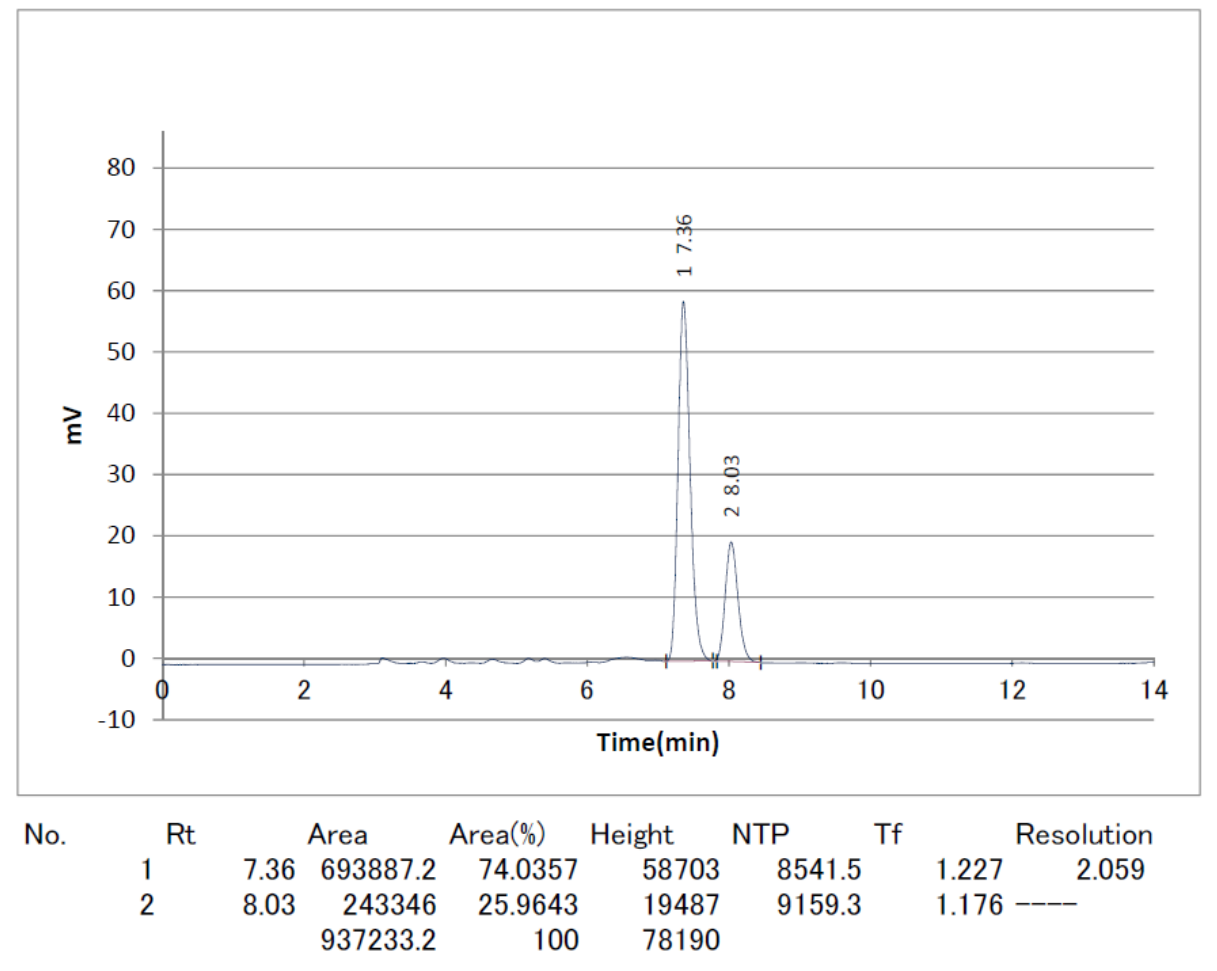


3. Optically active (100\% ee $(S)$, prepared from $(S)$-malic acid)

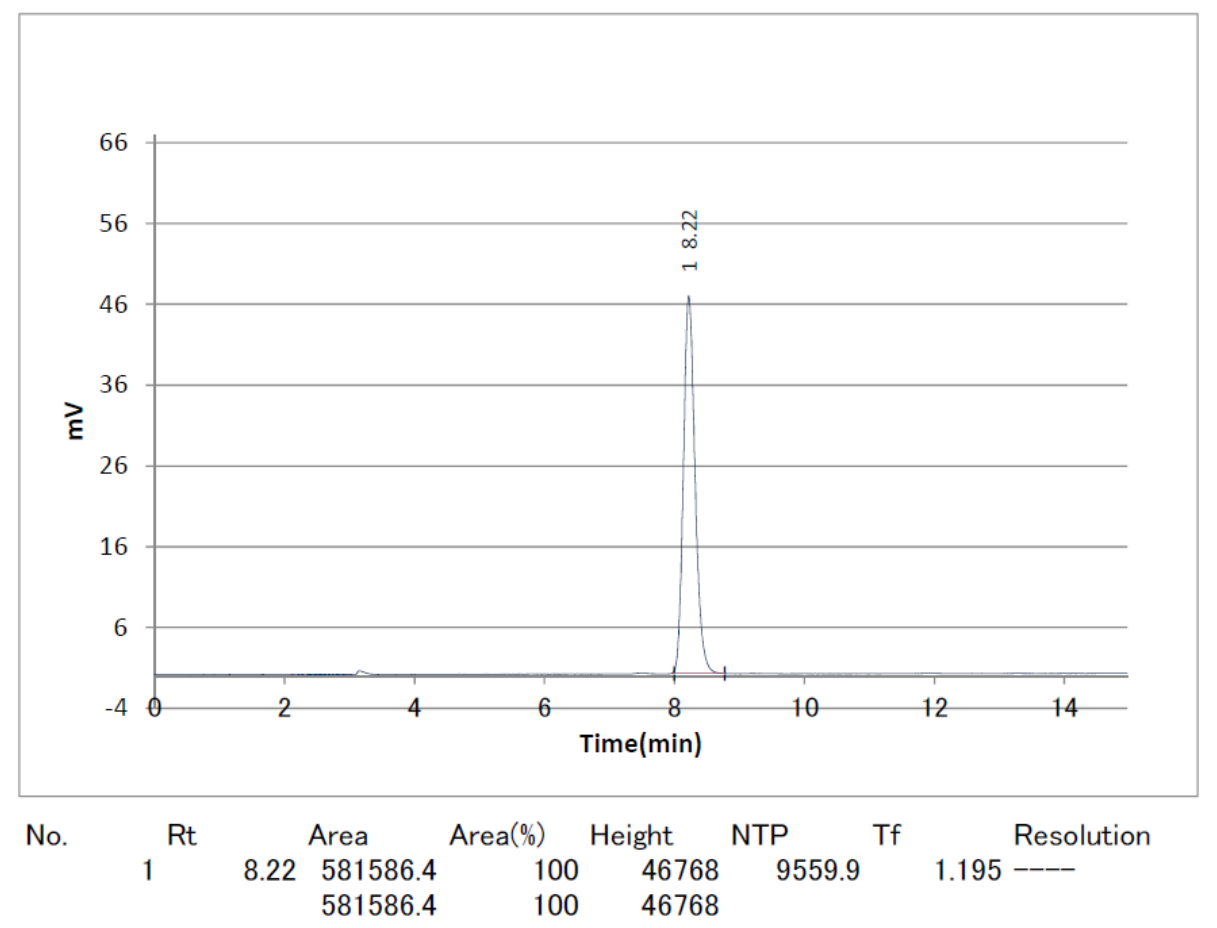

